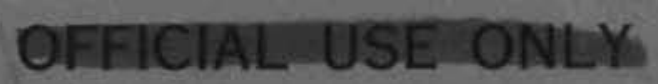

BNWL-404

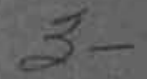

\title{
PACIFIC NORTHWEST LABORATORY MONTHLY ACTIVITIES REPORT FOR FEBRUARY 1967
}

\section{DEVELOPMENT REPORT}

\author{
DIVISION \\ OF \\ REACTOR DEVELOPMENT AND TECHNOLOGY \\ PROGRAMS
}

MARCH, 1967

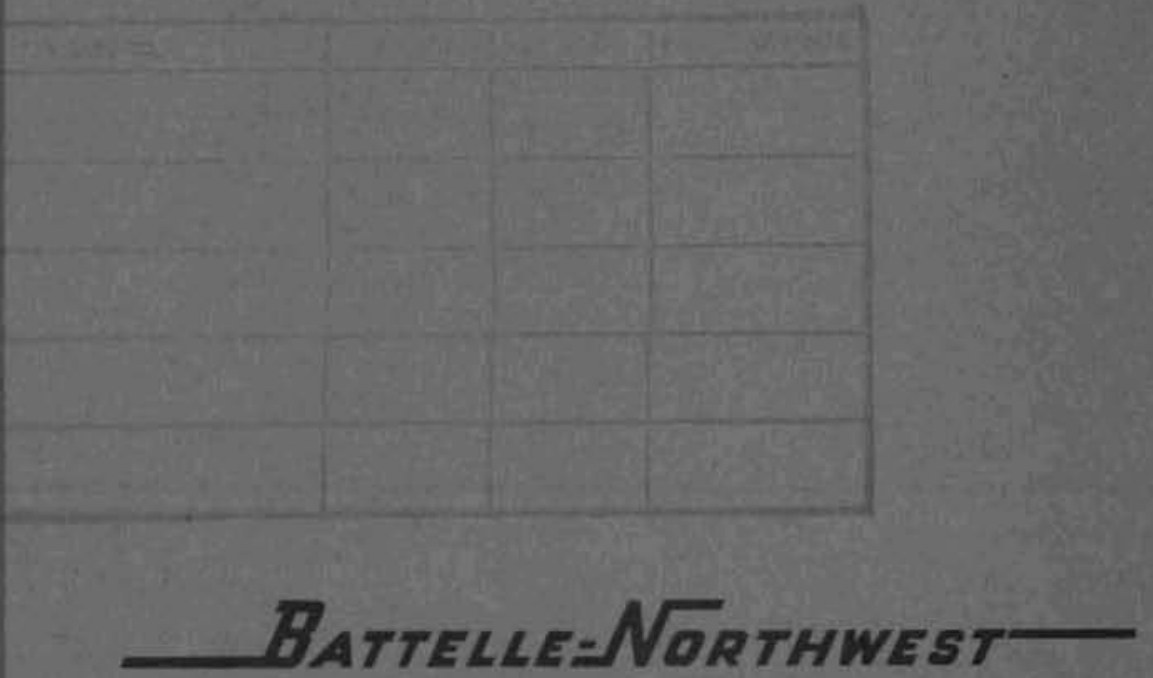

BATTELLE MEMORIAL INSTITUTE / PACIFIC NORTHWEST LABORATORY 


\section{INFORMATION CONCERNING USE OF THIS REPORT}

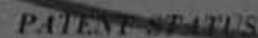

This document copy, since if is iromsmitied in odvance of potent clearance, is mode orgifable is

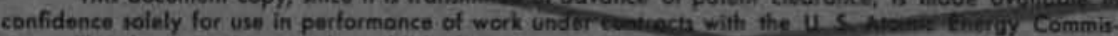

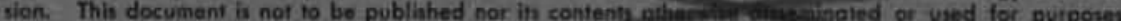
other than specified abovo before patont apprevaluersuch reiteate or wse has beemacured, upon requent,

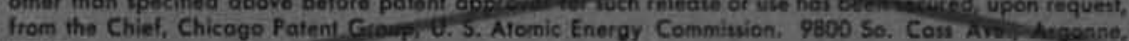
Iilinoiz.

\section{PRELIMINARY REPORT}

This repoit sontains infarmation of a pratiminary nature pimpared in the course of work unider Aromic Energy Commission Controct AT 45-1)-1830. This information is subjed to correction or modifica. tion upon the collection and evaluation of addifional data.

\section{LEGAL NOTICE}

This report was prepored os an account of Government sponsared work. Nelther the United Stotes. nor the Commission, nor any person acting on behalt of the Commission:

A. Makes any warranty or tepresentation, expensed or implied, with respect to the accurocy, coin: pleteness, or vsefuiness of the informotion comtoined in this report, of that the use of any informotion, apparatus, method, or process disclosed in thit report moy not infringe privately awned rights or

B. Assumes any liabilities with respect to the use of, or for damages resulfing from the use of any information, apporolus, method, of process dikclosed is this repart.

As used in the above, "person octing on behalf of the Conumission" Includes any employee or contractor of the Commission, or employee of such controctor, to the extent thot such emplayee or con. trector of the Commissios, or employee of such contractor prepores, disseminates, or provides access to. any information purnvent to his employment or contract with the Commisaion, or his employment with wech controctor.

\section{PACIFIC NORTHWEST LABORATORY RICHLAND, WASHINGTON \\ operated by BATTELLE MEMORIAL INSTITUTE}

for the

UNITED STATES ATOMIC ENERGY COMMISSION UNDER CONTRACT AT(45-1)-1830 


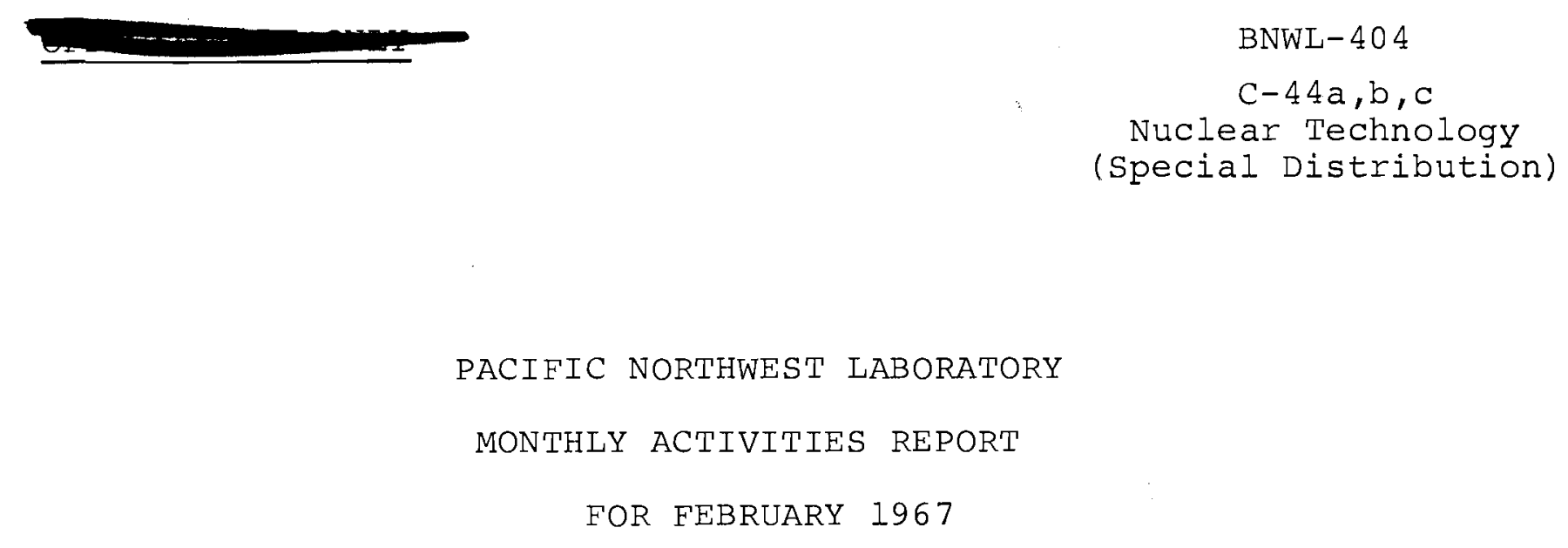

AEC DIVISION OF

REACTOR DEVELOPMENT AND TECHNOLOGY PROGRAMS

By

The Staff of Battelle-Northwest

S. L. Fawcett, Director

March 1967

PACIFIC NORTHWEST LABORATORY

RICHLAND, WASHINGTON 
Microwave and Tnerarea Detection of Coolant Impurities and lleasurement of In--reactor Temperatures . . . . 77 Upstream Boiling Burnout . . . . . . . . . . . . . 79

PLUTONIUM UTILIZATION PPOCRANI

Fuels Development . . . . . . . . . . . . . 80

Peactor Physics . . . . . . . . . . . . . 83

Reactor Engineering Development . . . . . . . . . . 88

Materials Development . . . . . . . . . . . . 90

Cycle ^nalysis . . . . . . . . . . . . . . . 92

Test peactor Operation . . . . . . . . . . . 92

EB.JP Demonstration Program . . . . . . . . . . . . 97

IJUCLEAR SAFETY

Containment Systems Experiment . . . . . . . . 9 98

Pressure Vessel Crack Monitoring. . . . . . . . . 103

Peactor Safety Analysis and Evaluation . . . . . . 104

Intermediate Level Waste Treatment . . . . . . . . 105

Fission Product Aerosol Containment . . . . . . . . 105

Disposal of Reactor off-cas into Soil systems . • . 107

Geophysical Exploration of Rattlesnake

Columbia River Sedimentation Studies . . . . . . . 107

Padioactive Resiaue Solidification . . . . . . . 108

Simulation Modeling of Expected Thermal ceneration

in Selected River Systems . . . . . . . . . 112

CUSTOMEP

Assistance to Isochem Inc. . . . . . . . . . 112 


\section{SUMMARY}

\section{CIVILIAN POWER REACTORS}

Nuclear Systems and Concepts Analysis

Complete Phase II calculations of the nuclear power industry are nearing completion. One optimum for a well debugged model was obtained for a case which included all reactors in the study and a growth curve for nuclear plants only.

Analysis of electrical demand is progressing. Growth factors for each of the 48 power supply areas over a 75-year period are nearly all calculated.

Phase II PACTOLUS results have been sent to the appropriate task force committees so that they may check our reactor mass flows against what they think the mass flows should be. Any existing errors in the Phase II data should show up as a result of this review.

\section{Conceptual Reactor Design Studies}

All but two volumes of the U.S. Geodetic Survey Water Supply Papers have been received. Flow and temperature correlations are continuing.

A summary report on heat dissipation system costs has been received from R. W. Beck and Associates. The data will be incorporated into the final report on this study.

Several additional calculations have been added to the steamCooled Fast Reactor simulation. These include fuel cycle cost calculations and the calculation of necessary input parameters, fission gas plenum sizing, compressibility effect in the hydraulics calculations, as well as several reformulations which make the simulation more flexible.

An estimate of the blanket thickness as a function of core size and height to diameter ratio was made for input to the two dimensional physics calculations.

A redirection of the extent of the physics parametric study coupled with the correction of a minor input error has resulted in obtaining partial results at this time. The physics methods and plan of attack was given preliminary concurrence by R. S. Carlsmith of ORNL. 


\section{USAEC-AECL Cooperative Program}

Duplicate unirradiated control creep tests conducted at $400 \mathrm{C}$ and $25.6 \mathrm{Kg}-\mathrm{mm}^{-2}(36,500 \mathrm{psi})$ resulted in average values of 3500 hrs for rupture time, $1 \times 10^{-5}$ for creep rate, 25\% for total elongation, and $85 \%$ for reduction of area. The creep rate is slightly higher than that for an in-reactor test at the same temperature and stress.

A report is being prepared to present the results of experiments performed to study boiling diversion of coolant flow in rod bundle fuel elements. This report will include descriptions of experimental facilities and test sections, results of the experiments, and comparisons of results with calculations performed using a digital computer program developed earlier.

riwo test sections are being fabricated for a study of the effects of rod spacing on boiling burnout in simulatec rod bundle fuel elements. The first test section simulates a fuel rod surrounded by adjacent fuel rods, and the second, a fuel rod adjacent to an unheated surface such as a pressure tube or flow shroud. In each test section the rod spacing can be varied by the replacement of a central rod with rods of various diameters.

Approximately 60 feet of test material has been receivea. Brittle fracture testing of the solution heat treated, quenched, and 15\% cold worked condition has begun.

\section{APPLIED AND REACTOR PIYSICS}

\section{Plutonium Criticality studies}

Criticality experiments were continued with PuO 2 -polystyrene compacts having an $\mathrm{H} / \mathrm{Pu}$ ratio of 5 and a Pu-240 isotopic content of about 12 wto. Several experiments were performed for ceneral Atomic in support of the Gas-Cooled Fast peactor program. The latter experiments utilize the fuel on hand and are extensions of the basic experiments to obtain data for criticality safety. The proposed GCFR experiments include measurements to determine the effectiveness of $\mathrm{DY}, \mathrm{Gd}$, and $\mathrm{Hf}$ when used as neutron poisons in the core.

\section{Phoenix Fuel Reactor Program}

A summary entitled "Approach to Critical Experiments with Phoenix Fuel" has been submitted for presentation of a paper at the 1967 Annual Meeting of the American Nuclear Society. 
Analysis of the CAF-Phoenix experiment continues; emphasis is on transport theory calculations.

A critical loading was achieved for the PRCF-Phoenix core with $16 \frac{1}{2}$ fuel assemblies.

Calculations on the PRCF-Phoenix experiment are high by about $7.5 \%$ in $k$. Between 3.5 and 4.5 was expected from the CAF-Phoenix experiments. The remaining 3 to $4 \%$ may be due, as yet, to untreated heterogeneities in the reflector.

Calculations indicate that the borated side plates may not be useful for over-all power peaking control.

Current 2-D burnup analysis of the MrT-Phoenix experiment substantiate the early 1-D calculations.

The parametric methods previously used for calculating heat transfer limits and estimating maximum permissible MTR operating power are being refined to accommodate three-dimensional power maps and to yield more precise heat transfer limits.

Since the completion of the Al-Pu fuel plates for the PRCF experiments, major emphasis by the Fuels Fabrication group has been placed on problems related to the fuel core loading of Al-Pu fuel elements in the MTR. Contacts between PNL and Idaho Nuclear have increased.

\section{High Temperature Reactor Physics Studies}

The pressure test of the reactor shell and piping was completed. The leak rate was reduced to less than the design criteria.

rihe Acceptance Tests on the Cooling Gas system were largely completed. Vacuum tests were started.

The Acceptance rest on the Electrical Control system was completed.

Final testing of the horizontal control and vertical safety rods is in progress.

The light duty oscillator is being testec. Design tests to high temperature are being prepared in the HTLTR mockup to reduce scheduling problems in the HTLTR.

is in progress.

Documentation of operational programs for the Control system 
Calculations of the temperature coefficients for the U-233 Th experiments have started.

An extreme test of containment of the U-233 - Th fuel for the first experiments has been partially completed.

Additional questions on the Safety Analysis Report have been answered by letter. The revised pages for the SAR are under internal review.

\section{REACTOR FUELS AND MATERIALS}

Fast Fuels oxides anci Nitrides

The UN-PuN synthesis facility is now being operated on a semicontinuous basis so that approximately 250 grams high purity mixed nitride can be produced each week.

A test capsule was designed for irradiation testing mixed nitride fast reactor fuel pins in the ETR.

Detailed discussions were held with designers, users, and vendors of shielded electron microprobes.

Sodium bonding of fuel pellets in stainless-steel cladding using near-prototypic conditions was attempted.

\section{Basic Swelling Stuäies}

Capsule P-15 (700 C, 100 psi, 0.2 at.\% BU) and capsule P-16 (625 C, 1000 psi, 0.35 at. $\%$ BU) are operating successfully. Capsule P-14 (700 C, 500 psi, 0.2 at. $\left.\frac{\circ}{\mathrm{BU}}\right)$ has been completed, and construction has started on two new capsules, p-11 (550 C, 5000 psi, 0.2 at. $\% \mathrm{BU})$, and P-12 (625 C, 5000 psi, 0.2 at. $\mathrm{BU})$.

Uranium and dilute uranium alloy specimens were recovered from three irradiation capsules: P-9 (450 C, 1000 psi, 1 at. 8 BU), 35 (525 C, 30 psi, 0.5 at. $\%$ BU), and 36 (450 C, 30 psi, 0.38 at. $\%$ BU). Specimens from capsule P-9 were too severely damaged for density measurements, but the other 20 psecimens from capsules 35 and 36 yielded swelling values that ranged from $0.6 \%$ for U + 4 wto Mo 0.1 wt: Si irradiated to 0.38 at. $\%$ BU at $450 \mathrm{C}$ to $105 \%$ for U + $140 \mathrm{ppm} \mathrm{Fe}-25 \mathrm{ppm} \mathrm{Al} \mathrm{-} 95 \mathrm{ppm} \mathrm{Si}-400 \mathrm{ppm} \mathrm{C}$ irradiated at $470 \mathrm{C}$ to 0.5 at.\% BU. Metallographic examination is in progress.

The modification of facilities to postirradiation anneal uranium at temperatures to $900 \mathrm{C}$ and pressures to $15,000 \mathrm{psi}$ is continuing . 


\section{Nondestructive Testing}

Work continued on an investigation of eddy current testing probe design and appropriate equivalent circuits are being examined both theoretically and experimentally. A single sensing coil was evaluated alternately as (1) an outside encircling coil, (2) an inside encircling coil, and (3) a surface probe to experimentally measure complex impedances at several different frequencies. These results are being incorporated into the development of equivalent circuits.

Ultrasonic wave studies with Kautz function analysis were temporarily discontinued due to other commitments. Further tests using dual ultrasonic frequencies remain unsuccessful in detecting mechanically closed unbonds in reactor fuel element cladding, although some novel effects were observed which may have worthwhile applications for ultrasonic imaging.

Basic electromagnetic test development efforts continued with the development of an equivalent circuit for simulating single frequency, multifrequency, frequency modulation, and pulsed eddy current nondestructive test techniques. Ladder networks were used to simulate defects at various depths and potential methods for simplifying the design of the multiparameter eddy current tester are under study. Transformation circuits for the transistorized multichannel eddy current tubing tester were fabricated, and previous measurements relating test coil diameter and frequency relationships were analyzed.

Efforts to improve the stability of the sinusoidal thermal wave system have continued with the correction of the difficulties found last month in the amplitude digitizer and phase printer. Subsequent testing showed this difficulty has been corrected, and the entire electronic readout system is again undergoing stability tests.

\section{Nuclear Ceramics}

Preliminary thermal-diffusivity data for sintered UN - 20 wto PuN showed an increase in thermal diffusivity with temperature from a value of $0.0360 \mathrm{~cm}^{2} / \mathrm{sec}$ at $260 \mathrm{C}$ to $0.044 \mathrm{l} \mathrm{cm} 2 / \mathrm{sec}$ at $1000 \mathrm{C}$. Above $1000 \mathrm{C}$, the diffusivity did not change appreciably with temperature. At $1575 \mathrm{C}$, the highest measurement temperature, the diffusivity value was slightly less than at $1000 \mathrm{C}$.

The thermal diffusivity of hypostoichiometric $\left(\mathrm{U}_{0} .8, \mathrm{Pu}_{0.2}\right)_{2-\mathrm{x}}$ $(\mathrm{x}=0.01)$ is less than the stoichiometric material from $100-.400 \mathrm{C}$.

Capsules containing $\mathrm{UO}_{2} .00$ specimens were irradiated for several hours with molten centers and then discharged at different rates to assess effects of cooling and solidification rate on postirradiation microstructure and fission fragment cistribution. 
Macrographs of cross sections from each specimen were qualitatively identical, but gamma-beta autoradiographs revealed a dramatic difference.

A ternary evaporator apparatus for studying $\mathrm{Pu}-\mathrm{O}-\mathrm{N}$ phase equilibria is essentially complete. Cerium is currently being used as a stand-in for plutonium.

Equipment was assembled and samples prepared for studying the solubility of oxygen in PuN.

Application of electron microscopy and microprobe techniques has continued on two mixed $\mathrm{UO}_{2}-20 \% \mathrm{PuO}_{2}$ specimens.

An etchant was developed for annealed pneumatically impacted $\mathrm{PuO}_{2}$

Neutron radiography is being developed to complement $\mathrm{x}$ - and gamma-radiographic techniques for high-temperature, sealed-capsule studies of materials. An antimony - beryllium (neutron) source is being used.

Single crystal specimens of $\mathrm{UO}_{2}, \mathrm{ThO}_{2}$, and polycrystalline $\mathrm{UO}_{2}, \mathrm{ThO}_{2}$, and $\mathrm{UO}_{2}-\mathrm{ThO}_{2}$ specimens were prepared, characterized, and distributed to domestic and foreign laboratories for use in basic studies and information exchanges.

\section{Nuclear Graphite}

The high temperature graphite capsule, GEH-13-13, continues to operate satisfactorily after completing one cycle in the ETR.

The long-term graphite irradiation test, H-3-14, was charged in the GETR for a scheduled three-cycle irradiation.

Data from the GETR graphite irradiation in Fi-3-24 show for the first time a net expansion in the parallel orientation. TSGBF irradiated to $9 \mathrm{x} 1021 \mathrm{nvt}(\mathrm{E}>0.18 \mathrm{MeV}$ ) at $1000 \mathrm{C}$ displays length changes of $+8 \%$ in the parallel direction and $+35 \%$ in the transverse direction. Improved graphites at the same exposure display dimensional changes of about $-0.3 \%$ transverse and $-3 \%$ parallel.

Samples from the ETR strain-to-fracture tests were recovered from the damaged capsule. Since they suffered no ill effects, the samples will be used in further irradiations.

Models for the calculation of thermal expansion coefficients and Young's moduli of polycrystalline material were applied to MgO and Zno. Results using the modified models were equal to the average of the constant-stress and constant-strain models. 
Measurements of the rate of oxidation of boronated graphite by $0.5 \% \mathrm{O}_{2}$ in helium have been extended to include the oxidation of "black" boronated graphite containing nominally 5\% boron as $\mathrm{B}_{4} \mathrm{C}$. At temperatures up to $680 \mathrm{C}$, the activation energy for oxidation is about $38 \mathrm{kcal} / \mathrm{mole}$.

The recent addition of 215,000 curies of cobalt-60 to the gamma irradiation facility increased the inventory of co-60 to 355,000 curies. The maximum dose rate in the central facility tubes is $2.34 \times 10^{7} \mathrm{r} / \mathrm{hr}$.

\section{Irradiation Damage to Reactor Metals}

Two additional pins containing Inconel 600 have been assembled for EBR-II irradiation. The testing of several alloys obtained from the G.E. nuclear superheat program is under way.

The effect of irradiation on the rupture life of AISI Type 304 stainless steel in an in-reactor test was found to be very severe at $840 \mathrm{C}$. A rupture indication was received after 6 hours under $3.52 \mathrm{Kg}-\mathrm{mm}^{-2}$ (5000 psi) stress during an in-reactor creep test, whereas an unirradiated control test lasted 926 hours at these conditions of temperature and stress.

Optical metallography, electron microprobe analysis, and transmission and replica electron microscopy are in progress on AISI 304 stainless steel irradiated at $650 \mathrm{C}$ to about $3.5 \times 1020$ fast fluence.

Encapsulated stainless steel tensile specimens have been charged in the ETR in order to explore the possibility of obtaining irradiation temperatures above $290 \mathrm{C}$ in the $\mathrm{G}-7$ hot water loop.

Stress-rupture tests on irradiated Inconel 600 specimens indicate that experimental treatments increase postirradiation rupture life $65 \%$ over that of the commercial treatment.

$\mathrm{X}$-ray diffraction phase analysis of Inconel 600 specimens given experimental treatments show that more $\mathrm{M}_{7} \mathrm{C}_{3}$ is present in specimens having the greater tensile ductility. This supports the hypothesis that the ciepletion of chromium around the grain boundaries to form these carbides imparts greater grain boundary ductility.

$\mathrm{X}$-ray diffraction phase analysis of Inconel $\mathrm{X}-750$ specimens indicates only ( $\mathrm{Cb}, \mathrm{Ti}) \mathrm{C}$ carbide phases rather than the expected $M_{7} C_{3}$ and $M_{2}{ }_{3} C_{6}$ phases.

Microprobe analysis of Nimonic 80-A shows that substantial chromium denuabion occurs around grain bounciaries due to chromium carbide formation in the bounciaries. 
Optical metallographic examination of XAP 005 and SAP 895 materials received from Atomics International (AI) is complete. Tensile, creep-rupture, and notched creep-rupture specimen designs are being evaluated through tests of non-program (Alcoa $1-585$ ) $7 \% \mathrm{Al}_{2} \mathrm{O}_{3}$ material. Two sheath capsules designed for elevated temperature irradiation in the $6-7$ hot water loop have been fabricated and shipped to ETR. These capsules incorporate thermal monitors which will be examinea after irradiation to evaluate the heat transfer characteristics of the ciesign.

Specimens of four zirconium alloys, exposec 88 days in the ETR G-7 loop in pHi-10 NFi $4 \mathrm{OH},<0.05$ ppm oxygen, absorbed only slightly more hycarogen than similar specimens exposed 37 days in the same environment.

Assembly of a Hopkinson bar loader is nearly completed. The bar loader will provicae capability for studying material behavior at extremely high strain rates. Experiments are planned to examine material behavior at the tip of a rapidly propagating crack.

The age embrittlement study of Hastelloy $\mathrm{X}$ and Hastelloy $\mathrm{W}$ weld metals has been completed. The results of this study indicate both weld metals will embrittle when aged at temperatures of 1000 to $1600 \mathrm{~F}(540$ to $870 \mathrm{c})$, and the rate of embrittlement is slower for Hastelloy $W$ than for Hastelloy $X$.

Tensile tests on AISI 304 stainless steel irradiated to $1.7 \times 1022$ nvt in the EBR-II have been completed. Uniform ductility was a minimum of $0.5 \%$ at $1500 \mathrm{~F}(815 \mathrm{C})$ test temperature. Considerable radiation hardening was found at test temperatures of $1400 \mathrm{~F}(760 \mathrm{C})$ and below.

The general laboratory area of 321-A Building was occupied during the month. The complete cleanup and renovation of four CANEL test stands and their associatec instrumentation is under way .

The prototype cell is nearly complete; changes required by the radiation leak checls are in the final stage.

A temporary liquid metal loading station is being constructed. The device will service the various CANEL apparatus until an atmosphere box becomes available.

The liquid metal capsule $\mathrm{CEH}-22-3$ has been discharged from the ETR after accumulating a fast neutron fluence of $1.38 \times 10^{21}$ nvt. A sodium-filled, inert-atmosphere, out-of-reactor capsule, designed to duplicate the thermal history of capsule GEH-22-3 has been assembled and is ready for the first of four simulated ETP cycles totaling 99.9 days at approximately $1100 \mathrm{~F}$ (595 C). 
The liquid metal capsule GEH-22-4 is now operating in cycle 87 and has achieved the design capsule operating temperature of $1400 \mathrm{~F}(760 \mathrm{C})$ under gas mixture control.

Glow discharge techniques have been developed for low temperature hydrogen permeation, effusion, and defect interaction studies of irradiated reactor alloys.

The model gas loop has operated a total of 3321 hrs since installation of the new heater; this includes 437 hrs during the past month. The system has operated well with no unscheduled shutdowns or equipment failures.

A scope design and drawing of a resistance heater to go into the vertical test section of the model gas loop was prepared. The Tiger $-V$ computer program is being used to size the components for this heater. A test specimen temperature of $2500 \mathrm{~F}(1370 \mathrm{C})$ is one design goal.

Further design study of the specimen test assembly from the standpoint of assembly and disassembly operations and handling has been initiated.

Additional measurements of pressure drop in the model gas loop continue to show that the specimen test assembly pressure drop will be within design limits of the ATR gas loop.

The surface contamination of niobium exposed 504 hrs at $2100 \mathrm{~F}$ $(1150 \mathrm{C})$ in the model loop has been identified by x-ray diffraction analysis as a Nb-N-O ternary compound. Exposure of test coupons in the heater discharge section of the model loop continues.

Thermally activated flow measurements on Fe specimens irradiated to a neutron fluence of $8.3 \times 1019 \mathrm{nvt}(\mathrm{E}>1 \mathrm{MeV}$ ) have been evaluated. Activation volume measurements confirm previous results at lower exposures that the defects introduced by irradiation produce only a small modification of the basic rate controlling mechanism.

A very pronounced dependence of hardening on carbon content has been shown by these experiments. Calculations on the jump frequency and migration distances of interstitials and vacancies substantiate the evidence that carbon traps interstitials and is a likely site for the nucleation of clusters.

Defect clusters 50-75 $\AA$ in diameter of a low density were observed in a thin foil of iron irradiated to a fluence of $9 \mathrm{x} 1019 \mathrm{nvt}$ $(\mathrm{E}>1 \mathrm{MeV})$.

Calibration tests on the following ultra high pressure units have been completed: piston cylinder tooling - $25.4 \mathrm{kbars}$ and $1500 \mathrm{C}$, 'belt' tooling - $37 \mathrm{kbars}$ and $1500 \mathrm{C}$, in-reactor hydrostatic cell - 
20 kbars and $100 \mathrm{C}$, and diamond ultra high pressure cell - 50 kbars and $22 \mathrm{C}$.

The solid form of benzene, used as a cell calibrant, is the same at 10 kbars and $22 \mathrm{C}$ as at 1 bar and $-5 \mathrm{C}$.

\section{ATR Gas Loop Operation and Maintenance}

Analytical instrumentation constructed by Montek, salt Lake City, has been operated by PNL personnel and released for shipment.

Additional R\&D programs are being concucted to assure quality control during the fabrication of the ATR heater.

\section{Metallic Fuels Development}

The irradiation of three tubular fuel elements of in 2.5 wto $U-1.0$ wto $\mathrm{Zr}$ clad with $\mathrm{Zr}-2$ continued in the $\mathrm{P}-7$ hot water loop at the ETR. Interim examinations sinow tinat 3\% fuel swelling has occurred after 2 at. $\%$ BU.

Twenty-four hollow core uranium fuel elements have been successfully irradiated in the ETR M-3 loop facility to a maximum burnup of $2580 \mathrm{MWd} / \mathrm{ton}$. Examination in the reactor basin showed that a small volume decrease has been experiencea by all elements. The maximum volume is 1.3\%. Eight of the elements were shippea to Battelle-Columbus for nondestructive neutron radiographic examination.

\section{Fast Reactor Dosimetry and Damage Analysis}

High temperature fluence monitors made from iron, nickel, and cobalt oxides in a matrix of magnesium oxide are being developed for use at temperatures in excess of $1200 \mathrm{C}$. whe first monitors of this type containing $C o O$ have been prepared and irradiated. The variation in the active metal concentration from monitor to monitor is small enough to permit use of the monitors without prior neutron-activation analysis.

Analyses have been made of an epithermal critical assembly using diffusion-theory and transport-theory codes with two sets of cross sections. The results indicate that greater differences are introduced by the computational method than by the two cross-section libraries. The HRe cross sections give results in agreement with those generated with fast reactor cross sections. 


\section{ENGINEERING DEVELOPNENT}

\section{Neutron Flux Monitors}

Planned ETR in-core testing of the U-234 - U-235 regenerative thermal neutron flux detectors moved a step with receipt of required capsule design and cable length information.

Microwave and Infrared Detection of Coolant
Impurities and Measurement of In-Reactor remperatures

Investigations with the experimental microwave system for detecting moisture in helium coolant gas revealed a sensitivity of $600 \mathrm{ppm}$ of water vapor at a temperature of $436 \mathrm{C}$.

Upstream Boiling Burnout

Another series of experiments were performed in the study of upstream boiling burnout. In these experiments a test section virtually identical to one used earlier was considered. Only difference between these test sections was in wall thickness and material. It was expected that the upstream boiling burnout behavior would be identical with both test sections; however, significant differences were observed. Several possible theories to explain these differences were proposed.

\section{PLUTONIUM UTILIZATION PROGRAM}

\section{Fuels Development}

An eight-rod FERTF test element was designed and fabricated to test defected and nondefected fuel rods operating under high performance conditions.

A FERTF test proposal for irradiating a 19-rod cluster of commercially fabricated rods containing $\mathrm{UO}_{2}-\mathrm{PuO}_{2}$ pellets was written and approved.

To evaluate the possibility of fragments from a failed rupture disk causing fuel failures, all fuel elements were discharged from the PRTR and examined. None of the fuel elements contained any fragments of the stainless steel rupture disk.

A simplified instrumentation system for measuring fuel rod pressure was fabricated and installed. 
Design of water-cooled power reactor type fuel capsules for irradiation testing in the Transient Reactor Test Facility (TREAT) was startē.

A fuel element with a flux wire attached by underwater banding techniques has been tested for fretting potential in a loop in the 314 Building.

An uncierwater "manipulator" or tray for the examination of FERTF fuels was fabricated last month. Negotiations were completed, and a contract was signed for an underwater profilometer.

A series of cost studies were completed, and the data were summarized for publication at the IAEA Symposium on "Uses of Plutonium As a Reactor Fuel," to be held in Brussels, Belgium, in March.

The majority of the plutonium isotopic analyses were completed for Yankee fuel samples ranging in exposure from approximately 10,000 to $40,000 \mathrm{MWd} /$ ton.

\section{Reactor Physics}

Analysis is continuing of the data collected during the Batch Core critical tests in PRTR.

Measurements have been made of the effect on power generation rate in a 19-rod HPD cluster in channel 1550 in PRTR when the $\mathrm{D}_{2} 0$ coolant is replaced by $\mathrm{H}_{2} \mathrm{O}$ coolant.

Two summaries entitlea "Critical Experiments with the $\mathrm{UO}_{2}$ 2 wto $\mathrm{PuO}_{2}$ Batch Core in the PRTR" and "Analysis of a UO2 - 19-Rod Cluster Experiment with the RBU Monte Carlo Code" have been submitted to the American Nuclear Society for presentation of papers at the 1967 Annual Meeting.

Evaluation is continuing of the relative merits of analytical chemistry methods versus reactivity methods for determining the concentration of $\mathrm{B}-10$ in $\mathrm{D}_{2} \mathrm{O}$.

Procurement of a lithium-drifted germanium detector system for the PNL gamma scanner has been initiatea.

The cross section ratio $\hat{\sigma}^{41} / \hat{\sigma}^{49}$ cannot be determind sensitively from the Al-Pu burnup data using a multivariable regression analysis.

Calculations were made to study the characteristics of various thorium fueled loadings in the PRTR. 
A summary, "Experiments and Calculations for $\mathrm{H}_{2} \mathrm{O}$ Moderated Assemblies Containing $\mathrm{UO}_{2}$ - 2 wto $\mathrm{PuO}_{2}$ Fuel Rods," has been submitted to the American Nuclear Society for presentation of a paper at the Annual Meeting of the ANS.

Calculations are being made to determine critical masses of $\mathrm{UO}_{2}$ - 4 wto $\mathrm{PuO}_{2}$ fuel in $\mathrm{H}_{2} \mathrm{O}$ moderated lattices.

Analytical correlation of temperature coefficients of reactivity, fuel element worths, and power peaking measurements of $\mathrm{UO}_{2}$ - 2 wto $\mathrm{PuO}_{2}-\mathrm{H}_{2} \mathrm{O}$ lattice criticals are in progress.

Preprocurement planning was completed on possible offsite fabrication of 400 to 10004 wto $\mathrm{PuO}_{2}-\mathrm{UO}_{2}$ fuel rods to be used for critical experiments in the PRCF. An advertisement for expressions of interest to fabricate 400 fuel rods for delivery before June 1 , 1967, was prepared for placement in the Commerce Business Daily.

Rods containing $100 \mu \mathrm{PuO}_{2}$ particles have been delivered completing the set for the 8 wto $\mathrm{Pu}-240$ series. Experiments with particle sizes 0,200 , and $350 \mu$ particles indicate a nonlinear variation of $k_{\text {excess }}$ with increasing particle size for a graphite lattice. This result disagrees with a calculated linear decrease and will be checkea using the $100 \mu$ rods. Delivery of another series of rods containing 24 wto $\mathrm{Pu}-240$ is expected within six weeks.

Cross sections for $\mathrm{Pu}-238$ and $\mathrm{Pu}-239$ are being revised in the BNW Master Library to reflect the recommendations of recent evaluations for the ENDF/B Library. Several modifications have been made to increase the speed of a new code which calculates thermal neutron scattering kernels by directly integrating the time-dependent correlation functions describing the motions of the scattering atoms. A large number of both point and group cross section calculations have been made for special purpose requests of customers both within and outside the department. Revisions have been made to improve the accuracy and efficiency of two codes used in calculating and preparing data for the ENDF/B Library.

A document has been written describing a computer code which computes the Dancoff correction factor. Included in the report are results of resonance absorption studies based upon the various methods available in the program.

\section{Reactor Engineering Development}

Calculations were performed to determine boiling burnout limits for an 8-rod fuel element to be irradiated in the PRTR Fuel Element Rupture Test Facility. Flow experiments have been scheduled to determine the actual coolant flow through the fuel and the amount bypassed around a basket tube enclosing the fuel element. 
Calculations were performed to evaluate two candidate fuel elements for the thorium loading. One design consisted of an 18rod cluster element operated at 64 watts/gm. It was found that this fuel would produce excessive surface heat fluxes from the boiling burnout standpoint and central fuel melting. A second design consisting of two concentric fuel tubes is being studied.

Two thermal hydraulic codes have been obtained from oak Riage National Laboratory. An assessment of the capabilities of these codes is under way to determine the feasibility of including them in the fuel cycle chain called"FULCYC".

Materials Development

A small autoclave facility has been constructed for use in determining the influence of reactor environmental variables of ceramic fuel dissolution behavior.

Shutdown radiation measurements are being taken during outages to provide information on the buildup of radioactivity in PRTR during batch core and neutral pH operation.

Twenty-four Zircaloy-2 and zircaloy-4 specimens from PRTR Test 72 were sampled for hydrogen analysis. Maximum in-flux hydrogen pickups for specimens exposed as-etched were 12 ppm for Zircaloy-2 and $20 \mathrm{ppm}$ for Zircaloy-4 after 209 days at 475 to $530 \mathrm{~F}$. Sections of PRTR in-flux Tube No. 5696 have been submitted to Radiometallurgy for metallographic aetermination of oxide thicknesses.

A crack propagation test was run on a tube with a $1 \frac{1}{2}$ " flaw at $300 \mathrm{C}$. The tube had a burst strength in the hoop direction of 36,000 psi.

\section{Test Reactor Cperation}

The PRTR operated at powers up to 6 Miv while conducting the initial batch core power tests. A total production of 9.46 MWd was obtained. Following these low level power tests, the P-4 rupture disc was found to have failed again. The reactor was defueled, and the primary system was flushed six times. At the end of the month, $63 \%$ and $12 \%$ of the missing pieces from the first and second rupture discs, respectively, have been recovered. I series of tests were conducted to determine the cause of the rupture disc failure. Results from these tests are being evaluated. 


\section{EBWR Demonstration Program}

The summary of a paper describing the high burnup results from the $\mathrm{UO}_{2}-\mathrm{PuO}_{2}$ capsule and rod tests was submitted to the American Nuclear Society for presentation at the meeting this June in San Diego. A description of a coauthored paper on the design, fabrication, and irradiation of EBWP fuel rods was submitted to the American Society of Mechanical Engineers for possible presentation at the meeting in Pittsburgh in November 1967.

NUCLEAR SAFETY

\section{Containment Systems Experiment}

A series of leakage rate tests was completed on the containment vessel at pressures of $60,30,15,10,5$, and 1 psig with a nominal leakage rate of $0.5 \%$ per day at 60 psig. Xenon tracer gas was injected into containment for evaluation in determining individual leak flow rates and to test the adequacy of sampling and analysis facilities. Three runs were performed in the Aerosol Development Facility. One run was to investigate iodine behavior in a painted tank which had been exposed to extended steaming. A second run was to study iodine behavior at the same conditions as previous runs except that steam condensation was prevented by heating the tank walls. A third run was to evaluate the analytical program with samples of a three-component aerosol. A computer program has been developed to calculate the heat flux to a wall based on the initial temperatures distribution and the transient temperatures at each surface of the wall.

\section{Pressure Vessel Crack Monitoring}

Development efforts continued on a program to develop a crack monitoring system utilizing the phenomenon of acoustic emission. Fabrication of three static bursts test samples was completed, and initial cracking was producea in one specimen preparatory to burst testing. Sensing probe development continued and pinhole-free dielectric layers were obtained with silicon monoxide-silicon dioxide layers. Design of an integrated emission-rate analyzer was completed, and the breadboard circuits were tested. Further work is in progress to upgrade the frequency response of the monitoring system presently being used for spectral analysis. 
Reactor Safety Analysis and Evaluation

Gamma heat monitoring experiments were performed in the Sandia Experimental Reactor Facility (SEPF). The results of these tests will form a basis for predicting the gamma heating of large fracture test specimens.

\section{Fission Product Aerosol Containment}

Shakedown operation of the $4 \mathrm{~m}^{3}$ spray chamber continuea with special attention given to temperature control. Laboratory and theoretical studies were devoted to the rates of removal of methyl iodicie by hycirazine under various conaitions.

\section{Disposal of Reactor Off-Gas Into Soil Systems}

Dimensionless graphs were under preparation to illustrate the flow as a function of radial distance from the injection well under continued pumping; these were based on additional improvements of the calculating methods.

\section{Columbia River Sedimentation Studies}

Analyses of the last upriver water and seciiment samples were completed and the results forwarded to the U.S. Geological survey.

\section{Radioactive waste Solidification}

Mixed sodium-rare earth sulfates which precipitate in PiN-2 waste changes from a finely diviced, easily suspended, solid to a coarser solid which tends to cake in the temperature interval 25 $50 \mathrm{C}$.

The second and third radioactive pot solidlfication runs in WSEP were conducted successfully. liowever, operating difficulties due to feed solids characteristics were encountered with the PW-2 feed used.

The sulfate and greater-than-flowsheet concentration of aluminum present in WSEP feed stock obtained from the Purex plant will not significantly affect melt properties during the WSEP Run 5 (a spray solidification run).

Simulation Modeling of Expected Thermal Generation in Selectec River Systems

Preparations continued for computer simulation of heat discharges from the vrescien reactors. 


\section{CUSTOMER}

\section{Assistance to Isochem, Inc.}

Experimental ( $\mathrm{Pu}, \mathrm{U}) \mathrm{O}_{2}$ pellets were preparea and analyzed for chlorine impurity. The results show that sintering of the coprecipitated 20 wto plutonia-urania powder significantly lowers the quantities of chlorine impurity that may be present in the feed material. 
DIVISION OF REACTOR DEVELOPMENT AND TECHNOLOGY PROGRAMS (F. W. Albaugh)

CIVILIAN POWER REACTORS

Nuclear Systems and Concepts Analysis (E. A. Eschbach)

Systems Analysis Task Force Activities

Complete Phase II calculations of the nuclear power industry are nearing completion. One optimum for a well aebugged model was obtained for a case which included all reactors in the study and a growth curve for nuclear plants only. The case which includes INR, LMFBR, HWOCR, and HTGR only is being run. Cases including LWR and LMFBR only, LWR and HWOCR on $l y, L W R$ and HTGR only, and LWR only are being prepared. All these cases are for a discount rate of 6\%. P second series of calculations based on no discounting is being preparea. Following this, the introduction of coal reactors and further calculation with these basic cases is planned.

A computer code for calculating the added capacity requirements needed to compensate for the aging of electrical power plants was completed. The code will be expanded and refined as soon as practicable.

The report generator for submitting the results of the linear program is being written and shoula be finished prior to the next Task Force meeting.

Analysis of electrical demand is progressing. Growth factors for each of the 48 power supply areas over a 75-year period are nearly all calculated.

Task Force Contributions

Phase II PACTOLUS results have been sent to the appropriate task force committees so that they may check our reactor mass flows against what they think the mass flows should be. Any existing errors in the Phase II data should show up as a result of this review.

POWERCO will be modifiea to give an improved breakdown of the power costs. The POWERCO results from the PACTOLUS runs were not included with the data sent to the task force committees because of some discrepancies in the present jrealiown (but not in the total power cost). 
A new table is being added to PACTOLUS output which will give some information about the reactor design. Information, initially, will include specific powers, conversion ratio(s) (at least one), doubling times, and some conservation indexes. Aaditional information will be computed as it seems desirable.

The FAST code is being modified to simplify the input and to make the input closely compatible with the formats suggested for submittal of Phase III data.

It is intended that the data preparation should be simple enough that a technologist could prepare decks with a minimum of supervision. In this light the code will be designed to automatically adjust the shutdown at the end of 30 real years, thereby eliminating the hand iteration previously required. This will be particularly valuable if the capacity factor schedule is changed for a reactor.

Code Libraries and Calibrations

Work is under way to calibrate the ALTHAEA burnup code with the latest available experimental burnup data such as the plutoniumaluminum fuel burnup data from PRTR(1) and the latest Yankee core evaluations. (2)

A new ALTHAEA nuclear library was made up incorporating Westcott's latest recommended $2200 \mathrm{~m} / \mathrm{s}$ values for the four major fissile nuclides. (3) This library is also available for the ALTHAEA revised four-group version.

The fast cross section library is being revised to eliminate duplication and include curiums and other isotopes normally used in the ALTHAEA library. BARNS was modified to provide the cards of the 26-group cross sections used for the makeup of the fast cross section library.

(1) D. E. Christensen, E. B. Peppard, and W. A. Reardon. "Burnup Data From Low Exposure Plutonium-Aluminum Fuel." BNWL-CC-904. November 1,1966 .

(2) F. P. Roberts, H. H. Van Tuyl, "Chemical Analysis of Spent Power Reactor Fuels." BNWL-SA-503. December 27, 1965.

(3) C. H. Westcott, et al. "A Survey of Values of the $2200 \mathrm{~m} / \mathrm{sec}$ Constants for Four Fissile Nuclides." Atomic Energy Peview IAEA, Vienna III 2 (1965). 
Reactor Systems Analysis

The program POWERCO, which calculates nuclear power costs from the physics data provided by PACTOLUS, has been modified frequently to give various breakdowns of the power cost. A further modification will be made to conform to the most recently designated breakdown.

\section{Conceptual Reactor Design Studies (J. C. Fox)}

Thermal Sink Limitations Study

All but two volumes have been received of the U.S. Geological Survey Water Supply Papers providing compilations of temperature and flow data. Flow and temperature correlations are continuing.

\section{Reactor Siting Study}

A summary report on estimated heat dissipation system costs for various site locations and dissipation means has been received from P. W. Beck and Associates, Denver, Colorado. The report has been reviewed, and the data therein will be incorporated into the final report on the siting study.

Steam-Cooled Fast Reactor

Blanket thickness calculations were made for the physics twodimensional analysis. Reasonable volumes of blanket material were determined, and the blanket material was distributed between the axial and radial blankets as a function of geometric buckling for different core volumes and height-to-diameter ratios.

Temperature constraints have not yet been added to the design simulation. Maximum clad and fuel temperatures have been observed as a function of core height-to-diameter ratio, number of pins per subassembly, number of subassemblies in the core, pin diameter, and core outlet temperature. A feel for the effect of each of these variables on material temperatures, cycle efficiency, and pressure drop is necessary in order to choose the parameters to vary and how to vary them in meeting the temperature constraints.

A number of small refinements were made in the design simulation. These refinements included: a model for fission gas plenum size was adaed, the compressibility contribution to pressure drop was included, and some changes were made in the forms of a number of equations to make the simulation more flexible. 
Calculations have been set up to convert the one-dimensional physics results and core design parameters into the inputs necessary for the fuel cycle cost estimates. The parameters calculated are:

- fissile and fertile fuel inventory in the core and radial and axial blankets,

- throughput of fissile and fertile material,

- the necessary breeding ratios will be supplied in parametric form (as a function of core, volume, smeared steam density and fertile-to-fissile fuel ratio) from the physics results.

The fuel cycle cost analysis was modified to match the form of the unit cost estimates expected from ORNL. The following unit costs were received in a phone conversation with $\mathrm{J}$. T. Roberts of ORNL on February 18, 1967. For a 10 tonne/day reprocessing facility, the unit costs would be $\$ 15 / \mathrm{kg}$ ( $U+P u)$ of core and blanket material. Post-reactor shipping costs are estimated to be $\$ 10 / \mathrm{kg}$ (U+Pu). This includes disassembly and shipping. The shipping time was estimated at 30-40 days for a core load.

Both the calculations for the input parameters and the fuel cycle cost estimates have been incorporated into the main MIMIC simulation. Runs are now being made to eliminate duplicate nomenclature between the design and economics calculations.

The physics parameter survey has been somewhat expanded. The complete scope is shown in the following table. Previously only the cases on the top left to lower right diagonal had been included as these represent the extremes and a central point.

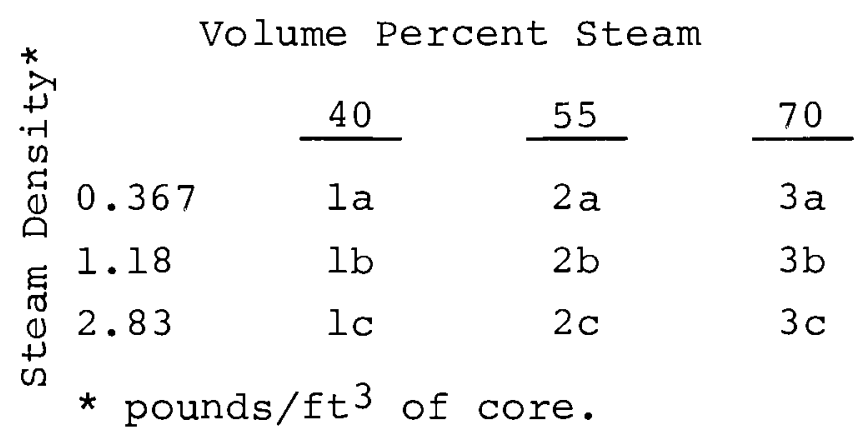

Reactor sizes from 4000 liters to 13,000 liters are considered and $\mathrm{H} / \mathrm{D}$ ratios of 1.0 to 0.25 will be examined. Partial results are available for cases on the diagonal of the table. These calculations utilized spherical geometry and the PNL cross sections. Current efforts are aimed at using shape factors to determine the effects of 
various H/D ratios, normalizing the existing results to the ORNL cross sections and filling out the cases from the table.

R. S. Carlsmith from ORNI visited the Laboratory on March 2, 1967, to discuss calculational methods and the general scope and plan of attack of the physics portion of the parametric study. He in general approved of our methods and offered valuable insight to the probable importance of some of the parameters.

USAEC-AECL Cooperative Program (J. J. Cadwell)

In-Reactor Measurements of Creep in Zr-2.5 $\mathrm{Nb}$ Alloy

Duplicate unirradiated control creep tests conducted at $400 \mathrm{C}$ and $25.6 \mathrm{Kg}-\mathrm{mm}^{-2}(36,500 \mathrm{psi})$ stress have been completed. The rupture times for these were 4026 and 3141 hrs, and the corresponding strain rates were $8.5 \times 10^{-6}$ and $1.1 \times 10^{-5} \mathrm{hr}^{-1}$. The total elongations were $21 \%$ and $29 \%$ for the 1 -inch reduced gage section and the reduction in areas were $86 \%$ and $85 \%$, respectively. The specimen with the longest rupture life and the slowest creep rate had the lowest total elongation. Examination of the specimen with $29 \%$ total elongation revealed a double neck. These two tests are expected to be quite useful in developing a strain rate to rupture time relationship which will be used in selecting the test conditions of stress and temperature for future tests.

The strain rates for these two tests are slightly higher than the $6.4 \mathrm{x} 10^{-6} \mathrm{hr}^{-1}$ observed for the in-reactor creep tests conducted at $400 \mathrm{C}$ and $25.6 \mathrm{Kg}^{-\mathrm{mm}^{-2}}$ stress.

Cross-Flow Mixing Between Parallel Flow Channels During Boiling

The experimental portion of the program to determine values of cross-channel mixing during two-phase flow in rod bundle fuel elements was continued. The basic purpose of this program is to obtain a method to predict local flow and enthalpy conditions in each subchannel of rod bundle fuel elements. This information will help provide a more accurate means to predict boiling burnout conditions.

A report describing the first set of experiments, recently completed, is in preparation. In these experiments a test section simulating two adjacent subchannels formed by rods on a square array located next to rods on a triangular array was considered. Measurements were made of subchannel flow rate and enthalpy at the exit of a test section, and this information was used to determine cross-flow mixing during boiling. The report will include descriptions of the experimental facilities and test section, results of the experiments, 
error analysis, and comparison of the results to calculations using the digital computer program developed earlier.

Final assembly of the new electrically heated test section was completed. In this new test section the flow passages formed by adjacent square pitch array fuel rods are simulated. This test section will be used to measure only the turbulent component of cross-flow mixing during boiling.

Effects of Rod Spacing on Boiling Burnout

An experimental program has been undertaken to determine the effect of rod spacing on boiling burnout in simulated rod bundle fuel elements. Two electrically heated test sections have been designed for this purpose. The first will be usea to investigate the effect of adjacent heated rods on boiling burnout by using a single rod surrounded by four simulated rods, as in a square rod array. The simulated outer rods are formed by a "4-lobe" tube. The four convex surfaces facing inwards simulate the adjacent heated surfaces, and the concave inner surfaces form the flow subchannels. The wall thickness of the concave inner surfaces is reduced at the outside to provide the proper heat generation in the subchannels. Design of the test section allows different diameter inner rods to be inserted, thus allowing adjustment of the simulated rod spacing. Roa spacings in the range from $0.015-$ inch to $0.080-i n c h$ will be consiciered.

The second test section is designea to investigate the effect of an unheated wall adjacent to a heated rod. The unheated wall is simulatea by a square unheateä tube surrounding the heated center rod. Design of this test section allows interchangeability of the same center rods in similar fashion as the previously described test section to allow the consideration of various roa-surface spacings.

All materials for both test sections have been received, and fabrication is unäer way.

Evaluation of Zirconium-2.5응 Nb Pressure Tubing

The general objective of this program is to evaluate $\mathrm{Zr}-2.5 \mathrm{Nb}$ as a pressure tube material with reference to the tests and reactor experience that has been obtained on zircaloy-2 pressure tubes.

Approximately 60 feet of test material was receivea. This material was supplied in the solution heat treated and 15\% cold worked condition. Difficulties were experienced by the manufacturer with wall thickness eccentricity. By machining, this material is usable. 
Crack propagation tests were done at room temperature on four heat treated test specimens. The heat treatment consisted of only a solution treatment at $880 \mathrm{C}$ and a quench, followed by 15\% cold work. The results are tabulated below:

\section{Crack Propagation Data for Zr-2.5 wto Nb Alloy}

\begin{tabular}{|c|c|c|c|c|c|}
\hline $\begin{array}{l}\text { Specimen } \\
\text { Ident. } \\
\end{array}$ & $\begin{array}{l}\text { Specimen } \\
\text { Condition } \\
\end{array}$ & $\begin{array}{l}\text { Test } \\
\text { Temp. } \\
\text { oc } \\
\end{array}$ & $\begin{array}{l}\text { Slot } \\
\text { Length } \\
\text { (in.) } \\
\end{array}$ & $\begin{array}{l}\text { Hoop Stress } \\
\text { at Failure } \\
\text { (psi) } \\
\end{array}$ & $\begin{array}{l}\text { Crack Length } \\
\text { at Failure } \\
\end{array}$ \\
\hline $29 A$ & $\begin{array}{l}\text { Solution Heat } \\
\text { Treated }+15 \% \mathrm{CW}\end{array}$ & 23 & $\frac{1}{2}$ & 171,000 & $\begin{array}{l}\text { Shear \& plane } \\
\text { strain fracture } \\
\text { full length }\end{array}$ \\
\hline $16 \mathrm{~A}$ & $"$ & 23 & $1 \frac{1}{2}$ & 61,000 & $\begin{array}{l}\text { Plane strain, } \\
\text { full length }\end{array}$ \\
\hline $12 \mathrm{~A}$ & i: & 23 & $2 \frac{1}{2}$ & 52,600 & $\begin{array}{l}\text { Plane strain, } \\
\text { full length }\end{array}$ \\
\hline $28 \AA$ & $" 2$ & 23 & 4 & 47,000 & $\begin{array}{l}\text { Plane strain, } \\
\text { full length. }\end{array}$ \\
\hline
\end{tabular}

Tube dimensions after machining were 18 inches long, 2 inches ID and 0.150 inch wall thickness.

The fracture mode observed with specimen $29 \mathrm{~A}$ was interesting in that, after failing the slot web, the initial crack propagated by shear until the length of the propagating crack was 2 inches each side of the initial $\frac{1}{2}$ inch millea slot at which point the crack propagated in a tensile mode. For the shorter slot length, $\frac{1}{2}$ and $1 \frac{1}{2}$ inch, the fracture strength is higher than for either the $30 \% \mathrm{CW}$ or $60 \% \mathrm{CW}$ material condition. The most significant behavior difference is that the solution heat treated, quenched, anc $15 \% \mathrm{CW}$ material appears to be much more prone to failure and crack propagation by the tensile mode, whereas the $30 \% \mathrm{CW}$ and $60 \% \mathrm{CW}$ fails predominantly by the shear mode.

Additional test specimens are being aged at $550 \mathrm{C}$ for $24 \mathrm{hrs}$ in preparation for brittle fracture testing.

A preliminary evaluation of ausforming type thermo-mechanical treatment of $\mathrm{Zr}-2.5 \mathrm{Nb}$ was made to determine the effect of this treatment on strength and mechanical isotropy. The specimens were canned in Zircaloy-2, heated to $1000 \mathrm{C}$, quenched in salt at various temperatures between 600 and $850 \mathrm{C}$, hot rolled to about $10 \%$ reduction, and. finally water quenched. Strength and mechanical anisotropy was determined by taking the knoop hardness on the rolling, transverse, and longitudinal planes of the specimens and two orientations of the indenter. The standard deviation of the hardness numbers was taken as a numerical index of the anisotropy of a specimen. Results of the test are summarized in the following table. 
The Effect of Ausforming on $\mathrm{Zr}-2.5 \mathrm{Nb}$

\begin{tabular}{|c|c|c|c|c|c|c|}
\hline $\begin{array}{l}\text { Hot Work } \\
\text { Temp. }{ }^{\circ} \mathrm{C} \\
\end{array}$ & $\begin{array}{l}\text { Hot Work } \\
\frac{\circ}{0}\end{array}$ & Ave. KHN & Pfter & $\begin{array}{l}\text { KHN } \\
1, \mathrm{~d} .500 \quad \mathrm{C}\end{array}$ & $\begin{array}{l}\text { Anisotropy } \\
\text { Index }\end{array}$ & $\begin{array}{l}\text { Ave. KHN } \\
\text { W.Q. }+6 \text { hrs a Temp. }\end{array}$ \\
\hline 600 & 5 & 201 & & & 6.1 & \\
\hline 600 & 9 & 220 & & & 11.8 & \\
\hline 600 & 11 & 224 & & & 7.6 & \\
\hline 650 & 11 & 222 & & 225 & 7.3 & 185 \\
\hline 700 & 12 & 220 & & 222 & 10.1 & 214 \\
\hline 750 & 0 & 221 & & 214 & 7.0 & \\
\hline 750 & 12 & 219 & & 231 & 5.4 & 207 \\
\hline 800 & 12 & 233 & & 240 & 9.1 & 221 \\
\hline 850 & 14 & 251 & & 248 & 7.3 & 242 \\
\hline
\end{tabular}

Thermo-mechanical procedure:

1) Seal $\mathrm{Zr}-2.5 \mathrm{Nb}$ plate in a $\mathrm{Zr}-2$ can.

2) Soak at $1000 \mathrm{C}$.

3) Quench in salt at hog working temperature.

4) Hot roll to desired o reduction.

5) Water quench. 
None of the specimens was significantly anisotropic compared to $30 \%$ colà worked $\mathrm{Zr}-2.5 \mathrm{Nb}$ which would have an index of 25 . The ausforming process appears to have caused a slight improvement in strength. Since the strength appears to increase with increasing hot recuction, strength increases could become significant at reductions in thickness of $100 \%$ or greater.

APPLIED AND REACTOR PHYSICS

Plutonium Criticality Studies (E. D. Clayton)

Basic Criticality Studies with Plutonium Compounds in Undermoderated Bange; Effect of Pu-240 on Criticality; Effect of Pesonance Absorbers

The series of criticality experiments with $\mathrm{PuO}_{2}$-polystyrene compacts and the remote split-table machine were continued. In this case the $\mathrm{H} / \mathrm{Pu}$ atomic ratio for the fuel mixture is 5, with the Pu-240 content being about $12 \mathrm{wt}$. For the $\mathrm{H} / \mathrm{Pu}$ ratio of 5 the spectrum is sufficiently fast that about 50\% of the fissions will be produced by neutrons with energy $>600 \mathrm{eV}$. Coinciaent with these basic criticality studies, which provide experimental ciata on plutonium and its various isotopes in connection with criticality safety, several experiments are being performea in support of the Gas-Cooled Fast Reactor (GCFP.) program.

The GCFR experiments are being done for General ptomic. These experiments utilize the fuel already on hand and are part of the GCFR critical experiment program to check calculational methods and basic neutronic data used in the GCFR ciesign. The proposed experiments also provide data on the effects of resonance and thermal poison materials in a spectrum similar to that resulting from steam or water entry into the GCFR core. In regard to this, material worth measurements are being made with Dy, Gd, and Hf. These materials are in the form of oxide powders placed in flat stainless steel containers, $6 \mathrm{x}$ $6 \times \frac{1}{4}$ in.

Compatible with the size of the neutron poison plates, a rectangular parallelepiped core with base dimensions of $12 \mathrm{x} 18$ inches was used in the first experiments. Criticality measurements were made in a clean assembly and then with the assembly containing three, $\frac{1}{4}$ inch thick plates of $\mathrm{Dy}_{2} \mathrm{O}_{3}$ spacea at $1 \frac{13}{2}$-inch intervals. There was insufficient material of 12 wto $\mathrm{Pu}-240$ available at an $\mathrm{H} / \mathrm{Pu}$ of 5 to obtain criticality in the configuration ciosen. Therefore, it was necessary to make use of some additional fuel of different pu-240 content with an $\mathrm{H} / \mathrm{Pu}$ ratio of 15 . This material was added to the top layer of the assembly. The results of measurements are presented in the following table. 


\section{UNREFLECTED CRITICAL CONFIGURATIONS OF PLUTONIUM COMPOUNDS}

\section{Fuel: $\quad \mathrm{PlO}_{2}$-Polystyrene Compacts}

Region I of Core

$(240 \mathrm{pu}-11.5 \mathrm{wt} \%, \mathrm{H} / \mathrm{Pu}=5)$
Region II of Core

\section{Length}

Width

Height

$12.12 \mathrm{in.}$

18.18 in.

9 in.

$12.12 \mathrm{in.}$

18.18 in

$9-3 / 4$ in.*

${ }^{*}$ Assembly contained three $1 / 4$ in. thick

plates of $\mathrm{Dy}_{2} \mathrm{O}_{3}$ spaced at $1-1 / 2$ in.

intervals

12.12 in.

18. Iú in.

$11.28 \mathrm{in.}$

\section{Height of Other Material}

1.79 in. $\left(24 \mathrm{O}_{\mathrm{Pu}}-2.2 \mathrm{wt} \%, \mathrm{H} / \mathrm{Pu}=15\right)$

4.36 in. $\left({ }^{240} \mathrm{Pu}-2.2 \mathrm{wt} \%, \mathrm{H} / \mathrm{Pu}=15\right)$

$0.44 \mathrm{in} .\left(24 \mathrm{O}_{\mathrm{Pu}}-8 \mathrm{wt}, \mathrm{H} / \mathrm{Pu}=15\right)$ 


\section{Phoenix Fuel Reactor Program (D. D. Lanning)}

\section{MTR-Phoenix Fuel Experiment}

CAF-Phoenix Fuel Experiments. Analysis is continuing of the recordings of reactor noise made auring the CPF-Phoenix experiments.

A summary, "Approach-to-Critical Experiments with Phoenix Fuel," by $w$. P. Stinson and C. M. Heeb has been submitted for presentation of a paper at the 1967 Annual Meeting of the American Nuclear Society.

CAF-Phoenix Fuel Experiment Analysis. Analysis of the waterreflected 19-can array was extenced to include neutron transport representations. The water-reflected array was used in preference to the beryllium reflected assembly because of its relative simplicity. The application of discrete angle approximation transport theory very early showed that transport calculations are very much more sensitive to the group structure than are diffusion theory calculations on the same spatial mesh. The table below shows the calculated keff for the CAF core for transport theory (S4 approximation) versus diffusion theory.

Comparison of Transport Theory anc. Diffusion Theory Calculations

(Est. Experimental keff is 0.948)

\begin{tabular}{|c|c|c|}
\hline Case Description & $\begin{array}{c}\text { Transport } \\
\text { Theory } \\
\text { keff } \\
\end{array}$ & $\begin{array}{c}\text { Diffusion } \\
\text { Theory } \\
\text { keff } \\
\end{array}$ \\
\hline $\begin{array}{l}\text { 1. } 17 \text { energy groups, anisotropic } \\
\text { scattering in the lab system }\end{array}$ & 0.982 & 0.954 \\
\hline $\begin{array}{l}\text { 2. } 4 \text { energy groups, anisotropic } \\
\text { scattering in the lab system }\end{array}$ & 1.070 & 0.971 \\
\hline $\begin{array}{l}\text { 3. } 4 \text { energy groups, isotropic } \\
\text { scattering }\end{array}$ & 1.082 & 0.971 \\
\hline
\end{tabular}

Increasing the transport approximation to eight double angles (s8 approximation) had a negligible effect on the calculated k. Computations of $k_{\infty}$ for the core material smear gave virtually identical values for both ciffusion and transport theory. The partitioning of the flux into the discrete energy group structure is virtually identical in both methods. The large difference between the two methods comes from the core leakage calculation. In general, one observes large àifferences between few group transport and diffusion theory calculations in small, strongly reflected cores where the core spectrum is very hard so that quite a few neutrons are thermalized 
in the refiestor. This describes most Phoenix fuel cores. With 17 groups, the transport $k$ calculation is still n,3\% higher than the diffusion theory result.

The computer code DTF was employed to obtain the transport theory results. The well-known error in the diffusion constant which appears when one is using anisotropic scattering with axial leakage was removed. In the course of making this correction, the version available was changed to read input cross sections as punched by HRG. The tape number and absolute program name for this unique combination are available on request.

PRCF Phoenix Fuel Experiment. Loading of fuel in the PRCFPhoenix core has continued during the month, and a critical loading was achieved with $16 \frac{1}{2}$ fuel assemblies in a $3 \times 5 \frac{1}{2}$ array. Total safety sheet worth was measured to be 215 milli-k. Progress has been delayed by numerous malfunctions of special neutron detectors used during the initial loadings.

Special castings for fuel element end fittings have been obtained which contain $0.1 \%$ and $0.2 \%$ natural boron in the aluminum. These end fittings will be used to study methods of depressing the thermal neutron flux peak located at the bottom end of the fuel assemblies.

PRCF-Phoenix Fuel Calculations. Current PRCF calculations are being carried out using the 2-D code EXTERMINATOR. The predicted number of fuel boxes to achieve criticality has continued to increase as more and more detail is added to the description of the reflector. Based on the CAF-Phoenix analysis, the methods used here are expected to overpredict $\mathrm{k}$ by between 3.5 and $4.5 \%$. The values in the table below include a $4 \%$ reactivity normalization.

Effects yet to be considered include a heterogeneous treatment of the Al beam tube simulators, more detailed examination of the axial leakage, and recalculation of the PRCF-Phoenix core using the techniques learned from the CAF-Phoenix experiment. It is possible that the 3.5 to $4.5 \%$ reactivity error in the CAF due largely to edge effects may be still greater in the PRCF mockup because of the higher surface to volume ratio for the PRCF experiment. 


\section{PPCF-Phoenix Loacing Estimates}

\begin{tabular}{|c|c|c|c|}
\hline $\begin{array}{l}\text { O. of Boxes } \\
\text { to be } \\
\text { Critical } \\
\end{array}$ & $\begin{array}{l}\text { Calculated } \mathrm{k} \text { at } \\
\text { Measurea Critical } \\
\text { i.e., } 16.5 \text { Boxes } \\
\end{array}$ & $\begin{array}{l}\text { Calculateo } \mathrm{k} \\
\text { Adjusted by } \\
\text { CAF Experience }\end{array}$ & Condition of Peflector \\
\hline 11.0 & 1.132 & 1.09 & $\begin{array}{l}2 \% \text { H20 in Be, i.e., } \\
\text { MTP conäition. }\end{array}$ \\
\hline 11.5 & 1.124 & 1.08 & $\begin{array}{l}10 \% \mathrm{H}_{2} \mathrm{O} \text { in Be app. } \\
\text { PRCF concition. }\end{array}$ \\
\hline 11.75 & 1.120 & 1.08 & $\begin{array}{l}\text { Above + Be partialiy } \\
\text { removea \& Al beam tubes } \\
\text { added in a homogenized } \\
\text { representation. }\end{array}$ \\
\hline 12.5 & 1.102 & 1.06 & $\begin{array}{l}\text { A.bove }+ \text { water gap adja- } \\
\text { cent to core caused by } \\
\text { interstices of Be tube } \\
\text { reflectors. }\end{array}$ \\
\hline 14.0 & 1.075 & 1.03 & $\begin{array}{l}\text { A.bove + water gap at } \\
\text { control sheet position. }\end{array}$ \\
\hline
\end{tabular}

MTP-Phoenix Euel Calculations

Borated Aluminum Side Plates. The effect of borated side plates adjacent to the beryllium reflector has been studied. The table below gives the results for the effect on power peaking and $k_{\text {eff }}$.

\begin{tabular}{|c|c|c|c|c|c|c|}
\hline Case & $\begin{array}{l}\text { Length of } \\
\text { Control Pod } \\
\text { Inserted in } \\
\text { Core }(\mathrm{cm}) \\
\end{array}$ & $\begin{array}{l}\mathrm{N} / \mathrm{b}-\mathrm{cm} \\
\text { Boron }\end{array}$ & $\begin{array}{l}\text { Wto } B \\
\text { in AI }\end{array}$ & $k_{\text {eff }}$ & $\begin{array}{l}\hat{\mathrm{p}} / \overline{\mathrm{p}} \text { Side } \\
\text { Reflector } \\
\text { Interface }\end{array}$ & $\begin{array}{c}\hat{\mathrm{p}} / \overline{\mathrm{p}} \text { Bottom } \\
\text { of the } \\
\text { Core }\end{array}$ \\
\hline 1 & 43.1 & 0.0 & 0.00 & 1.032 & 1.65 & 3.38 \\
\hline 2 & 43.1 & $3.0 \times 10^{-5}$ & 0.02 & 1.026 & 1.63 & 3.41 \\
\hline 3 & 43.1 & $3.0 \times 10^{-4}$ & 0.20 & 0.983 & 1.50 & 3.52 \\
\hline
\end{tabular}

The position of the maximum power peak was at the bottom center of the core away from the borated plates and, hence, was inversely affected by the addition of boron. The use of borated side plates will tend to suppress the power peaks along the edge of the core, but additional design features must be included to prevent the power generation from shifting into unroadea portion of the core and increasing the power peak in that region. 
MTR Burnup Calculation. In an effort to more clearly determine the burnup characteristics of the Phoenix MTR core, a series of 2-D diffusion theory burnup calculations are under way. This series is aimed at determining and understanding the heterogeneous behavior of the fuel burnup with special attention concentrated on core edge power peaks. The series of 2-D calculations range from a one-region burnup with no heterogeneous burnup effects to very detailed models with small burnup regions in the areas of high power. The results of the one-region burnup are shown in the table following, which is in close agreement with the very early 1-D burnups for the MTR-Phoenix experiment. The 2-D calculations use 4 energy groups and are carried out using the ASSAULT code.

\section{One Region 2-D Burnup Calculations}

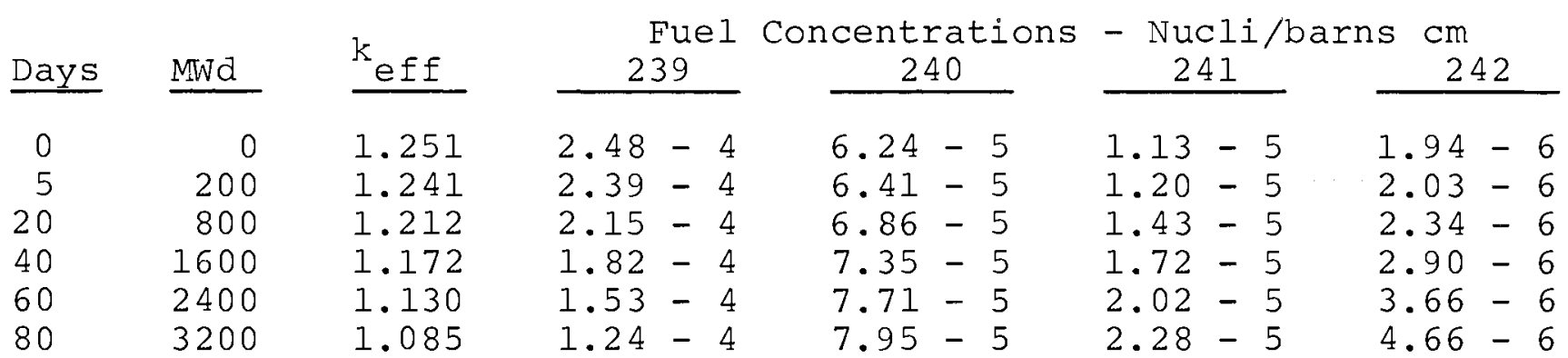

MTR Core Thermal Hydraulics Analysis

Previously, thermal hydraulic calculations for the MTR Core Phoenix Fuel Experiment were based on a parametric survey of horizontal and axial power peaking factors. The study was carried on in this manner because the power distributions available at that time were spliced two-dimensional results, and there was a good deal of uncertainty, not only in the calculated over-all peaking factor, but also in the estimated horizontal and axial power peaking contributions. Consequently, the thermal hydraulic calculations covered a wide range of possible horizontal and axial peaking contributions and, for this reason, used only approximate heat transfer limits.

Since three-dimensional power distributions are now available, the parametric study is no longer needed and specific cases will be investigated in more detail. Heat transfer limits, as dictated by incipient subcooled boiling, nominal heat flux, corrosion, and material integrity, can now be evaluated more accurately.

Idaho Nuclear, Inc., has a digital computer program, written in Fortran IV, for performing standard practice Mrr thermal hydraulic calculations. The program is available for our use, and if it can be adapted to the Univac 1107 or IBM 7090 computer systems, without undue difficulty, it will be used to perform the Phoenix core thermal hydraulics work. Since the Phoenix Core has fewer, but thicker fuel 
plates, it may be necessary to make some internal changes in this code. If the code cannot be used, the digital program which was used in the parametric heat transfer study will be modified to accommodate the three-dimensional power distribution and perform more precise thermal hydraulic calculations in strict accordance with standard MPP practice.

Fuels Fabrication anci Development

Since the completion of the A1-Pu fuel plates for the PPCF experiments, major emphasis has been placed on problems related to the fuel core loading of Al-Pu fuel elements in the MTR.

Discussions were held with personnel at Idaho Nuclear concerning the design, fabrication, and testing of fuel elements for the Phoenix test in the MTR. In general, the specifications for the Phoenix fuel elements will be patterned after the existing specifications for the MTP fuel elements. Development and testing work will concentrate on those aspects of the Phoenix fuel which differ significantly from the existing MTR fuel.

Work is under way to establish fuel ciesign, specifications, and potential commercial fuel fabricators. Irradiation test capsules are being prepared. Four plates containing depleted uranium as a stand-in for plutonium have been fabricated and are being evaluated. The results of this evaluation in conjection with existing technology will form the basis for the final process.

\section{PNL-Idaho Nuclear Corporation Contacts}

Ross Marsden visited on $2 / 16 / 67$ primarily to examine the PPCF mockup of the MTP core. He pointed out that nonrepresentative edge effects would be created by the water gap that can be removed by adding the Be triflutes at the core reflector interface. As a result, the MTR core mockup will be removed from the PRCF and the Be reflector will be restacked in the area adjacent to the core. All other facets of the mockup critical seemed to meet with his approval.

A trip was made on February 16 to the Idaho Peactor Test site. A number of problems which will be pertinent to the loading and running of the test were discussed. Detailed information is available in an internal report covering this trip.

A tentative trip to the MTP is planned for the week of March 27 , at which time the MTR will be shut down for a 3- to 4-day outage. P visit auring shutdown will allow a better estimate of experimental capabilities and problems which might be encountered during the Phoenix burnup experiment. 


\section{High Temperature Reactor Lattice Physics Studies \\ (R. E. Heineman)}

Reactor Construction

A pressure test of the shell was successfully completed after several attempts. The leakage rate was reduced to less than $0.4 \% / h r$ at a pressure of $5 \mathrm{psig.} \mathrm{The} \mathrm{gasket} \mathrm{seals} \mathrm{originally} \mathrm{provided} \mathrm{for}$ all openings will probably be reinforced with another type for the large door.

Acceptance Test Procedure 2804, Peactor Cooling Gas Systems, was completed, and the test data are being analyzed. Parts of it will be repeated after the gas dryer is piped into the system.

Acceptance Test Procedure 2800 , Vacuum Purge, was started without the vertical safety rods installed or the gas dryer system piped into the gas system. The test was interrupted to repair a leak from a bellows.

The gas dryer and its flow control valve were received. All major items of material and equipment have been received except the oscillators and the time-of-flight system.

The Acceptance Test Procedure 2803, Electrical Control System, was successfully completed, and the equipment appears to be well within the design requirements. The electrical heater system had been installed earlier and apparently functioned satisfactorily. Information from the test permitted a shorter and simpler program for heat control.

Nine horizontal control rods were completely assembled and delivered to the 318 Building. Checkout of the arive assemblies was set aside to allow work to proceed on the vertical safety rods.

The final setting of limit switches and brake tension was started. The rotary limit switch is being modified as a result of the testing. Delay in the delivery of limit switches with a wider range has extended the checkout time by about two weeks.

One Log $N$ monitor, which is part of the independent safety channels, was sent to the vendor for correction of a faulty part and a minor change to the period circuit. The unit was returned by the end of the month.

Reactor Equipment

Oscillators. Cold testing of the light duty oscillator continued. The unit was operated in oscillatory motion with control supplied by the logic unit. velocity measurements taken during the oscillatory motion show variations because of a varying frictional 
force. An accumulator was installed to maintain the servo valve pilot pressure long enough to permit the pilot spool to center when the hydraulic pressure is dumped by the dead end limit switch. Repairs were made to the Platecoil to body welds after pressure tests revealed the welás were leaking. The cable drum cover has been removed to permit additional reinforcing of the cover. The reinforcing was necessitated when the cover started to collapse during vacuum testing.

The light auty oscillator valve has been installed on the reactor. The heavy duty oscillator valve has been tested and is installed on the reactor. The light duty oscillator valve ( $4 \frac{1}{4} \mathrm{x}$ $\left.4 \frac{1}{4}\right)$ has been tested and is ready for use in hot testing the light duty oscillator.

The oscillator keys are ready for beneficial use, and the ram extension rocis have been drilled for the pins.

Design drawings describing the light and heavy duty oscillator electrical installation are 60\% complete. The arawings include elementary control diagrams, control room panel arrangement, and associated wiring and connections.

HTLTR Control Rod Drives. The problem of matching the input and output characteristics of the drive units to PMACS has been resolved. Repeatability and stability have been tested and satisfactorily äemonstrated. The supplier of the drive units completed an evaluation of one unit and reported the electromechanical performance very good as presently designed. They suggested the trouble was probably caused by the PMPCS counter logic being wired to receive synchronous insteaci of asynchronous pulses from the arrive feedback system output. A simple modification was made to the PMACS equipment to correct the problem. The PMACS computer was programmed to track the output pulse rates up to 125 pps. Performance of $100 \%$ repeatability in both directions was obtained with accuracies of less than \pm 0.001 inch over the total rod travel. Ill rod drive units will be tested in the 314 Building to determine optimum speeds. Final testing and adjustment will be completed in time to meet installation schedules.

HTLTR Control Rod Assemblies. Ten control rods have been assembled, inspected, crated, and delivered to the 318 Building. Eight rods were assembled in accordance with the drawings as to the number of UO2 fuel sections. The ninth rod contains a special arrangement with fewer $\mathrm{UO}_{2}$ fuel sections, and the tenth rod contains spare graphite and the balance of the $\mathrm{UO}_{2}$ fuel sections assembled for storage convenience. The remaining graphite parts, special tooling and assembly rack have also been delivered to the reactor. 
Vertical Safety Blades. Safety blade drop and withdrawal tests are being performed to establish limit switch and brake tension settings. The rotary limit switches are being exchanged for ones with wider ranges.

Programmed Measurement and Control Systems. Assistance was given in testing the heater control hardware of the HTLTR using the PMACS. The analog outputs that will be used to drive the heater control hardware were adjusted so that a range of 0 to +2 volts is available, instead of 0 to +12 volts as originally supplied.

Further testing of the HTLTR rod arive mechanism with PMACS showed that:

1. The arive mechanism responds erratically to certain drive pulse rates.

2. The actual position of the rod mechanism is properly detected by the rod position counter at all speecis tested (up to $150 \mathrm{~Hz}$ ).

3. If operating rates are restrictec to 0 to $30 \mathrm{~Hz}$ and 95 to $100 \mathrm{~Hz}$, proper operation will occur.

All rod mechanisms are being checked to be certain that their operation is the same as the one mechanism tested.

Changes were made to the mechanical oscillator simulator logic to allow automatic mechanical oscillations to be controlled. Testing has been accomplished using the control simulator, and recordings have been made to show the velocity of the mechanism during the oscillations.

\section{Reactor Operations}

A rough äraft of a document which describes the operating programs for PMACS has been written. It contains descriptions of the BASIC and the FUNCTIONAL PROCRAM SETS. Tables which show the alphanumeric display format, calibration and zero offset timing, and keyboard commands are included. This information will be updated anä used in writing the final document.

Of the 20 programs needed for operations, 19 have been specified, flow charted, and written. These 19 are considered necessary for either reactor hot or cold startups.

The twentieth program, Oscillator, is not necessary for reactor startup and therefore will be written after completion of the initial program library. No specifications or flow charts have been made at this time; however, the program is envisioned to be limited to keyboard commands from PMACS. 
The final program listings, flow charts, and narrative descriptions for the BINBTB; MICPO-TAPE INTERPUPT, and the IN-OUT programs are now completed. In adaition, detailed flow charts for the ROD movements anci monitoring program, and part of the nuclear safety logic showing NNUCLEAP 1 and 2 , ana the CORE LOAD mode have been completea and reviewea. General flow charts for the $1 / 10$ second interrupt program (MIME) and SCPAM. CHECK have been discussed. These flow charts anci descriptions are being used to complete the operating Procedures.

The neutron generator was operatea approximately 10 hours during the month for training purposes.

The horizontal control rods, which have been assembled with fuel, were received and stored under nuclear safety specifications.

Peactor Physics Program

Startup and Calibration Experiments. The HTLTP mockup will be used for design tests and experimental sample tests before the HTLTR is available. The light duty oscillator will be tested to high temperature to reauce the time needed for tests in the HTLTP. Modifications to the mockup coor have been completed, and the core face to oscillator valve plate support briage is being fabricated.

Three heater elements will be usea instead of four to permit operation at the full design power of the HTLTR heater elements. Two of the three elements were used earlier in the mockup and the third is a replica of the HTLTR heating elements.

Construction of supports for the experimental sample to be oscillated in the mockup has been completed, and construction of the sample and couplings is nearing completion. The oscillator will be hooked up to the mockup and the piece oscillated at room temperature. This will allow the oscillator to be aligned and the position of the piece to be determined before the mockup is sealec.

Samples to be placed in the mockup during the hot test have been prepared. These samples include balls of $\mathrm{Sm}_{2} \mathrm{O}_{3}$ in $\mathrm{Al}_{2} \mathrm{O}_{3}$ matrix and $\mathrm{Sm}_{2} \mathrm{O}_{3}$ in carbon matrix, $\mathrm{Gd}_{2} \mathrm{O}_{3}$ in graphite matrix, rhoaium, gold. and copper foils, Monel wire, anc samples of the rare earth oxide in nickel material as delivered and used in the safety blades. The weights of these samples before and after cycling to temperature will be compared, anc all the samples will be inspected for any external changes.

U-233 - Th oxide Experiments. Planning continued for the first U233 $\mathrm{ThO}_{2}$ lattice. Tests of fuel element containment were begun by the fuel fabrication group. Calculations of $k_{\infty}$ versus temperature 
were performed using GAMTECII-THERMOS. The calculated value of $\mathrm{k}_{\infty}$ at room temperature, 1.05 , is in good agreement with the value estimated previously for scoping the experiments.

A remaining question in the development of HTGP plants is the small net temperature coefficients for U233-Th232 fuels. Error limits in any current calculation permit the possibility of positive coefficients with certain lattice configurations at high temperature. The initial experiments proposed for the HTLTR with U233-Th232 are, therefore, important in defining error limits on calculational techniques. As a first attempt to compute temperature coefficients for $\mathrm{U}^{23}-\mathrm{Th} 232$ fuels, calculations were made for the initial HTLTP experimental composition consisting of a $7 \frac{1}{2}-$ inch graphite lattice and a 1.0-inch äiameter ThO2 rod (1.5 wto U-233).

The calculations were performed with the GAMTECII-THERMOS code combination over the temperature range 0 to $1000 \mathrm{C}$. The principal characteristics of the calculations were utilization of (1) Park's kernals for thermal neutron scattering with graphite and (2) NR and NRIA treatment of resonance absorption in Th-232 (over the entire temperature range). A positive coefficient of $k_{\infty}$ was obtained that decreased from $7 \times 10^{-5}$ to $3 \times 10^{-5} / 0^{\circ}$ with increasing temperature. The accuracy of the calculations is difficult to assess due to a lack of experimental data.

In technique, the calculations are not as sophisticated as they could be made. Errors are manufactured by omitting resonance treatment of U-233 and its interference effects on Th-232. Additional errors are involved from the NR approximation used for moderator scattering and from ignoring the density effects.

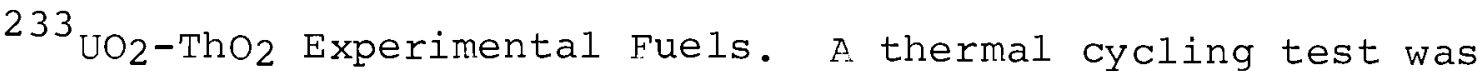
initiated to determine if the fines in a $\mathrm{UO}_{2}-\mathrm{ThO}_{2} \mathrm{mix}$ would "breathe through" its graphite cladâing. A 5 wto $\mathrm{UO}_{2}-\mathrm{ThO}_{2} \mathrm{mix}$ was vibrationally compacted to $70 \%$ of theoretical density into a graphite tube (1.06" ID $x 1.60 "$ OD $\times 10 " \mathrm{~L}$ ). The element was cyclea in a nitrogen atmosphere from room temperature to $1000 \mathrm{C}$ in four hours, heat soaked for two hours, and cooled. Smears taken in the graphite surface revealed a high count which decayed to background count within 24 hours. Later cycles gave a lower count rate. The probable origin of this contamination is from radon which has permeated through the graphite. Tests are continuing.

Safety Analysis Report. Questions raised by A. J. Pressesky, RDT Nuclear Safety Branch, were answered in a letter sent to the Richland Operations office early in February. I number of additional questions were answered by letter dated February 16. Pevisions to the SAR itself is under internal review and will be forwarded to the AEC early in March. 
While considering these questions, it was realized that the oscillator valves were not designed to be fail-safe. Steps are being taken to correct this design error.

REACTOR FUELS AND MATERIALS

Fast Fuels Oxides and Nitrides (R. E. Nightingale)

Fabrication and Irradiation Test of UN-PuN Fuel Capsules

The UN-PuN synthesis facility is now being operated on a semicontinuous basis so that approximately 250 grams high purity mixed nitride can be produced each week. Pressing and sintering studies were initiated to determine a procedure for reproducibly producing pellets of a given diameter and density (up to $90 \%$ TD).

A test capsule was designed for irradiation testing mixed nitride fast reactor fuel pins in the ETP. The design will accommodate 1/" diameter test pins operating at $40 \mathrm{~kW} / \mathrm{ft}$ with cladding surface temperature of approximately $700 \mathrm{C}$. Each test capsule will act as a calorimeter and will inclucie two thermocouples for monitoring the cladding surface temperature. Component procurement and fabrication is now under way. The first set of capsules are scheduled to be charged into the ETR for cycle 89 which begins April 24.

Electron Microprobe for Irradiatea Materials

Detailed discussions were held with designers, users, and vendors of shielded electron microprobes. Information gained included details of shielding, construction problems, probable effects of radiation on crystals and sensitivity, recommended installation environment, and purchase arrangements. Specifications for purchase are being preparea.

Compatibility Experiments on Mixed Oxide anc Mixed Nitride Fuels

Sodium bonding of fuel pellets in stainless steel cladding using near-prototypic conditions was attempted. Poor bonding of sodium to $\mathrm{UO}_{2}$ suggests inadequate precleaning of the pellets. The absence of sodium in most of the capsule void spaces indicates that continuous pressurizing of the sodium supply loop will be necessary during filling and soaking. A second experiment, using pressurized sodium, is in preparation.

Equipment for conducting heat tests on the souium-bonded capsules is about 75\% completeci. 


\section{Basic Swelling Studies (P. D. Leggett)}

The purpose of this program is to characterize and understand the behavior of fissionable materials during irradiation. The theories developed provide a basis for the engineering exploitation of metallic fuel materials in advanced reactor applications. Specimens under study at the present time include uranium with and without dilute alloy additions.

Irradiation Program

Capsule P-15 (700 C, 1000 psi, 0.2 at. $\%$ BU) continues to operate successfully. Capsule P-16 (625 C, 1000 psi, 0.35 at. $\frac{\circ}{0}$ BU) was charged into a reactor and is also operating successfully. Capsule P-15 contains four levels of U-235, and capsule P-16 contains three levels of U-235 which will provide different burnups in the same environments to enhance the evaluation of the effects of burnup and burnup rate.

Construction and ex-reactor testing have been completed on capsule P-14 (700 C, 500 psi, 0.2 at. $\%$ BU). Construction has started on capsule $\mathrm{P}-11(550 \mathrm{C}, 5000 \mathrm{psi}, 0.2$ at. $\%$ BU) and capsule $\mathrm{P}-12$ (625 C, 5000 psi, 0.2 at. $\%$ BU) . Capsules $\mathrm{P}-11, \mathrm{P}-12$, and $\mathrm{P}-14$ contain uranium specimens with various U-235 contents $(0.72,1.44$, 1.47 , and $2.88 \%$ U-235 specimens).

These capsules will provicie data needed to evaluate the effects of temperature (both alpha and beta phase), pressure, burnup, burnup rate, and minor alloying additives on the irradiation behavior of uranium.

\section{Postirradiation Examination}

Uranium and dilute uranium alloy specimens were recovered from three irradiation capsules: $\mathrm{P}-9$ ( $450 \mathrm{C}, 1000 \mathrm{psi}, 1$ at. $\left.\frac{\circ}{\mathrm{B} U}\right)$, 35 (525 C, 30 psi, 0.5 at. $\%$ BU), and 36 ( $450 \mathrm{C}, 30$ psi, 0.38 at. $\frac{\circ}{\circ}$ BU). Each specimen was photographed in three different positions, and the densities of the specimens recovered from capsules 35 and 36 were determined. The damage to the specimens from capsule P-9 was so extensive that no effort was made to obtain density measurements on these samples. The specimen materials, heat treatments, irradiation conditions and measured swelling are summarized in the following table for the specimens irradiated in capsules 35 and 36 . These capsules were intended to compare the irradiation behavior of several dilute alloys in the 400-600 C temperature range which has been identified as a temperature region in which maximum swelling is observed in uranium and uranium base alloys. In addition to the U $+\mathrm{Fe}-\mathrm{Al}-\mathrm{Si}$, $U+F e-S i$, and high purity-high carbon material already under study 


\begin{tabular}{|c|c|c|c|c|c|c|}
\hline $\begin{array}{l}\text { Specimen } \\
\text { Number } \\
\end{array}$ & Material* & Heat Treatment $(1)$ & $\begin{array}{c}\text { BU } \\
\text { At. } \%\end{array}$ & $\begin{array}{l}\operatorname{Irr} . \text { Tenp. } \\
{ }^{\circ} \mathrm{C}^{*}\end{array}$ & $\begin{array}{r}\text { Percent } \\
\text { Swelling } \\
\end{array}$ & $" R " * * *$ \\
\hline 35 A-1 & $\mathrm{U}+\mathrm{Fe}-\mathrm{Si}$ & As Extruded & 0.5 & 470 & 105 & 210 \\
\hline A-2 & HiPHIC & As Extruded & 0.5 & 470 & 49 & 98 \\
\hline$B-1$ & $\mathrm{U}+\mathrm{Fe}-\mathrm{Al}-\mathrm{Si}$ & $1000-24 h-W Q+525-24 h$ & 0.5 & 510 & 17 & 35 \\
\hline$B-2$ & $\mathrm{U}+4 \mathrm{MO}-0.1 \mathrm{SI}$ & Aged & 0.5 & 510 & 6.4 & 13 \\
\hline C-1 & $\mathrm{U}+\mathrm{Fe}-\mathrm{Al}-\mathrm{Si}$ & $1000-24 h-W Q+640-4 d$ & 0.5 & 510 & 21 & 42 \\
\hline $\mathrm{C}-2$ & $\mathrm{U}+4 \mathrm{MO}-0.1 \mathrm{Si}$ & Solution Treated & 0.5 & 510 & 2.4 & 5 \\
\hline D-1 & Sicral F-1 & 720 to $750-W Q+570-1 h$ & 0.5 & 525 & 16 & 33 \\
\hline$D-2$ & $\mathrm{U}+1.1 \mathrm{Mo}$ & $\$ 800$ at $20 \% / \mathrm{min}$ & 0.5 & 525 & 28 & 56 \\
\hline E-1 & $\mathrm{U}+\mathrm{Fe}-\mathrm{Al}-\mathrm{Si}$ & $730-15 m-O Q$ & 0.5 & 485 & 53 & 106 \\
\hline $\mathrm{E}-2$ & $\mathrm{U}+0.1 \mathrm{Al}$ & Aged & 0.5 & 485 & 31 & 62 \\
\hline $36 \mathrm{~A}-1$ & $\mathrm{U}+\mathrm{Fe}-\mathrm{Si}$ & As Extruded & 0.38 & $(275-340)$ & 14 & 37 \\
\hline$A-2$ & HiPHiC & As Extruded & 0.38 & $(275-340)$ & 7 & 19 \\
\hline$B-1$ & $\mathrm{U}+\mathrm{Fe}-\mathrm{Al}-\mathrm{Si}$ & $730-15 \mathrm{~m}-W \mathrm{Q}+525-24 \mathrm{~h}$ & 0.38 & $(350-400)$ & 15 & 39 \\
\hline$B-2$ & Sicral F-l & $800-2 h-F C+730-15 m-06$ & 0.38 & $(350-400)$ & 6 & 16 \\
\hline C-1 & $\mathrm{U}+\mathrm{Fe}-\mathrm{Al}-\mathrm{Si}$ & $1000-24 h-W Q+640-4 d$ & 0.38 & $(435-450)$ & 23 & 61 \\
\hline $\mathrm{C}-2$ & $\mathrm{U}+4 \mathrm{MO}-0.1 \mathrm{Si}$ & Solution Treated & 0.38 & $(435-450)$ & 0.6 & 1.6 \\
\hline D-1 & Sicral F-l & 720 to $750-W Q+570-1 h$ & 0.38 & $(430-480)$ & 34 & 91 \\
\hline$D-2$ & $\mathrm{U}+1.1 \mathrm{Mo}$ & $\$ 800$ at $200 / \mathrm{min}$ & 0.38 & $(430-480)$ & 36 & 96 \\
\hline E-1 & $\mathrm{U}+\mathrm{Fe}-\mathrm{Al}-\mathrm{Si}$ & $730-15 \mathrm{~min}-0 \mathrm{Q}$ & 0.38 & $(400-450)$ & 30 & 80 \\
\hline $\mathrm{E}-2$ & $\mathrm{U}+0.1 \mathrm{Al}$ & Aged & 0.38 & $(400-450)$ & 33 & 88 \\
\hline
\end{tabular}

* Compositions (ppm)

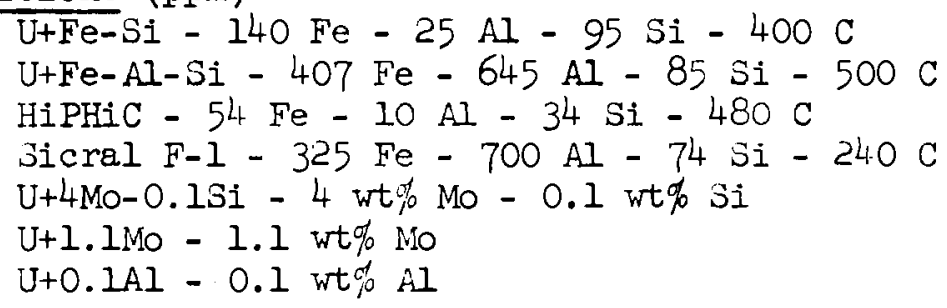

* Low Pressure ( $\sim 40$ psi), NaK capsule irradiations.

*** $R=\frac{\% \text { Swelling }}{A t . \% \mathrm{BU}}$

(1) Temperatures are in ${ }^{\circ} \mathrm{C}$, Times are in minutes, hours or days. 
in this program, Sicral $F-1$ and $U+1.1$ tto Mo alloy specimens prepared at Saclay Laboratory in France, and $\mathrm{U}+\hat{A}_{\mathrm{x}} \mathrm{w} \%$ " $\mathrm{O}$ $0.1 \mathrm{wt} \% \mathrm{Si}$ and $\mathrm{U}+0.1$ wto $\mathrm{Al}$ prepared at Atomics International were inclucied in these capsules. Is can be seen from the table, the $U+4$ wto Mo - 0.1 wto $S \dot{i}$ alloy specimens were much more resistant to swelling tiran any of the others. It would also appear that the solution treated specimens of this composition were more resistant than aged specimens. Metallographic examination of selected specimens is in progress.

\section{High Pressure Postirradiation Annealing}

The modification of facilities to postirraciation anneal uranium at temperatures to $900 \mathrm{C}$ anc pressures to 15,000 psi is partially completed. A prototype capsule and a cask have been fabricated, and uranium control specimens are being made. I new furnace and new thermocouples have been installed in the coldwall autoclave, and tests are now under way to establish that the desired temperatures can be achieved at the higher pressures.

\section{Nondestructive mesting (J. C. Spanner)}

Detection of Irradiation Induced Shift in Nil-Ductility-Transition Temperature

Development of critical angle ultrasonic metiods to detect neutron induced embrittlement in pressure vessel steels is continuing. Pesponse anomalies have been encountered on both irradiatec and nonirradiated samples, and equipment and methocis are being developec to minimize this problem.

Test samples have been fabricated and received, and the pulsed oscillator chassis was partially debugged. Irradiation capsule design is largely completed, and fabrication has begun. Closure weld design and fabrication remains to be done but is being delayed pending determination of the specimen holder design--this latter expected to be available before the end of February.

Fabrication of the ultrasonic mechanical manipulating facility has been completeä, and alignment procedures are under way in the laboratory. When crystals and crystal positioners are received, the aligned facility will be fully operational and will be put into service in the air lock in 324 Building.

Electromagnetic NDT Probe Design

A study to investigate the theoretical and practical aspects of eddy current sensing probe design and to apply the information 
obtained to the development of general guidelines for future probe construction is continuing. Efforts continued on both theoretical and experimental equivalent circuit development. A single sensing coil was used alternately as (1) an outsicie encircling coil, (2) inside encircling coil, and (3) a surface probe in order to obtain experimental data at several frequencies on the complex impedances of the various types of probes. The results obtained will be used to aid in the development of the equivalent circuits through comparison with the theoretical work.

One of the major goals of this study is to improve the sensitivity of probes. The use of tuned sensing coils is known to improve sensitivity; however, the effects of tuning are not included in the conventional analysis of the complex coil impedance (as a function of sample geometry, resistivity, permeability, etc.). Studies on the effects of tuning are continuing.

Fundamental Ultrasonic studies

Ultrasonic wave studies with Kautz function analysis were temporarily discontinued due to other commitments. Further tests using dual ultrasonic frequencies still have not shown any favorable results for detecting mechanically closed unbonds in reactor fuel element claddings, although some novel effects were discoverea which may have applications in ultrasonic imaging.

Since previous tests with two frequencies had shown that surface imperfections were a problem, a new approach was tried. In the previous test the low frequency, high powered beam was made to be incident at the critical angle. The surface waves that resulted were very sensitive to surface conciitions. Also in previous studies, the high frequency beam was macie to be incicient perpendicular to the surface.

In subsequent testa the low frequency beam was transmitted at normal incicience and a pair of high frequency probes used to transmit and receive at oblique incidence. It was assumed that sensitivity to surface irregularities would be reduced to tolerable levels using this combination. The above metiod, however, aid not accomplish the desired result, anci surface imperfections continue to be a problem. It now appears that the suspected mechanically closed unbonds were not detected as was apparently also the case for the initial test situation.

In applying both of the above methoas, it was observed that cross modulation of the high frequency sigrals with the high power, low frequency beam was taking place. whis was particularly pronounced when they both were macie to be simultaneously incicient over a known unbonded area in the interface between the fuel element cladding and 
fuel material. Even though the interface was probably not being alternately opened and closed, there still was some mechanism responsible for the cross modulation. More experiments are necessary before the effect can be more fully understood.

Since modulation does occur, it is believed that the effect can possibly be used for a novel method of ultrasonic beam scanning. If scanning proves feasible, the techniques could ultimately lead to new ways for imaging ultrasonic fields. Various methods to accomplish the beam scanning are being studied.

Electromagnetic Testing

During this report period advances were made in several project areas: (1) an equivalent circuit simulating the eddy current test was developed for analytical and experimental use in relating single frequency, multifrequency, frequency modulation, and pulsed eddy current nondestructive test techniques; (2) ladder networks were used to produce signals simulating those obtained due to defects located at different depths within a test specimen: (3) ideas which may lead to the simplification of the design of the multiparameter eddy current tester have been generated and are under study; (4) the transformation circuits (computer section) of the transistorized multichannel eddy current tubing tester have been fabricated, and (5) further analysis was made of the previous measurements of the relative effects of varying the eddy current test coil diameter and frequency.

In the past we have used a network consisting of an air cored transformer coupled to an artificial transmission line to simulate eddy current tests. This network was used either physically with measurements made of its response, or its analog was solved by use of an analog computer. The transformer simulates coupling of the test coil to the metal test specimen, and the transmission line simulates the test specimen. Length of the line corresponds to thickness of the test specimen and shunt resistance of the line corresponds to test specimen resistivity. I.lthough this simulator gives results similar to that of the eddy current test, resistance associated with the inductances in the physical arrangement causes undesired differences in performance. A simulator has been devised which uses only capacitors and resistors which gives improved performance. The improved performance is due to the fact that the capacitors have a higher $Q$ than the inductors. The new simulator promises to serve well in the comparative study of different methods of test coil excitation and signal analysis techniques. New simulators based on these principles give experimental results which are closer in agreement with the results of analyses. 
These networks have been used to simulate signals due to idealized flaws located at different depths within a test specimen, proviäing experimental signals which can be treated analytically.

The present combined study of single frequency, multifrequency, swept frequency (FM), anci pulsea excitation methods has lea to the generation of new icieas for improving the multiparameter eddy current test. Other ideas evolving from the study promise to lead to other important test concepts.

The transformation circuits (computer section) of the two frequency multichannel eday current tubing tester has been constructed and is ready for operational testing. Some circuit design optimizing is being performed on the breadboarded circuits of the amplifier and detector sections.

Aditional study of the results of tile previous measurements of the relative effects of coil ciameter and test frequency variation confirm the conclusion that a multiparameter test should be feasible using a single test frequency. It is envisioned that this type of test $\mathrm{will}_{\mathrm{l}}$ be most effective in the measurement of the indivicual thicknesses of a multilayer metal soecimen.

Infrared and Thermal Testing

Efforts to improve the stability of the sinusoidal thermal wave instrument, and to carry out experimental confirmation of the remote transient method for obtaining thermal surface impedance, have continued. Difficulties found last month in the amplitude digitizer anci phase printer of the sinusoidal wave system were corrected. Further tests showed that calibration of the phase aigitizer sometimes changea after an hour or so of warmup. This difficulty was corrected, and tests of the entire electronic readout system stability are again under way.

High quality operational amplifiers and multipliers for performing analog operations in the remote transient method have been obtainea. Samples of copper and teflon liave been testea in preliminary experiments using this equipment. Thermal surface impedance phase angles of -500 and -750 were obtained for the teflon and copper, respectively. The theoretically predicted phase angle for both materials is $-45^{\circ}$. Both of these naterials have previously been tested using the remote transient methou with a graphic rather than an electronic transiomation tecinique. rile results of the graphic technique were previously believed to be in error due to mechanical plotting äifficulties. However, the present electronically obtained results, which shoula be accurate within about 1\% based on guaranteed accuracies of the individual components, agree closely with the graphically obtainec results. Eviciently the disagreement between experiment and theory is not due to the transiormation methou. 
Further investigation is under way to determine the reasons for the difference between experimental and theoretical results.

Nuclear Ceramics (P. E. Nightingale)

Thermal Diffusivity of UN - 20 wto PuN

Preliminary thermal diffusivity data for sintered UN - 20 wto Pun showed an increase in thermal diffusivity with temperature from a value of $0.0360 \mathrm{~cm}^{2} / \mathrm{sec}$ at $260 \mathrm{C}$ to $0.0441 \mathrm{~cm}^{2} / \mathrm{sec}$ at $1000 \mathrm{C}$. Above $1000 \mathrm{C}$, the diffusivity did not change appreciably with temperature. At $1575 \mathrm{C}$, the highest measurement temperature, the diffusivity value was slightly less than at $1000 \mathrm{C}$. The samples were cut from pellets which had been sintered to a density of $12.1 \mathrm{~g} / \mathrm{cm}^{3}$ (85\% TD). X-ray diffraction patterns showed essentially single phase, solia solution nitride with a small amount ( 25 wto) of residual oxide phase present. The oxide phase was dispersed randomly throughout the sample.

Diffusivity measurements were made using the laser heat-pulse apparatus. The sample was heated in a dried, flowing $\mathrm{Ar}-8 \% \mathrm{H}_{2}$ atmosphere. An x-ray diffraction pattern showed that some surface oxidation had occurred during the run. However, diffusivity measurements at $260 \mathrm{C}$ both before and after heating to $1575 \mathrm{C}$ compare favorably, indicating that gross bulk oxidation did not occur.

Effect of Cooling Pate on Microstructure of Irradiated oxide Fuels

Two capsules containing $\mathrm{UO}_{2} .00$ specimens were irradiated for several hours with molten centers and then discharged at different rates to assess effects of cooling and solidification rate on postirradiation microstructure and fission-fragment distribution. One specimen was rapidly quenched by nearly instantaneous witharawal from the flux, while the other was witharawn over a period of three hours. Macrographs of cross sections from each specimen were qualitatively identical, but gamma-beta autoradiographs revealed a dramatic difference. The quenched specimen had a typical fission-fragment distribution in that it contained an annular depleted region bounding a central region which was somewhat enriched in radioisotopes. The inner and outer edges of this depleted region are the two currently contending candidates for the molten-zone boundary. In the slowly cooled specimen, nearly the entire central region was depleted in fission fragments which had segregated to a very narrow rim adjacent to the central void. Slow cooling apparently caused segregation and movement of the fission fragments toward the fuel center, the most probable mechanism being a zone-refining process. These results support the hypothesis that the outer edge of the depleted band represents the maximum melt radius, and the band itself arises from 
a gradual diminution in melt radius during irradiation, perhaps because of an improvement in fuel thermal conductivity as densification and rearrangement of porosity progresses.

Decay effects on features revealed by gamma-beta autoradiographs were studied by making autoradiographs of a $\mathrm{UO}_{2} .00$ fuel cross section at various times after discharge. In the time interval from 20 hours following discharge to three weeks following discharge, no changes in features occurred, even though the activity decreased by more than a ciecade.

Thermal Diffusivity of $\left(\mathrm{U}_{0.8}, \mathrm{Pu}_{0.2}\right)^{0_{2-\mathrm{x}}}$

The thermal diffusivity of hypostoichiometric ( $U_{0} .8$, Pu $\left._{0.2}\right)_{2} 0_{2}$ $(\mathrm{x}=0.01)$ is less than the stoichiometric material from 100-400 C. At temperatures from $400 \mathrm{C}$ to $1200 \mathrm{C}$, oxidation of the sample (in a äried Ar - 8\% $\mathrm{H}_{2}$ atmosphere) occurred and prevented a comparison. oxidation of the sample was indicated by the diffusivity data obtained on cooling which corresponded exactly to the data for stoichiometric oxide.

The sample was the same as used previously for measurements on stoichiometric material. The oxygen-to-metal ratio was reduced to 1.99 by heating at $1500 \mathrm{C}$ in dry hydrogen for 30 minutes.

Ternary Equilibria in the Pu-O-N System

A ternary evaporator apparatus for studying $\mathrm{Pu}-\mathrm{O}-\mathrm{N}$ phase equilibria is essentially complete. Cerium is currently being used as a stand-in for plutonium. Some difficulties have been encountered in finding a suitable holder for the cerium metal, since both $\mathrm{Al}_{2} \mathrm{O}_{3}$ and Beo are reauced by molten cerium at $1450 \mathrm{C}$. Thoria and tantalum crucibles are being studieà for possible use.

A vacuum of $5 \times 10^{-8}$ torr with an apparent leak rate (including outgassing) of about $1 \times 10^{-6} \frac{\text { torr }}{\mathrm{sec}}$ was achieved in the apparatus. Stable reproducible flow rates of $10 \times 10^{-3}$ and $2 \times 10^{-3} \frac{\mathrm{std} \mathrm{cc}}{\mathrm{sec}}$ were obtained for the nitrogen and oxygen, respectively.

Solubility of Oxygen in PuN

An oxygen analyzer and gas-metering lines were installed for synthesis of $\mathrm{Pu}(\mathrm{N}, \mathrm{O})$ in various $\mathrm{N}_{2}-\mathrm{O}_{2}$ atmospheres. Cas mixtures can be prepared and analyzed over the composition range of $\sim 10 \mathrm{ppm}$ up to 100,000 pprn oxygen in nitrogen. 
Present plans call for synthesizing PuN(0) in atmospheres of $30,100,300,1000$, and $3000 \mathrm{ppm}$ oxygen. Lattice parameters and chemical analyses of the resulting compouna(s) will be used to determine the maximum solubility of oxygen in PuN.

Samples are also being preparea of physical mixtures of $\mathrm{PuO}_{2}$ in PuN for $x$-ray diffraction analysis using a goniometer, a Debye camera, and a Guinier camera. PuN containing $0.1,0.3,1,3$, and 10 wto $\mathrm{PuO}_{2}$ will be examined to determine the minimum detection level for each of the three techniques.

Ceramography of Annealed Pneumatically Impacted $\mathrm{PuO}_{2}$

A room temperature etchant consisting of $40 \mathrm{ml}$ hydrofluoric acid (52\%) and $10 \mathrm{ml}$ nitric acia was developed for annealed pneumatically impacted $\mathrm{PuO}_{2}$. An etching time of 60-90 min was required to produce good grain structure. After etching, samples were soakea in dilute sodium hydroxide to neutralize any pore-entrapped etchant. P. final water rinse produced a clean surface.

\section{Electron Microscopy of Mixed Oxides}

In-microscope heating of mixed $\mathrm{UO}_{2}-20 \% \mathrm{PuO}_{2}$ specimens has been delayed by failure of a heating filament in the heating stage. Mechanical thinning of the specimens is continuing, with effort being concentrated on refinement of techniques to allow application to small specimens. Three impacted $\mathrm{UO}_{2}$ specimens are also being replicated and thinned for comparison with chemically thinned foils being prepared at Chalk Piver.

Electron microprobe examinations of the mixed oxide specimens did not identify the white phases previously reported. Improved surface preparation and a more detailed microprobe examination of these specimens is in progress.

Dynamic Neutron Radiography

Neutron radiography is being developed to complement $\mathrm{x}$ - and gamma-radiographic techniques for high temperature, sealed capsule studies of materials. An antimony - beryllium (neutron) source is being used. Investigation of various mocierator materials and source and moderator configuration is under way to maximize the thermal neutron flux in the collimated beam.

\section{Materials and Information Exchange}

Single crystal specimens of $\mathrm{ThO}_{2}$ and $\mathrm{UO}_{2}$ were prepared, characterized, and sent to General Electric Pesearch and Development Center 
for their use in basic studies. High purity $\mathrm{ThO}_{2}$ and $\mathrm{ThO}_{2}-4$ wto UO2 pellets were prepared and sent to the Bell Telephone Laboratory (Murry Hill) for their use in far-infrared stuáies. A cylindrical, polycrystalline $\mathrm{UO}_{2}$ specimen was prepared and sent to oak Ridge National Laboratory for in-pile thermal conductivity studies. Pneumatically impacted $\mathrm{UO}_{2}$ specimens were selectea and sent to A.E.C.L., Chalk River, Canada, for use in comparison thinning stuaies. In addition, $\mathrm{UO}_{2}$ pellets were selected, tested, and sent to Battelle-Northwest's Chemistry Department for use in dissolution and decontamination studies. Current requests for information and materials incluāe: $\mathrm{UO}_{2}$ crystals for $A N L$, ORNL, Pennsylvania state University; and PuO2 specimens for $\lambda_{\perp i L}$, OPNL, and Sandia.

U.S./Japan Pesearch liewsletter No. 5 was prepared.

Nuclear Graphite (P. E. Nightingale)

High Temperature Graphite Irradiations

The high temperature capsule, GEH-13-13, has completed one cycle of irradiation in the ETR. One thermocouple was lost during initial startup, but all the remainder are operating well. The maximum operating temperature averagea $1275 \mathrm{C}$ through the course of the cycle, which is $125 \mathrm{C}$ lower than the design temperature of $1400 \mathrm{C}$. The test is scheduled to remain in the ETP for three more cycles with discharge scheaulea in early June.

Irradiation of Nuclear Graphite

Graphite irradiation capsule, $\mathrm{H}-3-14$, was charged in the GETP on February 3 for a scheauled three-cycle irradiation. Eight of the nine thermocouples are functioning properly, and the capsule is operating at design temperatures of 300 to $800 \mathrm{C}$. The two capsule positions containing sample holders with telephone dial geometry were modified to contain 19 samples each. This modification increases the capsule capacity by 12 samples.

Irradiation of "Dimensionally stable" fraphite

The H-3-24 capsule was discharged from the GETR on January 31 , after satisfactorily operating for three cycles at a maximum temperature of $1000 \mathrm{C}$.

A nuclear-grade graphite, TSGBF, irradiateci at $1000 \mathrm{C}$ has experienced an expansion of $34.8 \%$ in the transverse orientation and an expansion of $8 \%$ in the parallel orientation at $8.7 \mathrm{x} 10^{21} \mathrm{nvt}$ 
$(\mathrm{E}>0.18 \mathrm{MeV})$. The calculated volume change for this material is +97\%. Two of the improved graphites display dimensional stability superior to any present reactor grade. One grade irradiated at $1000 \mathrm{C}$ has contracted $0.26 \%$ in the transverse orientation at an exposure of $8.8 \times 10^{21}$ nvt and $3.4 \%$ in the parallel orientation at $7.5 \times 10^{21}$ nvt. The other material irradiated at about $900 \mathrm{C}$ has an expansion in the transverse orientation of $0.3 \%$ at $6.5 \times 10^{21} \mathrm{nvt}$ and a contraction of $2.5 \%$ in the parallel orientation at $7.5 \times 10^{21}$ nvt. Neither material has shown any indication of turnaround at the present exposures.

The problem encountered with the thermocouples in this capsule appears to be mechanical rather than a result of nitriding or carburizing. Hot cell observations of the failea couples show that all six had broken at or near the point where they entered the graphite sample holders; all beads were intact and showed no evidence of corrosion or chemical reaction. Apparently the wires seized and were stretched by the difference in thermal expansion of the materials in the capsules. To overcome these problems, the next capsule in this series will include a new method of mounting thermocouples in the sample holders, and the lead-in wires will have greater freedom of movement along the length of the capsule. In the next capsule two of the nine Geminol couples will be replaced with 7-strand (0.003 inch) braided $w$ - 5\% $\mathrm{Ph}, \mathrm{W}-26 \%$ Rh thermocouples.

The next capsule in this series, H-3-25, scheduled for charging in the GETR on March 8 , is being fabricated.

Hanford Reactor Graphite Irradiations

Glassy Carbon. Several samples of glassy carbon pipe and rods have been irradiated to a total exposure of $6.4 \mathrm{x} 1020 \mathrm{nvt}$ (E $>0.18 \mathrm{MeV}$ ) at approximately $600 \mathrm{C}$. Samples with three heat treatment temperatures of 1000,2000 , and $3000 \mathrm{C}$ were included. All samples exhibited high contraction rates. A decrease in contraction rate with increase in processing temperature was found as is characteristic of nuclear polycrystalline graphite. The lengthchange data are given below. 


\begin{tabular}{|c|c|c|c|}
\hline \multirow{2}{*}{ Sample } & \multirow{2}{*}{$\begin{array}{l}\text { Heat ireatment } \\
\text { Temp., }{ }^{\circ} \mathrm{C} \\
\end{array}$} & \multicolumn{2}{|c|}{ Length Change, $:$} \\
\hline & & Length & Diameter \\
\hline \multicolumn{4}{|l|}{ Dipe } \\
\hline GC 10 & 1000 & -4.99 & -4.32 \\
\hline GC 20 & 2000 & -2.16 & $\begin{array}{l}-1.99 \\
-1.58\end{array}$ \\
\hline GC 30 & 3000 & -1.68 & -1.58 \\
\hline
\end{tabular}

Rod

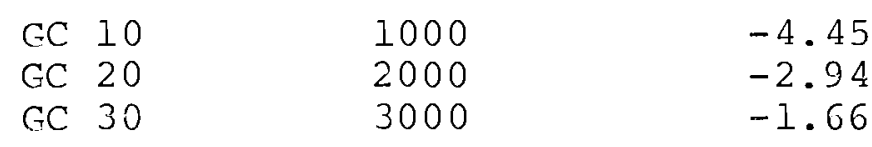

Cloth-Base Carbon Materials. Samples of three grades of layered, square weave, cloth-base carbon materials have been irradiated to an exposure of $3.0 \times 10^{20}$ nvt at approximately $600 \mathrm{C}$. The first material, consisting of carbon cloth and a carbon bona, contracted approximately $1.0 \%$ in all three directions; the second material, a graphite cloth and carbon bond, contracted about $0.97 \%$ in all three directions; the third material was made from a graphite base and graphite bond, and it contracted about $0.50 \%$ in all three directions.

Graphite Strain Tests in the ETR

The graphite strain test, GEH-13-60, irradiated in the ETP. during cycle 85, suffered three mishaps. (1) the lead tube was incorrectly bent prior to insertion in the reactor; but was rebent; (2) midway in the cycle, the gas supply line broke and the capsule was depressurized for about $5 \mathrm{hrs}$; and (3) during discharge the capsule lead tube caught on some piping in the discharge canal and broke when excessive force was used to free it. The break in the lead tube allowed canal water, which was contaminated by a previous rupture of a fuel element containing NaK, to saturate the samples.

The samples were returned to PNI, leached in distilled water to remove the contaminants, dried, and remeasured. They do not appear to have suffered any appreciable oxidation auring the time when the gas supply was off, nor to have been adversely affectea by the other events. Therefore, these samples will be used for additional irradiations.

Averaging Techniques in Polycrystalline Craphite

In the last monthly report two models were introduced to explain the thermal expansion coefficient and voung's modulus of polycrystalline graphite. The success of these models with graphite suggests 
that they might also be useful in describing less anisotropic ceramic materials.

The constant stress, constant strain, modified constant stress, and modified constant strain models were applied to Mgo and Zno. The Young's moduli predicted by the modified models were equal to each other and to the average of the constant stress and constant strain models. However, the values of Young's moduli found by averaging in the constant strain approximation is less than the value calculated by Chung. (1) He has used the constant strain model as initially proposea by voigt (2) to calculate the bulk and shear moduli. Young's modulus can then be calculated using the normal relationship for an isotropic material. It would appear the discrepancy between Chung's results and ours arises in the model itself. In the original voigt model the resultant young's modulus reflects a constraint on the crystallites to expand or contract perpendicular to the applied stress. The model used in this study and by Price(3) assumes no lateral constraint.

\section{Oxidation of Boronated Graphite}

Measurements of the rate of oxidation of boronated graphite by $0.5 \% \mathrm{O}_{2}$ in a helium stream have been extended to include the oxidation of "black" boronated graphite containing nominally 5\% boron as $\mathrm{B}_{4} \mathrm{C}$. The difference between "black" boronated graphite and the "grey" material previously employed is that there is no microscopic evidence that melting of the $\mathrm{B}_{4} \mathrm{C}$ occurred during manufacture of the "black" material, whereas melting did occur in the "grey" material. "Black" boronated graphite has a specific surface area a factor of 3 greater than that of the "grey" material.

In general, it has been found that the initial oxidation rate of the "black" material is faster than that of the "grey" material because of its higher surface area. However, the actual ratio of the rates varies with temperature, because the two materials exhibit different activation energies. As previously reported, the activation energy for the "grey" material is about $32 \mathrm{kcal} / \mathrm{mole}$ at temperatures between 580 and $780 \mathrm{C}$. At temperatures up to about $680 \mathrm{C}$, the activation energy observed for the "black" material is about $38 \mathrm{kcal} /$ mole, the difference being attributed to the greater ease with which the oxidant can penetrate the "black" boronated graphite.

(1) Chung, D. H., PhD Thesis, Pennsylvania state University (1966).

(2) Voigt, W., "Lehrbuch der Kristallphysik," (B. B. Taugner, Leipzig, 1928), p. 789 .

(3) Price, R. J., Phil. Mag., 12, 561 (1966). 
Three separate series of rate measurements at a temperature of about $730 \mathrm{C}$ have yielded rates which are greater when calculated from weight measurements than when calculatea from the gas-flow rate and the concentration of gaseous products. Because $\mathrm{B}_{2} \mathrm{O}_{3}$ is formed in the boronated graphite sample, the reverse should be true. At present we are trying to resolve this aiscrepancy.

An interesting feature of the oxiciation rate at $730 \mathrm{C}$ is the presence of a small initial hump in the rate-versus-time curves, indicating the occurrence of a fast initial reaction which subsequently decreases and is then overshadowed by the normal rate. This fast initial rate may result from the presence of machining dust on the samples, but it has never been detected previously.

\section{Gamma Irradiation Facility}

An additional 215,000 curies of cobalt-60 was added to the gamma irradiation facility. The total inventory of cobalt in the source is now 355,000 curies. Twelve cobalt pieces were transferred into the 13.5-ft cieep, water-fillea pool facility from two l4-ton casks. A capsule with melt wires was shippea in one of the casks which contained about 100,000 curies of co-60. The indicated temperature in the central cavity of the cask near the cobalt elements was $300 \pm 15 \mathrm{C}$ after 3 hrs. The cobalt was encapsulated in stainless steel cans in the form of hollow cylinders $1-7 / 16^{\prime \prime}$ OD $x 1^{\prime \prime}$ ID $x 16 "$ long.

Ceric sulfate dosimetry measurements were completed in a 2-inch diameter dry facility tube which extended from the source to 3 feet above the surface of the water. With the cobalt positioned around four 2-inch diameter facility tubes, the maximum dose rate was 2.34 $\mathrm{x} 107 \mathrm{r} / \mathrm{hr}$. The variation in dose rate over an 8 -inch length was less than 5\%. Two of the four facility tubes are equipped with heaters ana gas purge lines to perform irradiations at temperatures up to $500 \mathrm{C}$. The other two facility tubes are for irradiations near room temperature.

\section{Irradiation Damage to Feactor Metals (A. L. Bement)}

\section{Alloy Selection}

Two additional pins have been assembled for Inconel 600 irradiations in the EBP-II. These pins, to be inserted on a space available basis, contain eight tensile and three stress-rupture specimens to be exposed to soảium anc helium environments.

Work has begun in the testing of alloys obtaineci from the G.E. Nuclear superheat Program. One group of alloys irradiatea in the 
GETR and in the EBR-II is being tested at $1300 F(705 \mathrm{C})$ at a strain rate of $0.02 \mathrm{inch} / \mathrm{min}$. These data will be correlated with stress-rupture data being developed on the same alloys by GE-NMPO.

In-Peactor Measurements of Mechanical Properties

The purpose of the in-reactor measurements program is to determine the effects of irraciation on the mechanical properties of reactor structural materials. The effort is involved in measuring creep in AISI 304 stainless steel and nickel-base alloys during neutron irradiation.

In-reactor creep-rupture test results on AISI 304 stainless steel have indicated a much greater effect of irradiation on rupture life at $840 \mathrm{C}$ than at lower temperatures. Rupture indication in an in-reactor test was receivea after 6 hours under $3.52 \mathrm{Kg}_{-1} \mathrm{~mm}^{-2}$ (5000 psi) stress. In contrast, an unirraciated control specimen tested under the same conditions of temperature and stress did not rupture until 926 hours. Further metallographic studies will be pursued in an attempt to determine the cause of this aifference between in-reactor and unirradiated-control creep tests.

Irradiation Effects in Structural Materials

Stainless Steels. The purpose of this phase of the program is to determine the combined effects of irradiation and environment on the mechanical properties of stainless steels. Radiation-inauced property changes will be determined from irradiations and tests conducted at various temperatures on several alloys. Darticular emphasis will be placed on determining the existence of metallurgical instabilities and the mechanisms by which they are enhanced in a nuclear environment.

Optical metallography is being performed on AISI 304 stainless steel tensile specimens irradiated at $650 \mathrm{C}$ in NaK environment to about $3.5 \times 10^{20}$ fast fluence and subsequently tested at various temperatures. Electron microprobe analysis, as well as transmission and replica electron microscopy, is also in progress. Several encapsulated stainless steel tensile specimens have been charged in the ETP. G-7 hot water loop. The purpose $n f$ these irradiations is to explore the possibility of obtaining specimen irradiation temperatures between 400 and $600 \mathrm{C}$ in the loop.

Nickel-Base flloys. The purpose of this program is to determine the effects of modified microstructures on the irradiation stability of nickel-base alloys. Microstructural modifications are made by preirradiation thermal or thermomechanical treatments and are evaluated by tensile tests, stress-rupture tests, and microstructural examinations. 
Stress-rupture tests at $1350 \equiv(735 \mathrm{C})$ anc at the 1000-hr rupture stress of 9800 psi were completea on eight pretreated Inconel 600 specimens which vere irraciiateci at $540 \mathrm{~F}(280 \mathrm{C})$ to an approximate fluence of 1 x 1020 nvt (>I "ert). In experimental treatment increasea postirraciation ruptrire life 65\% over that of the commercial treatment. Whis treatment also gave the best postirradiation $1350 \mathrm{~F}(735 \mathrm{C})$ tensile ductility; hovever, irradiation still causec a marked reciuction in rupture life (approximately 5foldi) even for tile jest treatrent. Stress-rupture tests on the unirraciatec control specimens have been initiated.

Stress-rupture tests at $1350 \%(735 \mathrm{C})$ anc at the 1000-hr rupture stress of 37,500 psi are completec on seven pretreated Inconel x-750 specimeins which were irraciiated at $540 \%(280 \mathrm{C})$ to an approximate FIuence of 1 x $10^{20}$ nvt (>I "'eV).

Twelve tensile specimens of Inconel 600, representing several new preirradiation treatments, have been sent to the Ep? for irradiation at $540 \mathrm{~F}(280 \mathrm{C})$ to a goal fluence of $1 \mathrm{x} 10^{2} 0 \mathrm{nvt}(>1 \mathrm{MeV})$.

Postirraciation annealing studies of Hastelloy $\mathrm{X}-280$ specimens at $600 \mathrm{C}$ are continuing. Postanneal optical metallography is completeci, anci replica microscopy anc transmission microscopy are now in progress.

licrostructural analysis has veen initiated on broken tensile specimens of Inconel 600 , Inconel $X-750$, anä Hastelloy $X-280$ which were held as controls for those irraciated at $1250 \mathrm{~F}(675 \mathrm{C})$ and subsequently tensile testec at $1350 \mathrm{~F}(735 \mathrm{C})$. Optical metallography has been completed on the Inconel 600 anci Inconel $x-750$ specimens.

X-ray diffraction phase analysis of Inconel 600 and Inconel $\mathrm{x}-750$ tensile specimens has also been completec. The analysis on Inconel 600 shows that more ${ }^{n} 7 \mathrm{C}_{3}$ is formec as the aging temperature of the experimental treatments is increased. The higher postirradiation auctility imparted by these experimental treatments was hypothesized to be ciue to the removal of matrix chromium from the vicinity of the grain bounciaries to form $M_{7} C_{3}$ in or near the bounclaries. This mechanism would provicie a more plastic zone adjacent to the grain bounciaries, improving resistance to grain bounciary crack propagation. mhe phase analysis cata confirm that such a mechanism occurs. The better treatments from a ductility stancipoint corresponcied to greater ${ }^{17} \mathrm{C}_{3}$ anc, therefore, less chromium aujacent to the bounciaries.

The phase analysis of Inconel $x-750$ showed, surprisingly, no

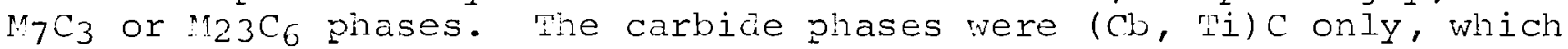
can at present be explainec by assuming that little carbon was available after the formation of this carbicie to allow formation of other carbicie phases. $\lambda$ chemical analysis is in progress to elucidate this point. A microprobe analysis of grain boundary carbides is also being unciertaken. 
Microprobe analysis of a Nimonic 80-A sample shows that the microprobe can detect chromium concentration gradients in the vicinity of grain boundaries. There is a denudation of chromium to the extent of about $2.5 \mathrm{wt}$ \% near grain bounciaries (compared to the general matrix concentration) as the chromium combines with carbon to form grain boundary carbides. This reduced concentration value agrees with similar data in the literature. Microprobe analysis will now be used to study the effect of experimental treatments on grain bounciary concentration gradients in the alloys being studied in this investigation.

SAP Alloys. The goal of the program is to evaluate the effect of irradiation at elevated temperature for extended periods on the tensile, creep-rupture, and notched creep-rupture properties of sintered aluminum products (SAP).

The optical metallography phase of material characterization on XAP 005 and SAP 895 is complete. This is an initial start on the complete material characterization which will include tensile, creep-rupture, and notch creep-rupture properties measurements.

In preparation for irradiations, preliminary capsule and specimen designs are being evaluatec. Tensile, creep-rupture, and notch creep-rupture specimens are being machined from nonprogram ( I Icoa M-585), 7\% $\mathrm{N}_{2} \mathrm{O}_{3}$ material for evaluation of the specimen cesigns.

Tiwo mockup capsules of the sheath capsule ciesign for irradiation at 575 and $750 \mathrm{~F}(300$ and $400 \mathrm{C})$ have been fabricated and shipped to ETF. Thermal monitors placed in the capsules will be retrieved after irradiation to evaluate the adequacy of the design. The temperatures of 575 and $750 \mathrm{~F}$ (300 and $400 \mathrm{C}$ ), which are above the c-7 10op temperature of $535 \mathrm{~F}(280 \mathrm{c})$, are obtained by controlling the heat loss with a helium gas gap. Heat is generated in the test specimen by gamma radiation. The sheath capsule design is based upon data obtained using the sTrC computer program.

Zirconium flloys - In-Flux oxidation. In-flux oxidation data were reportea in the January report for four zirconium alloys (Quadrant 219) exposed four cycles ( 88 cays) in the G-7 loop of the ETP. The test temperature was 270 to $280 \mathrm{C}$, and the environment was pH-10 $\mathrm{NH}_{4} \mathrm{OH}$, <0.05 ppm oxygen.

Hyarogen analyses on the 12 specimens in Quadrant 219 are reported in the following table. Hyarrogen analyses from similar specimens exposed 37 days in the same loop are inclucied for comparison. (See September 1966 report.)

The results of the 37-ciay exposure incicated relatively high fractional hydrogen absorption for zircaloy-2 in the in-flux ammoniated environment, compared. with G-7 loop experience in pH-10 
In-Flux Hyảrogen Pbsorption in zirconium plloys in $\mathrm{pH}-10 \mathrm{NH} 4 \mathrm{OH},<0.05 \mathrm{ppm}$ Oxygen

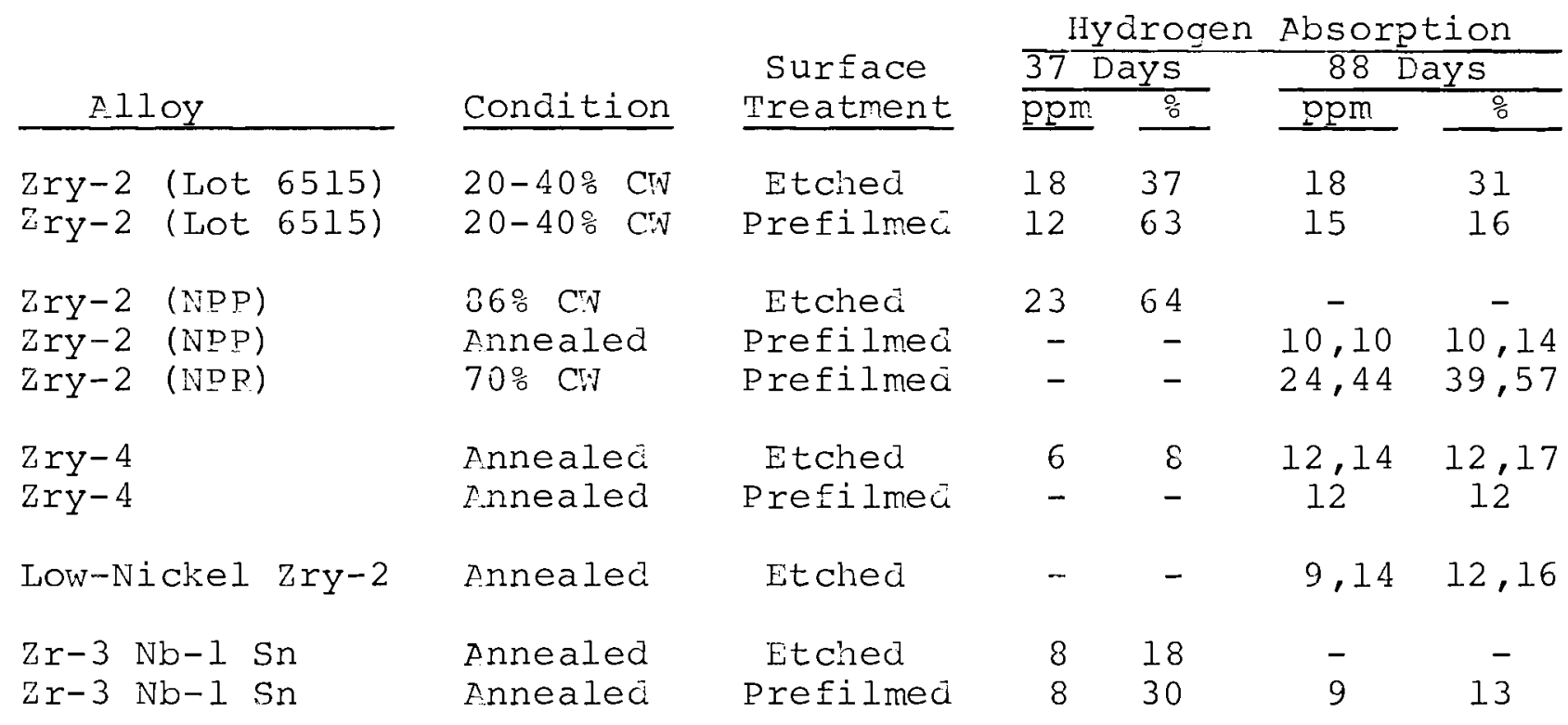

LiOH, $l$ ppm oxygen. However, actual hycirogen absorption (ppm) after 88 ciays was only slightly higher than absorption at 33 days.

Preliminary interpretation of short exposures in low oxygen, in-flux systems suggested that the combination of flux and hydrogen increasec the iraction of hyarogen absorbed (BNWI-88 and September 1966 Monthly Progress peport). However, with the benefit of longer exposures, it becomes increasingly apparent that hycirogen absorption characteristics of zirconium alloys are not adversely affected in the in-flux, ammoniated environment having hycirogen concentrations of 10 to $60 \mathrm{cc} / \mathrm{kg}$ of coolant.

In-Flux oxiaation and Hyariaing of mitanium. In the preceding month 1 y report, in-flux oxidation ata were reported for three etched titanium specimens exposed two cycles in the $\mathrm{C}-7$ 100p in pH-10 NH $4 \mathrm{OH}$ at 270 to $280 \mathrm{C}$ to $5.9 \times 1013 \mathrm{n} / \mathrm{cm}^{2}$, >1 Mev. Hycirogen absorption data for one of the three specimens were also reported. Subsequently, the two specimens not sampled for hyarrogen were weighed on the same microbalance used in pre-exposure weighings. This was possible because of the short lalf-life of titanium-5l ( $\overline{\mathrm{T}}_{1 / 2}=5.8 \mathrm{~min}$ ) and the relatively low impurity level (Grade II titanium). Following the microbalance weighing, duplicate hydrogen samples were talien from the two titanium specimens. Iy cirogen analyses anc revised weight gains appear in the following table. 


\section{In-Flux Oxidation and Hydricing of Titanium}

\begin{tabular}{|c|c|c|c|c|c|}
\hline \multirow[b]{2}{*}{$\begin{array}{l}\text { Specimen } \\
\text { No. } \\
\end{array}$} & \multicolumn{2}{|c|}{ Weight Gains, $\mathrm{mg} / \mathrm{dm}^{2}$} & \multicolumn{3}{|c|}{ Hyc̈rogen Absorption } \\
\hline & In-Cell Bal. & Microbalance & $\mathrm{ppm}$ & $\mathrm{mg} / \mathrm{Cm}^{2}$ & $\begin{array}{c}\text { \% of } \\
\text { Theoretical }\end{array}$ \\
\hline$T-1$ & $2.1 *$ & - & 31 * & 0.69 & 265 \\
\hline$T-2$ & 1.4 * & 4.1 & 30 & 0.67 & 131 \\
\hline $\mathrm{r}-3$ & $0.7 *$ & 2.9 & 28 & 0.62 & 171 \\
\hline
\end{tabular}

Fracture Mechanics

Luring the interim period the assembly of a shock loading device was nearly completed. Tiis cievice, formally known as a Hopkinson BarBlock Loader, will be an important tool in the study of material behavior at extremely high strain rates.

One of the principal areas of research to which the bar loader will be applied is analysis of rapid or unstable crack propagation. An understanding of material behavior during very high strain rates is an essential part of analyzing mechanisms controlling energy absorption at a crack tip during rapici propagation.

The experimental investigation to determine size effects on fracture toughness in $A 302-B$, DCB specimens is continuing. Fatiguing of $\frac{1}{2}$-inch and 1 -inch notch-bend specimens for the purpose of introducing a sharp fatigue starter crack was essentially completech. Testing of the $\frac{1}{2}-$ inch notch-bend specimens has commenced, and preliminary results indicate a static transition temperature considerably below that of the $\frac{1}{2}$-inch DCis specimens. This indicates that a higher degree of plane-strain restraint exists in a $\frac{1}{2}$-inch DCB specimen than in a l-inch notch-bend specimen.

\section{Hastelloy $X$ and Hastelloy in Weld Metals}

This investigation was concernea with the effects of prolonged exposures (in an inert atmosphere) at temperatures of 1000 to $1600 \mathrm{~F}$ $(540$ to $870 \mathrm{C})$ on the precipitation hardening of multipass welded IIastelloy $X$ and Hastelloy $w$ filler metals in dissimilar superalloy joints. Weld joint specimens of Hastelloy $x-280$ plate to $L 605$ plate and Hastelloy $\mathrm{X}-280$ plate to 316 SS plate were joined by the tungstenelectrode inert gas (TIG) welding process. The wela joint specimens were aged at $1000,1200,1400$, and $1600 \mathrm{~F}(540,650,760$, and $870 \mathrm{C})$ for periods of 500,1000 , and 5000 hrs. 
Both of the welc metals are solution-strengtheneci nicliel-base superalloys, and exposure at temperatures of 1000 to $1600 \mathrm{~F}$ (540 to $870 \mathrm{C})$ results in precipitation hardening. This investigation was primarily concerned with the effects of this hardening or age embrittlement on the ductilities of the two nickel-base weld metals. The effects of similar aging treatments on the mechanical behaviors of the superalloy base metals, Hastelloy $x-280$ and L605, were also investigated. The relative age embrittlements of these materials were evaluated from bend tesis, tensile tests, hardness tests, and metallographic examinations.

During this period the results of this study were prepared for presentation in a formal report. These results suggest the following conclusions.

1. Aging in the temperature range of 1000 to $1600 \mathrm{~F}$ (540 to 870 C) can embrittle Hastelloy $X$ wela metal as much as llastelloy $W$. The most severe embrittling temperatures are $1200 \mathrm{~F}(650 \mathrm{C})$ for Hastelloy $\mathrm{X}$ and $1400 \mathrm{~F}(760 \mathrm{C})$ for Hastelloy $W$. Aging Hastelloy $X$ at $1200 \mathrm{~F}(650 \mathrm{C})$ for 5000 hrs will decrease its room temperature and $1200 \mathrm{~F}(650 \mathrm{C})$ cuctilities to 2 to $3 \%$. Aging Hastelloy $\mathrm{W}$ at $1400 \mathrm{~F}(760 \mathrm{C})$ for 5000 hrs will ciecrease its room temperature äuctility to 2 to $3 \%$ and its $1400 \mathrm{~F}(760 \mathrm{C})$ cuctility to 5 to $7 \%$.

2. Poom temperature harciness ciata cio not adequately reflect the relative age embrittling effects on the ductilities of the materials stucied in this investigation. The room temperature harciness variations tenc to reflect the material strength variations. The aging will produce large differences in strength and ductility across welcied joints of Hastelloy $\mathrm{x}-280$ plate to $\mathrm{L} 605$ plate anc to $316 \mathrm{SS}$, with either Hastelloy $X$ or liastelloy $W$ welc filler metals.

3. Although they have similar chemical composition, the effects of aging on solution treated Hastelloy $\mathrm{X}-280$ base metal are significantly less than on as-welced Hastelloy $\mathrm{X}$ weld metal. Hastelloy $X-280$ base metal has a low room temperature ductility minimum of 10\% after 5000-hr aging at either 1200,1400 , or $1600 \mathrm{~F}(650,760$, or $870 \mathrm{C})$ and a low elevated temperature ductility minimum of $30 \%$ after 5000-hr aging at either 1000 or $1200 \mathrm{~F}(540$ or $650 \mathrm{C})$. In adition, the yield strength of Hastelloy $\mathrm{X}-280$ is relatively unaffected by aging in the temperature range of 1000 to $1600 \mathrm{~F}(540$ to $870 \mathrm{C})$.

4. The effects of aging on the yielci strengths of these materials should be considered when the ciuctility of the particular welcied joint is evaluated. Although the aging 
of the weld metals appreciably decreases ductility, there may be an equally significant increase in their yield strength. This suggests that the wrought base metal adjacent to the brittle wela metal will yield prior to the joint reaching the fracture stress of the weld metal and, thereby, prevent fracture of the welded structure.

5. An appraisal of the age embrittlement of a metal should include examinations of both room temperature and elevated temperature property variations. Generaliy, the room temperature properties exaggerate the effects of an aging on a metal. Although Hastelloy $w$ weld metal has a room temperature ductility of less than 5\% when aged for periods of 500 hrs or more at elther $1400 \mathrm{~F}$ $(760 \mathrm{C})$ or $1600 \mathrm{~F}(870 \mathrm{C})$, the ductility at these same temperatures is significantly greater than 5\%. Similar relationships are found for Hastelloy $X$ weld metal aged at 1000,1400 , and $1600 \mathrm{~F}(540,760$, and $870 \mathrm{C})$. However, both $1200 \mathrm{~F}(650 \mathrm{C})$ and room temperature ductilities of Hastelloy $X$, agea at $1200 \mathrm{~F}(650 \mathrm{C})$, are less than 5\%.

6. Determining the weld metal (Hastelloy $X$ or Hastelloy $W$ ) best suited to prolonged service in the temperature range of 1000 to $1600 \mathrm{~F}(540$ to $870 \mathrm{C})$ is a complex problem. The service life of a dissimilar metal welded joint with either of these weld metals will depend on the base metal properties, wela metal properties, service temperature, time at temperature, and the cuctility and yield strength variations of both the weld and base metals.

The age embrittlement of these materials may be a function of stress as well as temperature and time at temperature. Although the results of this study offer no insight into the additional effects of stress on age embrittlement, it has been observed that applied stress influences mass transport within the metal and the preferred locations of the precipitating phases. This ciscussion of stress effects is only intended to emphasize the caution to be exercised when comparisons of in-service behavior are inferred from incomplete laboratory test data. The results of this study may be sufficient for comparing Hastelloy $x$ weld metal with $H$ astelloy $W$ weld metal in one application but could be inadequate for some other application.

\section{Fast Peactor Supporting Studies}

Structural Materials and Fuel Cladding studies. The objective of this program is to determine the combinea effects of sodium environment and fast reactor irradiation on the mechanical properties of candidate fast reactor structural and cladiing materials. The 
program currently in progress is specifically directed at providing a basis for selection of optimum alloys for FFr'F application and at providing a description of material behavior in fast reactor service.

Tensile tests on annealed AISI 304 stainless steel irradiated to about $1.7 \times 10^{2} 2$ total fluence at about $1000 \mathrm{~F}(540 \mathrm{C})$ in the EBP-II have been completed. Tests conclucted over the temperature range, room temperature to $1500 \mathrm{~F}(315 \mathrm{C})$, provided the following significant information:

1. At all test temperatures below $900 \mathrm{~F}(480 \mathrm{C})$, the uniform elorigation was greater than 25\%, anc total elongation was never less than about $27 \%$. Between $900 \mathrm{~F}(480 \mathrm{C})$ and $1100 \mathrm{~F}(595 \mathrm{C})$, the uniform and total elongation decreased to 6.5 and $11.5 \%$, respectively. Mbove $1100 \mathrm{~F}(595 \mathrm{C})$, uniform ductility decreasea continuously to a minimum observeci value of about $0.5 \%$ at $1500 \mathrm{~F}(815 \mathrm{C})$. The total elongation, however, passeci through a minimum of $5 \%$ at $1300 \mathrm{~F}(705 \mathrm{C})$, then increasec to $9.2 \%$ at $1500 \mathrm{~F}(815 \mathrm{C})$.

2. I slight increase in ultimate strength cue to irradiation was observed at temperatures above $900 \mathrm{~F}(480 \mathrm{C})$. Below this temperature, ultimate strength was not affectec. I marked increase in yiela strength ciue to irradiation was founc at all test temperatures, with the yield strength approaching the ultimate strength with increasing temperature. Aloove $1300 \mathrm{~F}(705 \mathrm{C})$, the ultimate and yield strength are practically icientical.

The high temperature tensile ciata from the EBP-II irradiations closely approximate high exposure (6 x 1021 nvt) ciata from ETP, 290 C irradiations, but exlibit somewilat higher strength properties above $1100 \mathrm{~F}(595 \mathrm{C})$. In the ETP studies, however, the ultimate and yield strengths are nearly icientical for all test temperatures. Ductility losses in both EBP-II and ETP stucies are similar above $1100 \mathrm{~F}(595 \mathrm{C})$ with somewhat greater loss in the ETP experiments.

Optical metallography of the cested EBP.-II specimens is in progress. Below $900 \mathrm{~F}(480 \mathrm{C})$ iracture is transgranular, while at $1100 \mathrm{~F}(595 \mathrm{C})$ anci above intergranular fracture prevails. Electron microscopy of the as-irradiated specimens shows a complex defect state in which the dislocation loop ciensity is so high that the loops have interacted to form a network. The thermal stability of the network is thought to account for persistence of irraciiation hardening at the higher temperatures.

Final approval has been given for irradiation of the two EBP-II structural materials subassemblies fabricatec last month. Irradiations are expected to begin in the latter part of the month. 
Twelve MK-A-type, space-available pins have been charged into two subassemblies and inserted into the core of the EBP-II. Subassembly $\mathrm{X}-019$ contains eight of these pins and is scheduled for a fast fluence of $3.0 \times 1022$ nvt. Subassembly $x-020$ contains four pins and is scheduled for a fast fluence of 6.0 x 1022 nvt. These pins contain 124 tensile anä creep test specimens of AISI 304 and 316 stainless steel, evenly ciivided, of which half of each alloy is exposed to bulk sodium.

Test Facilities. The general laboratory area of Bullding 32l-A was completed and occupied during the month. Pour test stands from the CANEL equipment pool were installed, and complete cleanup and renovation of these test stands and the associated instruments are now in progress. These test stands will be placed in service for investigations under the LMFBR program.

The prototype cell is nearly complete. A radiation leak check indicated weak points in the cell around the door and the loading port. The changes required have been made on the door and are nearly complete on the loading port. Another raciation leak check will be made before the cell is accepteci for operation.

The shipping date for the liquid metal (sodium) loop from MSAR has been delayed to the end of llarch because of delays in obtaining valves.

A loading station for the measurement and ajispensing of liquid metal is being assembled. This station will be completed, and its associated equipment will be onsite in time to service liquid-metal, stress-rupture test apparatus placed into operation during the month of March.

Liquid-Metal Capsule Irradiations. The liquid-metal capsule $\mathrm{CEH} 22-3$, containing 316 SS tensile specimens, was discharged January 30, 1967, after 99.9 full power days and a fast fluence of $1.38 \mathrm{x} 10^{21}$ nvt. Arrival of the irradiated capsule at PNL is expected the week of March 6, 1967, for radiometallurgical examination and specimen retrieval.

Liquid-metal capsule GEH 22-4, containing 40 austenitic stainless steel specimens, has been charged in the $6-6$ position of $\mathrm{sTP}$. cycle 87 and is now accumulating fluence. Certain design modifications are incorporated into CEH 22-4 to permit higher capsule operating temperatures and to extend capsule life. During reactor startup the temperature of GEFi-22 capsules is controlled with 100\% helium. Ifter reaching full reactor power, the range of temperature control through gas mixing is establishec. The following temperature aistributions were observed for capsule CEH 22-4 in achieving a design operating temperature of $1400 \mathrm{~F}(760 \mathrm{C})$. 
GEH 22-4 Capsule Temperature (OF) Distribution

\begin{tabular}{|c|c|c|c|c|c|c|}
\hline \multirow[b]{2}{*}{$\begin{array}{l}\text { Thermo- } \\
\text { couple }\end{array}$} & \multirow[b]{2}{*}{ Position } & \multicolumn{5}{|c|}{ Gas Mixture } \\
\hline & & He & $\begin{array}{l}\text { He }-80 \\
\text { Ir-20 } \\
\end{array}$ & $\begin{array}{l}\mathrm{He}-70 \\
\mathrm{Fr}-30 \\
\end{array}$ & $\begin{array}{l}\text { He-60 } \\
\text { Ar- } 40 \\
\end{array}$ & $\begin{array}{l}\mathrm{He}-50 \\
\mathrm{P} r-50 \\
\end{array}$ \\
\hline 1 & Botton lva Column & 825 & 945 & 990 & 1035 & 1080 \\
\hline 2 & Center " " & 1065 & 1175 & 1220 & 1265 & 1310 \\
\hline 3 & Na Annulus & 830 & 950 & 1000 & 1040 & 1080 \\
\hline 4 & Top iva Column & 1175 & 1275 & 1315 & 1360 & 1400 \\
\hline
\end{tabular}

The capsule, having met design expectations, is being operated at the $1400 \mathrm{E}(760 \mathrm{C}), 50-50$ mixture, control point.

An inert (helium) atmosphere out-of-reactor capsule inas been assembled and is ready for its initial thermal cycle. This capsule contains annealed fISI 304 anc 316 stainless steel and will duplicate the thermal bistory of capsule CEH 22-3. operating conditions will be a temperature of approximately $1100 \mathrm{~F}(595 \mathrm{C})$ through four simulated EmP cycles, totaling 99.9 days.

Various heater geometries and capsule dimensions are being explorea in an effort to produce liquic-metal out-of-reactor capsules at considerably less cost than that requirec for their in-reactor counterparts. The envisioned out-of-reactor capsules would simulate in-reactor thermal gradient anc flow characteristics.

East Neutron Mechanisms. Substantial progress has been macie in perfecting glow discharge techniques for low temperature hydrogen permeation, effusion, and defect interaction stucies of irradiated reactor alloys. Hycirogen permeation rates that would require temperatures in excess of $400 \mathrm{C}$ with conventional gas phase hydrogen charging methods have been reacily obtaineà at room temperature for steel test specimens using these äischarge techniques. In addition, a hollow cathocie electrocie arrangement that significantly reduces specimen heating by the glow discilarge has been cieveloped for nonsteacy-state permeation experiments where naintenance of isothermal conditions is essential and has been difficult to achieve using other hyarrogen charging methods.

In some initial room temperature effusion studies using $0.005-$ inch steel specimens and a glow discharge technique as the hydrogen source, it has been determined that hydrogen desorption into a vacuum follows a second orcier rate law, which suggests that surface desorption and not matrix diffusion is the rate controlling effusion mechanism for these concitions.

Some interesting observations have also been made which indicate that a glor aischarge in an inert gas can significantly enhance the normal low temperature surface desorption rate of hyarogen; this effect 
will be explored further as it could provicie a neecied solution to the problem of rate-obscuring, phase-bounciary processes in low temperature hyärogen ciesorption studies of irraciateci alloys.

\section{PTP Gas Loop Supporting Stuciies}

Mociel Cas Loop Studies. The model gas loop inas operated a total of 332 hrs since installation of the new heater; this includes 437 hrs ciuring the past month with no unscheduled shutciowns or equipment failures.

A scope design anà carawing of a resistance heater to go into the vertical test section of the model gas loop was prepared. The $T$ iger-V computer program is being used to size the components for this heater. P test specimen temperature of $2500 \mathrm{~F}(1370 \mathrm{C})$ is one ciesign goal.

riest pssembly. Further study of the specimen test assembly design from the stanapoint of assembly and disassembly operations has been initiated. The purpose of this stuciy is to arrive at a final, detailed àesign of joints anci connections for remote assembly operations which are consistent with transfer facility equipment and capabilities anc with thermocouple instrumentation of the test assembly. This effort will lead to the formulation of cietailec hanciling and assembly procecures for transfer facility operation.

Thermal Iiydraulic Analysis. Aciditional measurements of pressure cirop açoss the specimen test assembly in the mociel gas loop were conaucted using improved methods for pressure ärop measurements. Pesults of these experiments were in reasonable agreement with similar tests conductea two years ago. This testirig continues to show that pressure arop across the test assembly will be within the ciesign limits of the ATR gas loop.

Temperatures which were calculated for a columbium hanger roci, with $2000 \mathrm{~F}(1095 \mathrm{C})$ helium and 25 watts/gram heating rate, are above the acceptable working range for columbium. Therefore, an effort is being made to reduce the roci temperature.

The effects of hollowing out the roci center are being calculated, and, if this does not lower the temperature sufficiently, some modification will be macie to the äesign of the sleeves which fit over the hanger rod anc hold the test pieces in the assembly.

Superalloy and Pefractory Metal Corrosion Studies. Electron microprobe analysis of the tantalum, niobium, molybdenum, and tungsten samples taken from the $2100 \mathrm{~F}(1150 \mathrm{C})$ heater discharge section of the model 100p after a 504-hr exposure failed to siow foreign metal contamination of their respective surfaces. Constituents of the black surface noted on tantalum and the surface case on niobium were not 
icientifiable by microprobe. Xway ciffraction of these two samples ciid reveal the nature of the contamination on the niobium sample. Strong diffraction lines suggest $\mathrm{Nb}-\mathrm{N}-\mathrm{N}-\mathrm{O}$, a ternary compound of niobium, nitrogen, anci oxygen of stoicliometry wo-ijo.9-0.1. (I) The contamination on tantalum, although not icientifiec by x-ray ciffrraction, may be similar to the niobium contamination.

Corrosion coupons in the lower temperature uischarge section of the loop /2025 (1105 C) T have about 732 lirs total exposure time at temperature. The coupons replacing tinose taken from the higher temperature section now have $228 \mathrm{hrs}$ exposure. Jithin experimental tolerances, these coupons follow the reight chance behavior estawlished by the first set. The samples are again in the mokel loop.

Damage Mechanisms in Iron

The objective of this program is to cietermine ho: interactions between irraciation inciuceci defects interact with moving aislocations to modify the mechanisms of plastic cleformation in a metal. Daciation camage anc tire role of interstitial impurities in alpha iron are currently being investigateá.

During this period, final evaluation of the tensile test results on iron irraciiated to $8.3 \times 1019$ nvt ( $\mathrm{E}>1$ "ev) was completed, and a paper describing the work was preparec for presentation at the AIME winter meeting.

Activation volume measurements on the material irradiated to $3.3 \times 1019$ nvt confirm orevious observations on material irradiatea to $1.4 \times 1013$ nvt that there is no major change in the rate controlling mechanism of dislocation motion due to the prociuction of cefects in the material. It was noted, however, that a cecrease in activation volume below that in the control sample is procuced at Iow strains in the zone refinea iron. mis was not noted in the first tests on the lower exposure material but has been found on subsequent tests at low strains. As the defects are removed from the slip plane, the activation volume increases vith strain to a value slightly higher than the control sarple. The reason for this behavior is unknown at the present time.

A pronounceci increase in lower yielc stress was noted in both Ferrovac $E$ and zone refined iron with the increase in Ferrovac $E$ roughly twice tile increase in the zone refinec iron. risis confirms the belief that carbon plays an important role in nucleating defect clusters in iron.

(1) N. Schoenberg. "Some reatures of the $\mathrm{Nb}-\mathrm{N}$ and $\mathrm{Nb}-\mathrm{NJ}-0$ systems," reta. Chem Scand., vol. 8, 208, 1254. 
Calculations on the jump frequency and migration distances of interstitials and vacancies in iron support the hypothesis that carbon traps interstitials. The jump rate and migration distance are such that interstitials should either be annihilated by vacancies or migrate to a grain boundary or dislocation sink unless trapped in the crystal. During irradiation the carbon atoms are the only sink close enough to trap an appreciable number of interstitials, although homogeneously nucleatea clusters in regions of spike overlap may also contribute.

Pecovery studies at $350 \mathrm{C}$ of material irradiated to $8.3 \mathrm{x}$ 1019 nvt show that the lower yield stress recovers only $47 \%$ for zone refined iron and $18 \%$ for Ferrovac $E$ in contrast to $100 \%$ and $92 \%$ recovery, respectively, in the $1.4 \mathrm{x} 1018$ nvt experiments. This indicates that smaller clusters cissociate anci anneal out first and that there are more small clusters in the $1.4 \times 1018$ nvt material.

Examination by transmission electron microscopy of a thin foil of Johnson-Matthey iron irradiated to 9 x 1019 nvt (E $>1$ M eV) has shown that defect clusters are visible in this material. The density was much lower than that observed in Mo irradiated to a comparable exposure but is about the same as reported by other investigators for iron. The clusters are about 50-75 in size or possibly smaller. The smallest ones are difficult to distinguish from the background.

\section{High Pressure Studies}

Calibration tests on the Ultra High pressure Temperature Apparatus have been 90\% completed. The piston-cylinder tooling has been calibrated to 25.4 kbars and $1500 \mathrm{C}$ by noting electrical resistance drops in cerium $(7.6 \mathrm{kbars})$ and bismuth (25.4 kbars) and volume changes in $\mathrm{RbCl}(5.6 \mathrm{kbars})$ and $\mathrm{KI}(17.2 \mathrm{kbars})$. The latter compounds were subjected to hydrostatic pressures by inserting them into collapsible cans filled with liquid pentane. The calibration points observed in this case lie on the same calibration curve as determined by the electrical resistance method showing that the cans transmit the pressure with very little frictional loss. The 'belt' high pressure tooling has been calibrated to $1500 \mathrm{C}$ and $37 \mathrm{kbars}$ by noting electrical resistance drops in bismuth $(25.4 \mathrm{kbar})$ and thallium ( $37 \mathrm{kbars).} \mathrm{The} \mathrm{final} \mathrm{calibration} \mathrm{point} \mathrm{will} \mathrm{be} \mathrm{at} 59 \mathrm{kbars,}$ at which pressure barium undergoes an electrical resistance increase.

Calibration tests on the in-reactor hydrostatic pressure cell have been extended to $20 \mathrm{kbars}$ at $100 \mathrm{C}$. This was done by noting volume changes in $\mathrm{PbCl}(5.6 \mathrm{kbars}), \mathrm{KI}(17.2 \mathrm{kbars})$, and $\mathrm{KCl}$ ( 19.2 kbars). Some difficulty has been experienced in using Ga as a liquid pressure transmitting media. It has not been possible, thus far, to generate over $10 \mathrm{kbars}$ on this element without fracturing the containment vessel. Further tests will be made with redesigned vessels. 
Calibration tests on the Diamond High Dressure Cell to 50 kbars at $22 \mathrm{C}$ have been completed. Continuous calibrations of samples surrounded by molybdenum washers were obtainea by noting both the shift in the (200) line spacing of $\mathrm{NaCl}$ and the pressure-induced optical absorption shift of TlBr. Preliminary analysis shows that the actual pressure is lower than that determined theoretically (force/area) by as much as a factor of two. This would explain why workers in the field constantly overestimate the transition pressure of solicis observed to undergo phase transitions in diamond opposedanvile, high pressure cells.

The solid form of benzene at $22 \mathrm{C}$ and $10 \mathrm{kbars,}$ which was reported earlier (December 1966), has tentatively been identified as the 1-atmospiere, low temperature, face-centered-orthorhombic phase.

Peactor Handbook

Efforts have been initiated to write the Nickel and Nickel-Base Alloy Chapter of the USAEC Peactor Handbook, Third Edition. This chapter will be authored by T. T. Claudson. One co-author, Walt Titus of Aerojet ceneral Nucleonics, has been assignec responsibilities for a portion of the chapter. One additional author has been requested from the staff of International Nickel Company, Inc. An outline of the chapter contents was submitted to $W$. $D$. Chernock of Combustion Engineering who is acting as the group leader for Part B: Cladding and structural "aterials section of the hancbook. $\pi$. L. Bement was askea by $W$. P. Chernock late in the month to autior the chapter on zirconium and zirconium Alloys. An outline for this chapter is being preparea.

A compilation of reference material for chapter 39 (Hyäricies) has been started by J. B. Vetrano, author. About 100 references have been accumulated, and contacts have been macie with the principal laboratories which have been active in research or development of hyärides for nuclear applications. In outline of the chapter has been prepareci.

$$
\text { ATR Gas Loop Operation ana Maintenance (C. } D \text {. Last) }
$$

ATR Gas Loop Support

Vendor Data Peview. Pinal contract submittals for the ATR gas loop components are being reviewed. Previous comments are being incorporated so complete engineering files on the components will be available for future reference and use.

ATP Gas Loop lieater. A continuing research program is being conducted to upgrade and improve the components used to assemble the ATR heater. In order to proviaje adequate quality assurance during 
the construction of the gas heater, a detailed review of joint designs, welding fabrication techniques, and inspection techniques was performed. Because of the gas heater's severe operating conditions, number of dissimilar materials, problems associated with major repairs, and consequences of failure, detailed welding procedure specifications and nondestructive testing procedure specifications were prepared. Mockup test joints and welding procedure qualification tests are in process.

For the less conventional type joint designs, programs were established to develop welding techniques and noncestructive testing metinods and equipment. Electron beam welding techniques were established for the molybdenum heater tubes, and unique ultrasonic testing equipment was designed and constructed for inspection of the molybdenum welds. Electrical resistance heating tests were conducted on welded nichrome preheater element mockup joints. The results of these tests revealed that a minor joint desion modification was necessary.

Inspection of Hygrometers for the ATP. Transfer Facility. The transfer facility for the gas loop is designed to operate with dry air at a dew point of $-150 \mathrm{~F}$. The instrumentation for measuring the dew point was inspected by PNL and Ebasco personnel to determine acceptability of the units.

Performance of the hygrometers was monitored by supplying them with a gas of a known dew point. The gases were generated by use of a tempering coil and cold bath. Liquid nitrogen was used to prepare a gas that contained less than $2.5 \times 10^{-19} \mathrm{~mm}$ water vapor. Although this value is lower than the hygrometers will measure, it did provide the zero point gas to determine whether the zero suppression on the hygrometers was adequate to give a base line within the accuracy of our specifications.

After the system had been dried out, the recorder indicated a reading of $0.06 \mathrm{ppm}$ which corresponas to a frost point of $-136 \mathrm{~F}$ at the local atmospheric pressure. This put the minimum reading within the tolerance of the specifications.

other monitors in the system are used at the higher range of water vapor, and the accuracy in these ranges was checked and found to be adequate. Based on our requirements and specifications, the system was accepted for shipment. 
Metallic Fuels Development (C. A. Last)

Irradiation of Thorium-Uranium-Zirconium Fuel Elements

Irradiation of three Zircaloy-2 clad Th - 2.5 wto U (93.2\% U-235) - 1.0 wto $\mathrm{zr}$ tubular fuel elements uncier water cooled power reactor conditions continued in the $\mathrm{P}-7$ loop in the ETP. Three aciciitional fuel elements which were being irradiated in the M- 3 loop are being stored in the basin at the ETR site.

The current status of the six test elements is summarized in the following table. The temperature data for fuel elements GEH-10$64,65,71$ are corrected for a temperature rise across an oxide buildup on the clad. The fuel swelling of each element is determined each reactor cycle by weighing the elements in water. The amount of swelling that is observed is about the thepretical minimum that would be expected from fission product builciup ( $1.5 \%$ per at. $\frac{\circ}{8}$ BU). No detectable change in the external appearance of these elements has occurrea.

High Exposure Uranium Irraäiation Test

The second cycle of irradiation of 24 hollow core uranium fuel elements in the $M-3$ hot water loop of the ETp has been successfully completea. Nine of the fuel elements have been irradiated for one reactor cycle and 15 for two reactor cycles. The accumulated exposures range from a maximum of $2580 \mathrm{MW}$ /tton to a minimum of $805 \mathrm{MWd} /$ ton. The maximum fuel core temperatures ranged from $360 \mathrm{C}$ to $520 \mathrm{C}$. These fuel elements, 0.45 inch diameter by 6.25 inches long and clad with Zr-2, are part of an irradiation test that has been designed to operate uranium fuel rods at elevated alpha phase temperatures to burnups greater than $10,000 \mathrm{Mvd} / \mathrm{ton}\left(6 \mathrm{x} 10^{20} \mathrm{fissions} / \mathrm{cm}^{3}\right)$. The variables being studied in this test include fuel composition, external restraint, and internal void volume. The combined effects of the plastic character of uranium curing irradiation and the restraints from the cladding and system pressure are expected to cause the uranium swelling to be accommodated by a central hole. Two uranium compositions are being used: Alloy 1 , containing $U+350 \mathrm{ppm} F e-800 \mathrm{ppm} \mathrm{A1;}$ and Alloy 2, containing U $+150 \mathrm{ppm} F e-100 \mathrm{ppm} \mathrm{Si.} \mathrm{A} \mathrm{fuel} \mathrm{enrichment}$ of $4.5 \%$ U-235 is being used to achieve the desired burnup rate $(10,000 \mathrm{Mvd} / \mathrm{ton}$ in one calendar year) and temperatures. Fuel rods of both compositions were fabricated by coextrusion to 0.450 inch diameter with 0.025 inch and 0.050 inch thick $\mathrm{zr}-2$ cladding.

Visual examination of the elements in the ETP basin after the second cycle of irradiation showed no evidence of changes in the external diameter, no evidence of corrosion at the welds or on the zr-2 cladding, and no evidence of fretting corrosion between the end 
IRRADIATION DATA ON Tr-2.5 Wt\% U - 1 Wt $\%$ Ir FUEL ELEMENTS

\begin{tabular}{|c|c|c|c|c|c|c|c|c|}
\hline \multirow[b]{3}{*}{ GEH-10 } & \multirow{3}{*}{$\begin{array}{l}\text { Percent } \\
\text { Fuel } \\
\text { Swelling }\end{array}$} & \multirow{2}{*}{\multicolumn{2}{|c|}{ BURNUP }} & \multirow{3}{*}{$\begin{array}{c}\text { Surface } \\
\text { Temp. } \\
{ }^{\circ} \text { C } \\
\end{array}$} & \multirow{3}{*}{$\begin{array}{c}\text { Maximum } \\
\text { Core } \\
\text { Temp. } \\
{ }^{\circ} \mathrm{C} \\
\end{array}$} & \multirow{3}{*}{$\begin{array}{l}\text { Specific } \\
\text { Power } \\
w / g m \\
\end{array}$} & \multirow{3}{*}{$\begin{array}{l}\text { Surface } \\
\text { Heat Flux } \\
\text { Btu/Hr/Ft }\end{array}$} & \multirow[b]{3}{*}{$\begin{array}{l}\text { Thermal } \\
\text { Cycles* }\end{array}$} \\
\hline & & & & & & & & \\
\hline & & $\begin{array}{l}\text { Fissions/cm } \\
(\mathrm{MWD} / \mathrm{T}) \\
\end{array}$ & At.\% & & & & & \\
\hline $65 *$ & 3.2 & $\begin{array}{l}5.9 \times 10^{20} \\
(17,300)\end{array}$ & 1.98 & 295 & 455 & 38 & $5.5 \times 105$ & 357 \\
\hline $64 *$ & 1.8 & $\begin{array}{l}4.2 \times 10^{20} \\
(12,000)\end{array}$ & 1.38 & 285 & 410 & 29 & $4.3 \times 105$ & 296 \\
\hline $71^{*}$ & 1.1 & $\begin{array}{l}2.8 \times 10^{20} \\
(7,900)\end{array}$ & 0.90 & 295 & 480 & 43 & $6.2 \times 10^{5}$ & 157 \\
\hline $72 t$ & 0.1 & $\begin{array}{l}1.5 \times 10^{20} \\
(4,300)\end{array}$ & 0.49 & 300 & 490 & 43 & $6.2 \times 10^{5}$ & 103 \\
\hline $70 t$ & -0.5 & $\begin{array}{l}1.3 \times 10^{20} \\
(3,900)\end{array}$ & 0.45 & 295 & 470 & 39 & $5.6 \times 10^{5}$ & 103 \\
\hline $84^{\top}$ & 0.1 & $\begin{array}{l}0.9 \times 10^{20} \\
(2,500)\end{array}$ & 0.29 & 290 & 440 & 33 & $4.8 \times 105$ & 58 \\
\hline
\end{tabular}

* Heat generation conditions during ETR Cycle 86, temperatures corrected for. oxide buildup.

$†$ Heat generation conditions during ETR Cycle 84, temperatures not corrected for oxide buildup.

* A thermal cycle is defined as a change from 90 - 100\% of maximum reactor power to 0 - 10\% of reactor power and return to 90 - $100 \%$ of reactor power. 
caps and the fuel element holders. The bowing observed on four elements after the first cycle of irradiation did not increase during the second irradiation cycle.

Submerged weights obtained on each element in the reactor examination basin were used for calculating the volume changes during the irradiation. Each element shows an accumulated decrease in volume, with the maximum being 1.3\%. Comparing volume changes which occurred curing each of the two reactor cycles, it appears that on the two highest exposure elements the volume decrease stopped during the last cycle. These two elements also have the largest void volume in the uranium core. The volume continued to decrease on the remaining elements curring the second reactor cycle.

Eight fuel elements were removed from the test before the start of the third irradiation cycle. These eight elements are being shipped to the Battelle pesearch peactor for neutron radiography. The radiographs will provide an insight into what is occurring in the uranium around the central voids, without resorting to destructive examination. Following the raaiography the elements will be returned to the ETR for additional irraciation. The eight elements removed from the test were replaced with five $\mathrm{zr}-2$ dumies and three new fuel elements.

Efforts to eliminate the problem of porosity in the welds and braze layers of elements to be used as replacements for those now being irradiated have continued. Porous welds on three elements selected for weld testing were removed by machining, but on rewelding by the tungsten-inert gas process, porosity again appeared on one of the elements. Further work on brazing and welaing will be necessary to obtain acceptable elements for irráiation.

Fast Peactor Dosimetry and Damage Analysis

(P. E. Nightingale)

High Temperature Fluence Monitors

Work is in progress to ajevelop high temperature fluence monitors useful at temperatures in excess of $1200 \mathrm{C}$ that will not react with their environment. Other investigators have used an $\mathrm{fl}_{2} \mathrm{O}_{3}$ matrix, but the variation in metal content from pellet to pellet has required indivicual calibration of each pellet. In an attempt to eliminate the need for individual calibration, ceramic flux monitors composed of a magnesium-oxide carrier and doped with 1 wto of the metallic oxides of either iron, nickel, or cobalt have been fabricated using the following process:

- Mix ${ }^{n} g 0$ carrier with cioping compouna.

- Ball-mill mixture for 16 hrs in alcohol.

- Dry powder and mix $10 \%$ binder (20\% carbowax in $\mathrm{H}_{2} \mathrm{O}$ ) with powder. 
- Pre-sinter at $1100 \mathrm{C}$ for 3 hrs to remove binder.

- High fire pellets at $1500 \mathrm{C}$ for $4 \mathrm{hrs}$.

Thirty small pellets of each type approximately 0.150 inch diameter and 0.150 inch long were produced. Fifteen of each type were taken at random and irradiated to determine the pellet-topellet variation in metal content. Comparison of the cobalt monitors at the 95\% confidence level shows the $\mathrm{Al}_{2} \mathrm{O}_{3}$ matrix pellets to vary in monitor metal content $\pm 12 \%$, whereas the Mgo matrix pellets vary only $\pm 0.7 \%$

The improved consistency eliminates the need for neutronactivation calibration of each individual monitor, which is required with the $\mathrm{A}_{2} \mathrm{O}_{3}$ pellets. MgO oxide pellets can be batch calibrated in the same manner as any carefully made metal alloy without a loss of accuracy.

The nickel and iron pellets are being counted and a complete summary of the test should be available by the next reporting period.

\section{Epithermal Peactor Experiment}

D. dosimetry experiment in the Epithermal Critical Experiment Laboratory peactor (ECEL) was conducted in cooperation with Atomics International and several other laboratories. This has afforded the opportunity to compare dosimetry practices and methods of calculating neutron spectra.

The neutron spectra in the core used in these experiments (core 14-13) were calculated by three methods: (1) a diffusion-theory code (CAESAR-IV) and a revised set of LOS Alamos cross sections; (2) a transport-theory code (Program S-XIII) with the Los Alamos cross sections; and (3) the transport-theory code (Program S-XIII) and Hanford Revised GAM cross sections (HRG). The third calculation was made to determine the accuracy obtained with the HPC cross sections, which have been used almost exclusively in thermal reactor analyses. The HRG library has a more detailed group structure than is available with fast reactor cross section libraries, such as the LASI cross sections, and will be useful in damage and dosimetry studies if it gives accurate results.

All input data except cross sections were identical in each analysis. Nuclear concentrations, spatial mesh, and geometric representation were the same.

The multiplication constant, $k$, is a parameter which can be measured precisely and thereby provide a check on the accuracy of an analysis. Agreement of calculated and measurea multiplication constants for the ECEL test would indicate good accuracy in the resonance 
energy range but is not necessarily indicative of accuracy in the energy range of damaging neutrons. Values of $k$, calculated in the analyses and the experimental value are:

\begin{tabular}{|c|c|c|}
\hline \multicolumn{2}{|c|}{ Me thoa } & \multirow[b]{2}{*}{$\mathrm{k}$} \\
\hline Code & Cross Sections & \\
\hline CAESAR-IV & LPSL & 0.9678 \\
\hline S-XIII & LPSL & 1.0196 \\
\hline S-XIII & HiPG & 1.0222 \\
\hline EXPEPIMENTAL & & 1.00093 \\
\hline
\end{tabular}

The results indicate that differences due to the computational method, i.e., transport-theory vs aiffusion-theory, are greater than those caused. by the cross sections used. Cross section differences in the transport-theory code cause differences in $k$ of only $0.3 \%$, while the change in calculational method introduced a difference of $5 \%$

The spectra calculated in these analyses also indicate that the calculational method introauces more difference in the flux above an energy, $E_{L}$, than do the cross sections. This is illustrated in the following table.

\begin{tabular}{|c|c|c|c|}
\hline$E_{L}, \mathrm{MeV}$ & CAESAP-LASL & $S-X I I I-L \lambda S L$ & S-XIII-HPG \\
\hline 1.0 & 0.152 & 0.131 & 0.122 \\
\hline 0.5 & 0.261 & 0.236 & 0.200 \\
\hline 0.18 & 0.444 & 0.383 & 0.337 \\
\hline 0.1 & 0.528 & 0.463 & 0.428 \\
\hline 0.01 & 0.786 & 0.730 & 0.738 \\
\hline 0.001 & 0.936 & 0.918 & 0.92 \\
\hline
\end{tabular}

The spectrum calculated with the CAESPR cocie has a larger component in the energy range from $0.01 \mathrm{M} e V$ to $0.5 \mathrm{MeV}$. This could have a significant impact on the analysis of damage in materials since a large fraction of displacements is caused by neutrons in that range. Data from a variety of resonance and fast neutron monitors, which were irraciated in the ECEL core by the participating laboratories, are being analyzed and may resolve some of the cifferences. 
ENEINEEPINC DEVELOPMENT

Neutron Flux Monitors (W. G. Spear)

Pegenerating Detectors (Thermal Flux)

Major effort was devoted to establishing the comprehensive test program for the regenerative detectors at the ETR. The necessary cable lengths were determinea by inserting a physically similar dummy capsule into the reactor. A 50-mg sample of the U-234 - U-235 regenerative material was compounded and forwarded to the detector fabricator along with the cable information. Test capsule design recommendations were received, thus basic assembly ciesign can now be initiated.

The original experimental U-234 - U-235 neutron flux detectors are continuing to demonstrate expected performance ciuring use in a Hanford production reactor. During detector operation the U-234 transmutes by thermal neutron capture to U-235, thereby replacing the burnup loss. This effect serves to maintain nearly constant sensitivity during reactor in-core use. In interim technical report is being prepared to describe the regenerative detector performance at high thermal neutron flux levels.

Beta Current Cenerator Detectors (Thermal Flux)

A prepared technical report, now in process of clearance for release, documents the development and extensive testing of the B-ll self-powered neutron detectors. An included analysis of the experimental and theoretical factors served to define operational and design characteristics of the beta current detector. In this concept the B-ll sensitive emitter material reacts with thermal neutrons ( $n$,gamma) to form the short-lived B-12 isotope, which ciecays rapidily to C-12 with the emission of $13.4 \mathrm{MeV}$ beta particles. The emitted beta particles constitute a measurable electric signal related in magnitude to the incident neutron flux level.

Beta Current Cenerator Detectors (Fast Neutron Flux)

The Be-9 isotope is being investigated as a possible detector material for fast neutron flux. This isotope undergoes an ( $n$,alpha) reaction, with a 0.1 barn cross section at $3 \mathrm{MeV}$, to provide a beta particle emission ( $23.5 \mathrm{MeV}$ ) with a relatively short half-life of 0.8 second. The beta emission generates a signal current proportional to the neutron flux level. In an experimental chamber, beryliium in an oxide or powdered metal state would be encapsulated in a suitable 
sheath opaque to the alpha particles but transparent to the generated betas which would escape for signal generation. To avoid interference signals aue to high gamma levels of $1010 \mathrm{~F} / \mathrm{hr}$, the balanced twin-lead, twin-chamber concept developed in the thermal flux cetector investigations will be consiäered for use.

Evolved Gas Detection Concept (Fast Neutron Flux)

In this unique concept of fast neutron detection, an evolved hydrogen or helium gas woula be collected from a simple capsule and evacuation tube assembly inserted into the reactor core. Gamma interference problems could be minimized by the location of the electronic instrumentation in the less destructive environment external to the core. In this detector ( $n, a l p h a)$ or $(n, p)$ reactions with $B-10$ or other materials would release helium or hycirogen in quantities proportional to the neutron flux. Calculations indicate that about 1011 atoms/sec of helium gas would evolve from one gram of $B-10$ at an incident fast neutron flux level of $1013 \mathrm{nv}$. It these levels the evolved gas could be measured by a mass spectrographic or optical spectrometer instrument. It is expectec that a flux of $1010 \mathrm{nv}$ or greater could be detected using the evolved gas concept.

\section{Microwave Detectors (Thermal Teutron Flux)}

As the resonant frequency of a microwave cavity containing is a function of the included plasma electron density, creation of the plasma by an inciclent neutron flux causes establishment of an equilibrium electron density, where its value is cietermined by electron generation rate and by the competing dissipation mechanisms. Using this method, the neutron flux density can be cietermined through measurement of the cavity resonant frequency shift. The following methoas can cause production of the required plasma: (1) for thermal flux, a gas such as $H^{--3}$ can be used, where an $(n, p)$ reaction with subsequent ionization of the gas by the chargea particles creates the plasma; and (2) a material such as U-235 or a special regenerating mixture of isotopes could be used, where the fission fragments cause gas ionization.

To avoid sensitivity loss experienced when a dielectric capsule (quartz) was used to enclose the detector gas, a gas-tight seal to the microwave cavity is being sought. Dight obtained vacuum-tight waveguide sections were brazed (in pairs) to various cavities. In each case the waveguide seals openeci. Changed designs of seals have failed to circumvent the difficulty. In a parallel effort, metalized ceramic seals were brazed airectly to the cavity ports. It is suspected that the large differential expansion between ceramic and Invar contributed to the failure of this sealing technique. The remaining seals are being brazed at a much lower temperature in an attempt to achieve a vacuum seal to the cavity. All otier brazes on the cavity assembly were fully vacuum tight. 
Once a satisfactory vacuum-tight seal is achieved, two reactor experiments will be conducted. One cavity will contain He-3 to determine the increase in sensitivity due to the deletion of the quartz capsule from the cavity, and the other will contain a foil of U-235 to demonstrate the applicability of this approach for plasma generation.

This also has application to fast flux measurements wherein it is expectea that gas ionization could be causea by fast fission fragments of an appropriate isotope such as U-238.

Microwave Detectors (Fast Neutron Flux)

Microwave techniques have airect promise for measuring fast flux density using methods similar to those used for measurement of thermal neutron flux. However, fast flux cross sections are small and gamma levels are high in anticipated fast flux reactors and compensation for the gamma interference must be achievea. It appears possible to achieve this by locking the generator frequency to a gamma reference cavity. Any aifference frequency between the reference and neutron sensitive cavity could then be related to the fast neutron flux density.

Another method of measuring fast flux would be to relate the incident flux with a gas-induced frequency shift of a microwave cavity through which gas from a beryllium (or other appropriate material) fast reaction is passed. The amount of gas evolved would depend upon the flux density, and the frequency shift of the cavity would depend upon the number of gas molecules within the cavity. Theoretical considerations indicate an instrument sensitivity of about $1011 \mathrm{nv}$ for a reasonable gas evolution rate of $10^{-2}$ atoms $/ \mathrm{sec} / \mathrm{nv}$ could be achieved in this manner.

Microwave and Infrared Detection of Coolant Impurities and Measurement of In-Peactor Temperatures (W. G. Spear)

Microwave Detection of Impurities in Coolant cases

Moisture content of an otherwise pure gas changes the dielectric constant of the gas. Thus, the amount of water vapor can be determined by measuring the dielectric constant through the change in the resonant frequency of a microwave cavity. Measurement of the phase shift in a section of waveguide can provide similar information.

Experiments at room temperature, using the frequency shift method, produced a sensitivity of $85.5 \mathrm{~Hz}$ per one part per million of water vapor in helium gas. Theoretically, the sensitivity should 
be $145 \mathrm{~Hz} / \mathrm{ppm}$. The dielectric constant of water vapor, a function of temperature, can be expressed in the following equation:

$$
k-1=52.75 \times 10^{-5}+\frac{2.78}{\mathrm{~T}}
$$

As the temperature increases, the dielectric constant decreases and the sensitivity is correspondingly decreased. F second factor in the reduction of the sensitivity is the reduced number of gas molecules in the cavity at the higher temperature.

In experiments at a temperature of $436 \mathrm{C}$, the sensitivity was reduced by a factor of 7.88 , as compared to a theoretical reduction of 5.24. With the present microwave system, the sensitivity at this higher temperature is approximately $10.86 \mathrm{~Hz} / \mathrm{ppm}$. Since $9.5 \mathrm{kHz}$ can be measured in a reliable manner, changes of $111 \mathrm{ppm}$ are detectable at room temperature and $875 \mathrm{ppm}$ at $436 \mathrm{C}$. Changes in techniques and revised instrumentation approaches are expected to provide improved sensitivity.

\section{$\underline{\text { High Temperature Measurements }}$}

Efforts are being directed to the development of advanced methods of measuring high temperatures within an operating nuclear reactor. Two methocis are being investigated to determine their practicality in the measurements of high temperatures. One method is based on the frequency shift of an inserted microwave cavity as its temperature is changed.

Several experimental assemblies, subjected to temperature as high as $1000 \mathrm{C}$, yielced sensitivities of approximately $300 \mathrm{kHz} /{ }^{\circ} \mathrm{C}$ with a nearly linear response of frequency shift versus temperature. Evacuation of the microwave components to minimize internal oxidation was necessary during the experimental tests. As a result of the difference pressure across the waveguide wall and the softening of the copper waveguide at the highest temperatures, an appreciable distortion of the input waveguide occurred during tests. However, the temperature sensor continued to operate properly and produced consistent data. It was noted that at a given temperature the resonant frequency of the microwave cavity was several $\mathrm{MHz}$ lower than it had been prior to distortion of this waveguide. To correct this problem, strengthening sections are being brazed to the input waveguide.

The second temperature measurement method requires utilization of a microwave radiometer, now being purchased. A matched load and input transmission line is being designed for use with radiometer. 
Infrared Techniques

Fabrication of mechanical parts for the Mark II hygrometer has proceeded as scheduled with a major portion now complete. That work which remains before the hygrometer will be ready for testing is as follows: (1) mechanical assembly including misce1laneous fabrication and revision as required, (2) electrical wiring and functional test of the complete electronic assembly, and (3) optical filter fabrication and optical alignment. There are no difficulties anticipated at this time. The basic instrument design incorporates significant improvements over the Mark I mociel.

\section{Upstream Boiling Burnout (D. P. Dickinson)}

Another series of tests in the study of upstream boiling burnout was completed. These tests were performed on a test section consisting of uniformly heated nickel tube, 70 inches long with an ID of 0.435 inch and a wall thickness of 0.065 inch. It was virtually identical to a test section used in previous tests except that the latter was of Inconel with a 0.188 inch wall. The tests were run with water flowing vertically upward at a pressure of 1500 psig and at mass velocities of 3, 5, and $7 \times 106$ lb/hr-ft2. Inlet conditions considered varied from slightly subcooled to $70 \%$ quality.

Significant and unexpected differences were observed between the boiling burnout behavior exhibited by this test section and the behavior exhibited by the previous test section under the same conditions. For inlet qualities near zero, the burnout heat flux was the same (or somewhat greater) with both test sections; however, at higher qualities, the burnout heat flux with the new test section was much less. The slope of the graph of burnout heat flux versus quality was more negative; the minimum in this graph (when found at all) was shifted to lower heat fluxes and to higher quality. Upstream burnout occurred less frequently and was observed only at high quality. By contrast, good agreement had been obtained in previous tests between different 0.188 inch wall Inconel test sections.

It, therefore, seems likely that at the higher qualities burnout was retarded by the thick-wall and/or low thermal conductivity of the test section material. (Nickel has four times the thermal conductivity of Inconel.) It may be that fluctuating flow conditions caused fluctuations in the heat flux to the water with the result that heat was alternately stored in the wall and released. A thick wall could absorb heat with a smaller temperature rise and so be less susceptible to burnout. An alternate explanation is that a hot surface of low conductivity is more easily wet by an impinging 
liquid drop since heat is transferred to the drop more slowly, and a vapor barrier is less apt to form between the drop and the metal. This could result in a higher burnout heat flux in a flow regime where liquid droplets impinge directly onto a dry wall. In order to distinguish between the effects of test section material and wall thickness, a new test section of 0.065 inch wall Inconel was designed and construction started.

Further study was made of postburnout heat transfer. The thin-wall nickel test section had only a small temperature drop across the electrically heated wall and, thus, permitted much more accurate measurement of the temperature of the heat transfer surfaces. with inlet qualities above $30 \%$, the rise in surface temperature as the heat flux was increased beyond burnout was only moderate. Heat fluxes up to 2-8 times burnout resulted in surface temperatures no more than $150 \mathrm{C}$ above the boiling point. In some tests at the higher qualities, the heat flux was increased far enough that the burnout spread from its initial location (upstream) until it covered the entire heated surface. While the burnout heat flux depended strongly on axial position, there was little dependence on circumferential position, except at the downstream end where a several-fold circumferential variation of burnout heat flux was observed.

Also, further study was made at the decrease in pressure drop observed with increasing heat flux just before burnout. The new test section had pressure taps at 12 -inch intervals to permit measurement of local pressure drops. In general, at the lower qualities (below about $20 \%$ at the inlet), the pressure arop fell over the downstream portion of the heated length as the heat flux was increased near burnout but rose over the upstream portion. (Pll these burnouts were downstream.) This decrease in pressure drop was not encountered at the higher qualities.

\title{
PLUTONIUM UTILIZATION PFOGRAM (F. G. Dawson)
}

\author{
Fuels Development
}

\section{FERTF Testing}

An eight-rod FERTF test element was designea and fabricated to test defected and nondefected fuel rods operating under high performance conditions. The ciesign incorporates a centrally located neutron absorber plug and a variable thickness sleeve in the surrounding basket. This arrangement provides for adjusting FEPTF rod powers to desired levels without significantly limiting the heat generation of the Batch core fuel elements. The FEPTF 8-rod cluster is presently undergoing thermal hydraulic flow testing. 
A FERTF test proposal for irradiating a 19-rod cluster of commercially fabricateä rods containing $\mathrm{UO}_{2}-\mathrm{PuO} 2$ pellets was written and approved. Under the proposed conditions, the pellet containing rods in the FERTF element will operate at a maximum power of $20 \mathrm{~kW} / \mathrm{ft}(460,000 \mathrm{Btu} / \mathrm{hr}-\mathrm{ft} 2)$ and with a maximum fuel temperature of approximately $2400 \mathrm{C}$.

PPTR Fuel Element and Examination

The failure of a second rupture disk introduced metal fragments into the PRTR primary coolant system. These fragments could conceivably become lodged in the PRTP fuel elements in such a manner as to cause failures by fretting or boiling burnout. To evaluate this possibility, all fuel elements (78) were discharged from the reactor and examined. None of the fuel elements contained any fragments of the stainless steel rupture disk. The fuel is to be recharged when flushing of the PRTP primary coolant system has been completea.

\section{Instrumented PPTR Fuel Elements}

A simplified instrumentation system for measuring fuel rod pressure was fabricated and installed. The system was checked and found to perform aảequately.

\section{TREAT Capsule Design}

Design of water-coolea power reactor type fuel capsules for irradiation testing in the Transient Reactor Test Facility (TREAT) was started. Except for a shortened fuel length and simple cylindrical end plugs, the basic design of the capsules will be prototypic of PRTR fuel rods.

Flux Monitor Wire Fretting Test

Flux monitor wires are attached to six PPTP fuel elements. The wires are held in place by passing them between an overlapped section of the cluster banding. The flux wire is free to flex between cluster bands. Thirteen, rather than six, cluster bands are used on fuel elements with flux wires to minimize flexing. No fretting was observed on a recent test made under PRTR flow, pressure, and temperature conditions. A fuel assembled by underwater banding techniques was recently tested under the same conditions without any evidence of fretting. 
During the latter part of this second test two cluster bands were removed, leaving the wire much freer to flex at the tip and in the middle of the fuel. Testing uncier these conditions lasted approximately three weeks. No fretting was observea. This result provides assurance that the fuel elements will perform acceptably, even if a cluster band is inaävertently broken.

Underwater Equipment

An uncierwater "manipulator" or tray for the examination of FEPTF fuels was fabricated last month. Installation in the PPTP. basin has been delayed aue to the slow delivery of a replacement gear reducer. The gear reciucer has been received and installeci, and testing of the apparatus will soon be completed. Installation will be completed in March.

Negotiations were completed, and a contract was signed for an underwater profilometer. The profilometer will be used for the dimensional inspection of irradiated FEPTF elements. Dimensional profiles with an accuracy to 0.0001 inch can be obtained with this instrument. Delivery has been promised for the first of June.

\section{Fabrication Cost Studies}

In recent months a series of cost analyses have been performed. They are based on a model cievelopeć earlier at Battelle-Northwest Laboratories (BNWL-273). The purpose was to establish the effect of plant throughput capacity on the cost of fuel elements enriched with high exposure plutonium and to compare the costs with those for fuel elements enriched with uranium-235. pnother study was undertaken recently to investigate the fabrication cost incentive for delaying the addition of plutonium into fuel material until vibratory compaction. rihe studies were completed, summarized, and prepared for presentation at Brussels, Belgium.

\section{High Exposure Plutonium Studies}

The majority of the plutonium isotopic analyses were completed for Yankee fuel samples ranging in exposure from approximately 10,000 to 40,000 MWd/ton. Further analyses to determine the content of americium, cesium, curium, and neodymium is in progress.

Surface dose rate measurements were made on two Phoenix type, 20 wto $\mathrm{Pu}-\mathrm{Al}$ fuel plates; one was clad with 0.020 inch of aluminum and the second was unclad. The Pu-240 content was approximately 19 wto. The unclad plate had a surface dose rate of approximately 2.5 pad/hr, and the clad plate had a surface dose rate of approximately $1.5 \mathrm{Pad} / \mathrm{hr}$. 
The gamma spectrum was observed to be the same for both plates with the exception of the number of photons in the photo peaks below $60 \mathrm{KEV}$. Both the dose rates and the number of photons $\leq 60 \mathrm{KEV}$ were reduced about $40 \%$ by the 0.020 inch of aluminum $\bar{c}$ ladding.

$\mathrm{PuO}_{2}$ measurement on two samples of shippingport plutonium, containing approximately 75 grams of plutonium each, revealed surface dose rates of about $3.3 \mathrm{Rad} / \mathrm{hr}$.

A plutonium nitrate sample was purified from Yankee Fuel, irradiated in cores $I, I I$, and IV, to an estimated exposure of approximately 40,000 $\mathrm{MWd} /$ ton which will be usea for energy spectra analyses. Attempts are under way to obtain a sufficient quantity of this fuel to make plutonium dose rate measurements.

\section{Reactor Physics}

\section{$\mathrm{D}_{2} \mathrm{O}$ Moderated Systems}

Batch Core Experiment in the PPTR. Positive period data collected during the Batch core critical tests in the PRTP have been converted to reactivity values using the PEPIOD-REACTIVITY code. These results are being usea to determine the moderator level coefficient of reactivity for the core at various critical moderator heights, core sizes and boron concentrations. A good determination of the moderator level cuefficients of reactivity is essential to the evaluation of the rest of the critical test results.

Measurements of relative fuel rod powers in 19-rod clusters of UO2 - 2 wto $\mathrm{PuO}_{2}$ have been made in the center channel (1550) and in a channel in the first ring of PRTR, using the PRCF gamma scanner. The measurements were made with either $\mathrm{D}_{2} \mathrm{O}$ or $\mathrm{H}_{2} \mathrm{O}$ cool ant in the center channel. The maximum rod power in the center channel was found to be increased $\sim_{10}$ when the $\mathrm{D}_{2} \mathrm{O}$ coolant was replaced with $\mathrm{H}_{2} \mathrm{O}$ coolant, in good agreement with the calculations reported previously.

Two-dimensional calculations of critical core configurations determined during critical tests have been made using the code 4-K ANGIE. The calculated value of keff for the 55-element core was about 2.5\% low. A re-evaluation of the cross sections used in the calculations is under way.

Calculations have been made to estimate the reactivity worths of the various possible configurations of the FEPTF 8-rod basket assembly in PRTR. Critical measurements have been scheduled in PPTR. which will test the reliability of the calculations.

Calculations have been performed to determine the fuel enrichment appropriate for capsule tests in the TREAT reactor. 
A summary entitled "Critical Experiments with $\mathrm{UO}_{2}-2$ wto $\mathrm{PuO}_{2}$ Batch Core in the PRTP," by P. I. Smith, J. W. Kutcher, and J. H. Lauby, has been submitted to the Imerican Nuclear society for presentation of a paper at the 1967 Annual l"eeting.

Determination of Boron-10 Concentration in D20 Samples. Samples of standard solutions of boron in $\mathrm{D}_{2} 0$, which were used to establish a boron sensitivity curve in the TrR, have been analyzed by the Analytical Laboratory using isotopic ailution techniques. Preliminary results for the 24.9 wppm B-lo solution agree to within $1.5 \%$ of the accepteci value. Work is continuing on the remaining samples.

Gamma Scanning Facility. Specifications have been drawn up for a lithium-drifted germanium detector system for use with the PNL gamma scanner, and a request for bias has been sent to possible vendors.

Plans are under way to relocate the gamma scanner in the PPTP experimental basin area. Concurrent with the relocation, equipment which will permit automatic scanning of fuel samples and rapid changes in collimator apertures will be designed.

Burnup studies for Al - 1.8 wto PuAl Fuel. Least-squares analyses of four sets of plutonium burnup data are nearly completed. Recent efforts have been directed toward obtaining fits to the data that are compatible with the basic cross sections of Pu-239 and Pu-24l. The least-squares analyses of these data are insensitive with respect to the ratio $\hat{a} \mathrm{~A} / \mathrm{A} 49$ of $\mathrm{flux}$-averaged cross sections. It is observed that a change in this parameter $\left(\hat{\sigma}_{a}^{41} / \hat{\sigma}_{a}^{49}\right)$ is compensated for by changes in the other parameters without noticeably affecting the quality of the fit. By fixing $\hat{\sigma} 41 / \hat{S}^{4}=1.14$ and then performing the leastsquares analysis, the remaining parameters (ratios of other fluxaveraged cross sections) fall close to the computed values.

Thorium Fuel Calculations. Physics calculations have been made for various loadings of thorium fuel in the PPTP. Several fuel element geometries and fuel compositions were investigated. The fuel compositions considered were U-235 - Th and Pu-Th systems. Metallic and ceramic fuel elements were studied. The metallic elements were nested cylinders, and the ceramic elements were clusters of rods. From these studies a candidate metallic and/or ceramic element will be selected for a feasibility study for a burnup experiment in the PRTR.

PBU Calculations. A summary entitled "Analysis of a $\mathrm{UO}_{2} 19$-Pod Cluster Experiment with the RBU Monte Carlo Code" was submitted for presentation of a paper at the Annual Meeting of the American Nuclear Society. 
An error was found in the table of the incomplete gamma function used in the RBU Doppler broadening routine (CHPSI). Examination of the incomplete gamma function indicates that a parabolic fit would yield a greater accuracy of the function with less computer time than the linear fit now used. Constants for the fitting parabolas are being determined using the least squares fitting code LEARN.

$\mathrm{H}_{2} \mathrm{O}$ Moderated Systems

Experiments with $\mathrm{UO}_{2}$ - 2 wt: PuO2 Fuel Pods. I summary entitled "Experiments and Calculations for H20-Moderated Assemblies Containing $\mathrm{UO}_{2}-2$ wto $\mathrm{PuO}_{2}$ Fuel Rods" was submitted to the ANS for presentation of a paper at the Annual Meeting.

Preliminary Calculations for $\mathrm{H}_{2} \mathrm{O}$-Moderated Lattices of UO2 4 wt: Puo2. Calculations are in progress to determine critical masses for $\mathrm{H}_{2}$ O-moderated lattices of $\mathrm{UO}_{2}$ - 4 wto $\mathrm{PuO}_{2}$ fuel rods. Two isotopic compositions of $\mathrm{Pu}$ and three lattice pitches have been considered. The codes THERMOS, HRG, TEMPEST, and HFN are being used in the analysis.

Analytical Correlations of PRCF Critical Experiments. Calculations of temperature coefficients of reactivity, fuel element worths, and power peaking around a water hole are being performed. These calculations provide analytical results for comparison with experimental results from recent $\mathrm{PRCF}$ experiments in $\mathrm{H}_{2} \mathrm{O}$-moderated cores containing $\mathrm{UO}_{2}-2$ wto $\mathrm{PuO}_{2}$ fuel rods.

\section{Physics Measurements}

Fabrication of PRCF Fuel Rods. Critical experiments in the PRCF require fabrication of about 10004 wt: $\mathrm{PuO}_{2}-\mathrm{UO}_{2}$ fuel rods. Each rod is to contain approximately $1.1 \mathrm{~kg}$ of the plutonia enriched fuel. The isotopic content of the plutonia is to be either 10-12\% or $16-17 \% \mathrm{Pu}-240$.

Evaluation of the planned work includes possible commercial fabrication of either packed particle or pelletized fuel rods. Preprocurement planning was completed; fuel rod design drawings and fuel specifications also have been prepared. An advertisement for expressions of interest to fabricate 400 fuel rods for delivery before June 1, 1967, was prepared for placement in the Commerce Business Daily. 
The set of fuel rods containing $100 \mu \mathrm{PuO}_{2}$ particles has been delivered and completes the particle size series for the 8 wto Pu-240 material. The series contains sets of four rods with discrete particle sizes of $0,100,200$, and $350 \mu$ particles indicate a nonlinear variation of $k$ excess with increasing particle size. Calculations with the computer code GDANS predicts a nearly linear decrease over this range of particle sizes. Further measurements including the $100 \mu$ particle size will be made to study this disagreement.

Another series of particle size rods containing a nominal 24 wto $\mathrm{Pu}-240$ is being fabricated with particle sizes of $0,100,350$, and $700 \mu$. Delivery of these rods is expected within six weeks.

\section{Code Development}

Program CHAD. The computer program CHAD for handling differential elastic scattering data was updated in order to punch the Legendre coefficients onto cards. The Fortran IV version-13 of CHAD calls for an on-line punch; however, the IBM 7090 has only an offline punch, and an output file for the punch subroutine had to be created. After this was accomplished, several runs were made with CHAD to calculate input data for the ENDF/B neutron cross section library.

Program ABACUS. The ABACUS program was recompiled in an attempt to fin $\bar{d}$ the numerical differences from the IBM 7090 to that of UNIVAC 1107. The UNIVAC 1107 version of the Clebsch-Gordon and Pacah coefficient function routines were converted from Fortran IV to Fortran II for use on the IBM 7090. There are still numerical differences between the two versions, but they are significantly smaller.

BNW Master Library. The low energy description of U-235 was changed to eliminate a slight discontinuity below $5.0 \mathrm{x} 10^{-3} \mathrm{ev}$. All versions of $\mathrm{U}-235$ were updated to include the change.

The ENDF/B resonance parameters supplied by $P I$ and $C E$ for $\mathrm{Pu}-238$ and $\mathrm{Pu}-239$ have been key-punched and will be introduced into the master library after they have been included in several UNI-BPOAD (UNICORN + DOPCRS) computer runs. A preliminary version of Pu-238 was placed on the master library tape in order to have resonance parameters available for immediate use.

Calculation of Scattering Kernels via Numerical Fourier Transforms. work continued this month on a new code which will calculate thermal neutron scattering kernels by a direct integration of the time-dependent correlation functions describing the motion of atoms in the scattering 
system. Recent advances include the following:

1. The correlation functions often have a relatively simple functional form at large times, and the large time contribution to the kernels can then be evaluated analytically. A subroutine which evaluates this contribution for $\sigma\left(E_{O} \rightarrow E\right)$ has been written, debugged, and checked against known results. It will later be generalized to calculate the corresponding contribution to the first Legendre moment of the cross section $\sigma_{1}\left(E_{0} \rightarrow E\right)$ as well.

2. The subroutine for evaluating differences of error functions has been modified to improve its speed and accuracy.

3. A subroutine to subtract the large time contribution from the integrand before the numerical Fourier transform is evaluated, whose speed greatly affects the speed of the entire program, is being modified to run faster.

Cross Sections for Transmutation Calculations. Few group cross sections for a large number of isotopes, principally in the actinide series, are being calculated from BNW Master Library data at the request of personnel in $\mathrm{N}$-Department, General Electric Company. Several changes have been made in BARNS to tailor the calculations to the request. Calculations of epithermal group values and resonance integral data have been made for 47 of the isotopes, and calculations of multitemperature thermal group data are in progress.

Revised Data Tapes for GRAINS. The GRAINS code calculates the reactivity of a mixed fuel consisting of one component randomly dispersed in grains in a metal matrix of another component. The code itself is being modified elsewhere in the department to expand the number of fuel isotopes from 4 to 6 . The additional cross sections for Pu-241 and Pu-242, needed by the expanded code, have been calculated by BARNS from BNW Master Library data, and revised epithermal and thermal data tapes for GRAINS have been completed.

Program DANCOFF. A document has been written which describes the computer code DANCOFF. This code computes the DANCOFF correction factor (i.e., accounts for mutual resonance shadowing among fuel rods in a lattice) using three different methods. Included in the report are results of resonance absorption studies based upon these three methods. 
Reactor Engineering Development

PRTR Fuel Element Rupture Test Facility

Boiling Burnout Limits for 8-Rod Element. Calculations were performed to determine boiling burnout limits for an 8-rod fuel element to be irradiated in the PRTR Fuel Element Rupture Test Facility (FERTF). The FERTF element consists of eight 0.565 inch diameter fuel rods arranged in a circle around a 0.983 inch diameter nonheat generating central rod, and encircled by a "basket tube." Minimum spacings between adjacent fuel rods, between fuel rods and the central rod, and between fuel rods and the basket tube are all 0.100 inch.

No boiling burnout data are presently available for this particular fuel geometry. However, its configuration is similar in certain respects to both rod bundle fuel elements and to tubular fuel elements contained in unheated flow tubes. Therefore, boiling burnout information on the FERTF element can be obtained by examining available boiling burnout conditions for these similar configurations. Literature on boiling burnout was searched to obtain experimental data applicable to the FERTF element. Data at pressures of about $1000 \mathrm{psig}$ and mass velocities ranging from 1 to $2 \mathrm{million} \mathrm{lb} / \mathrm{hr}-\mathrm{ft}^{2}$ conditions applicable to the FERTF) were found for (a) 19-rod bundles with spacings from 0.074 to 0.112 inch and (b) for annuli with spacings from 0.090 to 0.125 inch. Curves, of boiling burnout heat flux versus local coolant enthalpy, were constructed from these experimental data for mass velocities of $1,1.5$, and $2 \mathrm{million} 1 \mathrm{~b} / \mathrm{hr}-\mathrm{ft} 2$.

Since most of the experimental data were obtained under bulk boiling conditions, it was necessary to extrapolate the data into the subcooled region which is of principal interest for the FERTF. Therefore, it was desirable to apply a large burnout safety margin. Consequently, a second set of curves was drawn at heat fluxes $1 / 3$ lower than the boiling burnout heat flux curves (safety factor of 1.5). These lower curves were used as boiling burnout limits. Calculations were then performed to determine outlet subcoolings which would allow fuel at some axial position to just reach, but not exceed, a boiling burnout condition. These calculations produced linear plots of limiting tube power versus outlet subcooling for different mass velocities. Typical limits given by these plots are summarized in the following table:

\begin{tabular}{cccc}
$\begin{array}{c}\text { Mass Velocity* } \\
\left.\text { (millions lb/hr-ft }{ }^{2}\right)\end{array}$ & $\begin{array}{c}\text { Outlet Subcooling* } \\
\left(\text { OF }^{*}\right)\end{array}$ & $\begin{array}{c}\text { Tube Power } \\
(\mathrm{kW})\end{array}$ \\
\cline { 2 - 3 } 1 & 0 & 690 \\
1 & 150 & 1010 \\
2 & 0 & 825 \\
2 & 100 & 1340
\end{tabular}

*For coolant flowing inside basket tube. 
Since only total coolant rates through the tube can be measured in the FERTF, it is necessary that the relationship between total flow and flow inside the basket tube be established before operating limits for measurable parameters can be determined. This information will be established by hydraulic experiments scheduled for the latter part of February.

PRTR Thermal Fiydraulics Support Work

Thermal Hydraulıc Limits for PRTR Thorium Loading. Calculations were performed to evaluate various fuel element designs proposed for a thorium loading for the PRTP. One of the proposed designs consists of an 18-rod cluster (comparable to the present 19-rod cluster with the center rod removed) of ThO2 rods enriched with U-235.

This design called for $3 / 8$ inch fuel diameter and an average power density of 64 watts per gram of fuel. Calculations indicated that some melting would occur at the centers of fuel rods. Maximum surface heat fluxes would be on the order of $900,000 \mathrm{Btu} / \mathrm{hr}-\mathrm{ft} \mathrm{t}^{2}$. Although a thorough study of boiling burnout conditions has not been made, the possibility of operating at such heat fluxes is felt to be questionable.

Two possible methods were suggested for maintaining maximum core temperatures below the melting point of $\mathrm{ThO}_{2}$ and for reducing the maximum surface heat flux to a value nearer to present operating values. These were:

1. Use the proposed geometry and dimensions but reduce the average power density to about 45 watts per gram.

2. Substitute a bundle of 36 rods (by adding an 18-rod outer ring) with a fuel rod diameter of about $1 / 2$ inch for the proposed 18-rod element, and maintaln the 64-watt per gram power density.

Another proposed design consisted of two concentric fuel tubes made of Zircaloy-clad U-235 enriched metallic thorium. Design dimensions and operating conditions for such a loading are still being investigated. Equations were developed for determining temperature distributions within the fuel tubes and heat fluxes at each surface (inner and outer surface of each tube).

These equations will be used to examine the suitability of the designs from the thermal hydraulic standpoint when dimensions and desired operating conditions become better definea. 
BWR and PWP with PuO2 Fuel study

Two thermal hydraulic codes have recently been obtained from oak Ridge National Laboratory. They are as follows:

1. ORNL version of Theme 1:

A thermal hydraulic code for analysis of the hot channel in a fuel bundle.

2. The Modified U-3 Code:

A thermal hydraulic code for axial flow with mixing in fuel bundles.

The Modified U-3 Code was written in FORTRAN II and has been converted to FORTRAN IV; thus, it is compatible with computer processes at Hanford. It is intended to test the codes by comparing results with COBRA, a sophisticated thermal hydraulic code developed at Hanford which allows for interchannel mixing. These codes may be used as part of the chained codes, FULCYC, to give detailed reactor power limitations, based on thermal hydraulic considerations.

\section{Reactor Components Development}

FERTF Support Work. Testing of the flow separator is in progress by the Equipment Development Unit. Preliminary tests resulted in less efficiency than was calculated for the test conditions (approximately $55 \%$ actual particle removal vs $95 \%+$ calculated). Modifications to the test mockup to more closely auplicate the reactor installation has been suggested by the designer. These changes include: (1) provide a straight section at least 10 diameters long upstream of the separator inlet; (2) isolate the two bypass streams. These changes will be accomplished and further tests run.

Fretting studies of the wire bound fuel element were interrupted due to a leak in the process tube pressure cap. Pepair to the cap was made and testing resumed. To date, the element has undergone 727 hrs of testing at $155 \mathrm{gpm}, 1075 \mathrm{psig}$, and $525 \mathrm{~F}$.

\section{Materials Development}

Ceramic Fuel Dissolution studies

Work on the ceramic fuel aissolution program during the past month has been directed toward the construction of a small autoclave facility to be usea to determine the influence of reactor environmental variables on ceramic dissolution behavior. Construction of the facility has been completed, and the system has been pressure tested. Experimental operation is scheduled for March. 
jhutdown Radiation Measurements

Systematic measurements on shutdown radiation levels are being made during the startup with the PRTR short core and neutral pH primary coolant. Recent measurements were made following low power operation; no unusual radiation fluctuations or buildup trends have been noted.

Postirradiation Examination of PRTR Zircaloy Corrosion Specimens

Sixty tubular zircaloy-2 and zircaloy-4 corrosion specimens were exposed in the PPTR at a position normally occupied by a fuel rod (PRTR Test No. 72). In-flux oxidation data were reported in the preceding monthly report. The specimens were exposed 209 days in $\mathrm{pH}-10 \mathrm{LiOH}$ at 475 to $530 \mathrm{~F}$.

Hydrogen samples were taken in duplicate from 24 of the influx specimens. Out-of-flux standards also were sampled. Maximum in-flux hydrogen pickup by Zircaloy-2 exposed as-etched was 12 ppm $\left(0.18 \mathrm{mg} / \mathrm{dm}^{2}\right)$, representing $13 \%$ of the corrosion hydrogen. For etched Zircaloy-4 at the highest flux position, the maximum hydrogen pickup was $20 \mathrm{ppm}\left(0.31 \mathrm{mg} / \mathrm{dm}^{2}\right)$ and $18 \%$ of the corrosion hydrogen. The fact that the pickup is higher for Zircaloy-4 than for Zircaloy-2 is unusual but is not of great concern since it does not occur consistently at the lower flux positions. However, the hydrogen contents of the unexposed base metals are being re-evaluated. Hydrogen analyses are not yet complete for autoclaved DPTP specimens from Test 72 .

\section{PRTR Tube Corrosion Surveillance}

Six sections from PRTR tube No. 5696 were submitted to Radiometallurgy during February for metallographic determination of oxide thickness. The extent of in-flux oxidation and hydrogen absorption will be evaluated from results. Specimens from tube 5696 are expected to be available for postirradiation analysis within the next month. Specimens will be taken from each tube section for hydrogen analysis.

\section{PPTR Pressure Tube Evaluation}

The PRTR reactor safeguards program includes study by destructive examination of the effect of reactor environment upon the Zircaloy-2 pressure tubes. Work in progress is composed of determining a hydrogen limit on unirradiated tube specimens of different flaw lengths and crack propagation tests at various temperatures. The respective objectives are to determine a hydrogen limit and to provide crack propagation data. This work is continuously improving the basis for judgment of irradiated specimens. 
A tube has been hydrided with 275 ppm hydrogen and is being prepared for thermal cycling at operating pressure. This tube will have a $1 \frac{1}{2}$ inch flaw machined in it. The cycling test will determine if hydrides oriented by stress intensification at the tip of flaw can cause a crack to propagate at operating pressure.

D crack propagation test was run at $300 \mathrm{C}$ on a 20 -inch tube with a $1 \frac{1}{2}$ inch slot milled $80 \%$ through its wall thickness. The specimen failed at $3000 \mathrm{psi}$, which is equal to a hoop stress of 36,000 . This value is about $6000 \mathrm{psi}$ higher than we expected from an extrapolation of existing data.

Cycle Analysis

Transient Behavior Studies for Survey Codes

The current version of ALTHAEA used for such studies has been plagued by an error for roughly six months. Early in this period a procedure was found for circumventing the error, and hence, the search for it became relatively low key. It has finally been proven to be definitely a system error, and the search has been turned over to Computer Science corporation. They have not as yet continued the search.

Current work is now being directed toward inclusion of the current system into the latest version of ALTHAEA. Also, work is being directed toward extending the system to the one-dimensional mode of ALTHAEA operation.

\section{Test Reactor Operation}

\section{Operating Experience}

Pertinent data for the month are as follows:

1. Production . . . . . . . . . . . . . . 9.46 MWd

2. Critical Efficiency . . . . . . . . . 7.28\%

3. Total Experimental Time Efficiency . . . . 18.63\%

4. $\mathrm{D}_{2} \mathrm{O}$ Losses

a. Indicated Stack Loss (1/26/67-2/22/67) . 900 lbs

b. No physical inventory was obtained this month.

5. Helium Loss . . . . . . . . . . 68,840 scf

6. Hours Critical . . . . . . . . 48.9 hrs.

The following is a list of reactor shutdowns with a brief explanation of the cause of each: 


\begin{tabular}{|c|c|c|}
\hline $\begin{array}{c}\text { hutdown } \\
\text { No. } \\
\end{array}$ & Date & Reason for shutdown \\
\hline 1 & $1 / 26 / 67$ & $\begin{array}{l}\text { During primary system heatup, the reactor was } \\
\text { intentionally shut down from } 6 \mathrm{MW} \text { when control } \\
\text { problems were experienced with } \mathrm{S}-80 \text {, pressurizer } \\
\text { pressure control valve; } \mathrm{s}-30 \text {, deaerator level } \\
\text { control valve; and } \mathrm{s}-31 \text {, deaerator pressure con- } \\
\text { trol valve. The reactor had operated for } 8.0 \text { hrs } \\
\text { at a maximum power level of } 6 \mathrm{MW} \text {. }\end{array}$ \\
\hline 2 & $1 / 26 / 67$ & $\begin{array}{l}\text { After operating for } 0.8 \text { hrs at a maximum of } 2 \mathrm{MW} \text {, } \\
\text { the reactor was intentionally taken subcritical } \\
\text { when the moderator level exceecied the permissible } \\
\text { limit. Boron was removed from the moderator, then } \\
\text { reactor operation was resumed. }\end{array}$ \\
\hline 3 & $1 / 26 / 67$ & $\begin{array}{l}\text { After operating for } 1.1 \text { hrs at a maximum power } \\
\text { level of } 2 \mathrm{MW} \text {, the reactor was intentionally shut } \\
\text { down to repair a } \mathrm{D}_{2} 0 \text { leak on valve } \mathrm{M}-8 \text {, the } \\
\text { moderator inner plenum pressure control valve. }\end{array}$ \\
\hline 4 & $1 / 26 / 67$ & $\begin{array}{l}\text { The reactor was intentionally shut down because } \\
\text { of excessive D20 losses ( } 63 \text { lbs/day). The reactor } \\
\text { had operated for } 5.8 \text { hrs at a maximum power level } \\
\text { of } 6 \text { MW. A flange leak between the pressurizer } \\
\text { and the H-95 safety relief valve was located and } \\
\text { repaired. The high } \mathrm{D}_{2} 0 \text { losses from this leak were } \\
\text { responsible for both this and the previous reactor } \\
\text { shutdown. }\end{array}$ \\
\hline 5 & $1 / 28 / 67$ & $\begin{array}{l}\text { The reactor was intentionally taken subcritical } \\
\text { while flux chambers were repositioned. The } \\
\text { reactor had been critical for only } 10 \mathrm{~min} \text {. No } \\
\text { significant power level had been achieved. }\end{array}$ \\
\hline 6 & $1 / 29 / 67$ & $\begin{array}{l}\text { After satisfactorily completing low power ( } 6 \mathrm{MW}) \\
\text { tests, the reactor was intentionally shut down to } \\
\text { charge the peripheral fuel elements. The reactor } \\
\text { had operatea for } 31.4 \text { hrs at } 6 \text { MW maximum. Because } \\
\text { of the P-4 rupture disc problem, the reactor has } \\
\text { not operated since shutdown No. } 6 \text {. }\end{array}$ \\
\hline
\end{tabular}

During the reactor outage that began on $1 / 29 / 67$, valve $\mathrm{P}-4$ was deactivated so the seal ring could be replaced to correct an external $\mathrm{D}_{2} 0$ leak. After the valve was returned to normal, a routine shutoff test was performed to make sure the valve was functioning properly. This test, conducted on $2 / 6 / 67$, indicated the $\mathrm{P}-4$ rupture disc was broken. The valve was removed and the disc failure confirmed. Inspection of the disc revealed an area of eight square inches was missing from the center, and the remaining portion resembled the 
failed $\mathrm{P}-4$ disc that was reported last month. Because this was the second disc to break, and the failure occurred within 37 days of installation, parallel efforts were initiated to (1) locate and remove the missing pieces of disc material, and (2) determine the cause of the disc failures.

The reactor was defueled, and all fuel elements and test assemblies that had been in the primary system were inspected. No pieces or particles of metal were found on any element or test assembly. Ten fuel elements were found with flakes of some, as yet unidentified, nonmetallic material lodged between the rods or on the bands. Some of this same material was found in the cone screens during the primary system flushes.

Efforts to locate the missing disc by visual inspection of the area downstream of the P-4 valve were unsuccessful. Therefore, cone screens were installed in all 84 process tube nozzle jumper openings and the primary system was flushed six times. Following each flush, of at least $24 \mathrm{hrs}$, the screens were inspected for foreign material. At month end, $12 \%$ of the missing piece had been recovered. Also, recovery of the previously failed disc was advanced from $50 \%$ to $63 \%$ by these six flushes.

A solid blank was installed in place of the rupture disc in the $\mathrm{P}-4$ gate valve, and high speed pressure recording equipment was set up to measure the pressure drop across $\mathrm{P}-4$ with the valve closed. Primary system conditions that have existed during the past several months have been duplicated in a series of 10 special tests to determine the disc failure mechanism. Pesults of these tests are being evaluated at month end.

Process Technology

Batch Core Power Tests. Performance of the batch core power tests continued to February 6 , when the routine test of the rupture disc integrity in the primary system main block valve showed that the disc was broken. Power Test No. 9 and its Supplement No. 1 were completed.

batch core are:

Preliminary measured temperature coefficient values for the

$$
\begin{array}{llll}
\text { Fuel-Primary Coolant }(100-350 \mathrm{~F}) & -0.04 \mathrm{mk} / \mathrm{O}_{\mathrm{F}} \\
\text { Moderator } & & +0.1 \mathrm{mk} / \mathrm{O}_{\mathrm{F}}
\end{array}
$$

During the reactor operating period of 24 hrs to 6 MW ending January 29, 1967, the plutonium in solution in the moderator system increased from $0.5 \times 10^{-3}$ grams to $5 \times 10^{-3}$ grams as determined by alpha measurements. The diameter of the plutonium particles in solution was less than $0.05 \mu$ as determined by filtering the moderator sample. 
The final report on the irradiation of the salt cycle element (PRTR Test No. 118) was issued.

The PRTR transmutation accountability code, ISOPRO, has been revised and updated to handle current fuel types. The code has been debugged and is now operational.

An initial sample of primary system solids (i.e., "hot crud") was obtained from the pressurized sample system during reactor operation to 6 MW. This sample is being measured for quantity and sizes of particles and for gamma and alpha activities.

Corrosion Monitoring. A carbon steel corrosion probe was installed in the outlet of the core blanket gas system. This probe showed an initial corrosion rate of $0.5 \mathrm{mils} / \mathrm{mo}$ in this moist gas. The indicated corrosion rate for this probe is expected to vary with the moisture content of the core blanket helium.

X-ray examinations were made of selected locations in the PPTP primary, secondary, shields, process water, and helium systems. Most of the observed sites showed little or no increase in depth of penetration during the past two years. The exceptions were branch lines in the soft water and process water system which showed active corrosion buildup and pitting sufficient to penetrate the pipe wall and start leaking in four to five years. Accordingly, the examination frequency for these sites has been increased to once per year.

\section{Improvement Work Status}

\section{Work Physical Completed:}

DC RL-21, Rev. 1. Temporary and permanent piping changes were required to permit rupture loop decontamination. Temporary piping has been removed and permanent piping has become an approved part of the rupture loop system.

NPC-371. An enclosure has been installed around the ventilation unit for the rupture loop equipment room to prevent backflow of potentially contaminated air to nonregulated areas.

NPC-423. Rupture loop drain valve, RL-109, failed in service and was inaccessible for repair. Piping was rerouted to place the valve in an accessible location.

Design Work Completed:

DC-295. A gross gamma monitor will be installed in manhole No. 3 to provide a final check on all PRTR streams whlch go to the river. This is a part of Project BCP-013. 
DC-301. A charcoal filter will be installed on the fueling vehicle air exhaust to absorb iodine if released during fuel chargedischarge operation. This is a part of Project BCP-013.

NPC-411. A holder will be provided for storage of the new heavy duty sling for the reactor hall crane.

Work Partially Completed:

New Instrument Power Supply

FERTF Delta $P$ Tap Relocation

Remote $\mathrm{D}_{2} 0$ Addition Station

Rupture Loop Bypass

Rupture Loop Particle Removal Equipment

Remote Readout for Primary System Instruments

TW Tank Bypass

Battery Room Air Exhaust

Drip Cover for MCC-4

TW Tank Discharge Line Heater Wiring

New A- and B-Cell Sump Pumps

Remote Venting of Primary Pumps

Pressurizer Level Control

Automatic operation of RL-18 valve

Design Work Partially Completed:

Project BCP-013 - PRTR Decontamination and Waste Control

Analysis of $\mathrm{HX}-1$ and Primary Pump Supports

New Storage Basin Tray

Dual Safety Circuit

Dual Containment Valves

Dual Fog Spray Control Valve

Primary System Filter

Water Chiller Control Revision

$\underline{\text { Projects - Technical Guidance }}$

BCP-007 - PRTR Waste Handling. This project is to provide improved waste handling capability and control of reactor systems during accident conditions. Design is complete, and over-all construction is estimated to be 70 \% complete.

BCP-013 - PRTR Contamination and Waste Control. This $\$ 65,000$ project is to provide improved contamination and waste control during accident situations at PRTR. Over-all design is estimated to be $75 \%$ complete. 


\section{EBWR Demonstration Program}

Irradiation Testing of EBWR Prototype Fuel Rods

Pneumatically impacted, $\mathrm{UO}_{2}-1.5$ wto $\mathrm{PuO}_{2}$, vibrationally compacted, Zircaloy-clad $(1.07 \mathrm{~cm}$ OD) fuel rod specimens have successfully attained estimated maximum burnups to 27,000 MWd/ton of fuel. Production-run rods (148 cm long) and capsules with short sections $(8-10 \mathrm{~cm}$ long) of rods of the type currently in the Experimental Boiling Water Reactor (EBWR) are included in the irradiation tests. No failures have occurred, and tests are continuing.

Three full length rods with burnups to $9220 \mathrm{MWd} / \mathrm{ton}$ and 30 capsules with burnups to $18,300 \mathrm{MWd} /$ ton have been examined to date. Capsules have operated at maximum initial linear powers to $39 \mathrm{~kW} / \mathrm{ft}$ $(1280 \mathrm{~W} / \mathrm{cm})$ with associated heat fluxes to $1.2 \times 106 \mathrm{Btu} / \mathrm{hr}-\mathrm{ft}^{2}$ $\left(374 \mathrm{~W} / \mathrm{cm}^{2}\right)$. The two remaining capsules in the MTR have estimated maximum burnups of 27,000 MWd/ton and 25,600 MWd/ton. Both capsules will probably be discharged at the end of cycle 257 (about March 6 , 1967), and each will have accumulated nearly 900 effective full power days. Analytical data on burnups and isotopic concentrations in 25 capule specimens indicate good agreement with the predicted values from flux monitoring wire burnup data and computer (MELEAGER) ( 1 ) isotopic data. Mass spectrographic data on fuel (18,300 MWd/ton) irradiated in the Materials Testing Peactor (MTR) are (in atomo):

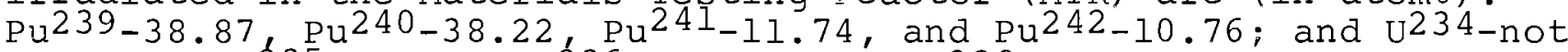
detected, $\mathrm{U}^{235}-0.0234, \mathrm{U}^{236}-0.0240$, and $\mathrm{U}^{238}-99.953$. Initially, the $\mathrm{U}$ contained 0.22 at: $\mathrm{U}-235$ and the $\mathrm{Pu}$ contained 91.53 at. $\frac{\mathrm{P}}{\mathrm{Pu}-239}$ and 0.69 at. $\% \mathrm{Pu}-241$. Specimens with burnups $>8000 \mathrm{MWd} / \mathrm{ton}$ are currently being analyzed for $\mathrm{Pu}-236$ and $\mathrm{Pu}-238^{-}$contents. One specimen $(18,300 \mathrm{MWd} / \mathrm{ton})$ tested in the MTR contains $5.0 \times 10^{-7}$ at. $\frac{\mathrm{P}}{\mathrm{P}-236}$ and 0.42 at. $\mathrm{Pu}-238$ in the $\mathrm{Pu}$.

Two full size rods (5760 and 9220 MWd/ton burnups) were in good condition externally and internally, and the cladding showed no evidence of hydriding. No autoradiographic (beta-gamma and alpha) sign of fission product or alpha-emitter migration into the $\mathrm{ZrO}_{2}$ pellet at the fuel-plenum junction was observed. No fuel-zircaloy interaction was detected in the rods or in the two highest burnup capsules which were examined.

With present EBWR operation at $42 \mathrm{MW}$, the maximum rod heat flux is $60 \mathrm{~W} / \mathrm{cm}^{2}$. The rods, however, were designed for the originally specified maximum EBWR conditions $\left(158 \mathrm{~W} / \mathrm{cm}^{2},<27,500 \mathrm{MWd} /\right.$ ton or $6.8 \times 1020$ fissions $/ \mathrm{cm}^{3}$ ) which were later modified because of reactor control problems. The PNI irradiation tests continue to indicate that the rods in EBWR will exhibit excellent behavior to the burnup

T1) J. R. Triplett and G. J. Busselman. MELEAGER - A Burnup code for Fuel Cycle Analysis, HW-68100. March 1961. 
of most interest in this experiment, 9000-10,000 MWd/ton, and to higher burnups. It is estimated that the fission gas release for rods to burnups of $\sim 9000 \mathrm{MWd} /$ ton for the above present and original conditions would bev6\% and $35 \%$, respectively.

The summary ${ }^{(2)}$ of a paper describing the high burnup results from the above $\mathrm{UO}_{2}-\mathrm{PuO}_{2}$ capsule and rod tests was submitted to the American Nuclear Society for possible presentation at the meeting this June in San Diego. A description(3) of a coauthored paper on the design, fabrication, and irradiation of EBWR fuel rods was submitted to the American Society of Mechanical Engineers for possible presentation at the meeting in Pittsburgh in November 1967.

\section{NUCLEAR SAFETY}

\section{Containment Systems Experiment (J. M. Batch)}

Experimental Facilities

The final pipe jumpers to the simulator were installed as were the thrust and lateral sway braces. Construction forces completed preliminary tests of the blowdown facility equipment in preparation for the final "acceptance test procedures" and operational tests.

Containment Leakage studies

The nominal $0.5 \%$ leakage tests were completed. These tests were conducted by adjusting individual leakage points at 60 psig to a nominal $0.5 \%$ day total leakage rate, then determining leak rates for three days at pressures of $60,30,15,10,5$, and 1 psig. The 10-psig test included a step leakage increase to test the sensitivity of the instrumentation. A summary of the data follows.

(2) W. J. Bailey. Irradiation of Impacted, $\mathrm{UO}_{2}-\mathrm{PuO}_{2}$, Packed Powder Fuel, BNWL-SA-1065. January 27, 196/.

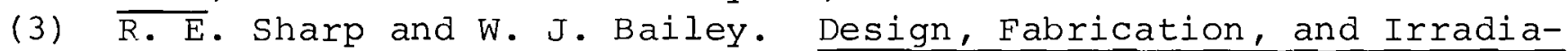
tion of UO2-PuO2 Fuel Rods for the Experimental Boiling water Peactor. (proposed paper). 


\begin{tabular}{|c|c|c|c|c|}
\hline Date & $\begin{array}{c}\text { * Referenoe } \\
\text { Method }\end{array}$ & $\begin{array}{c}\text { *Absolute } \\
\text { IEthca }\end{array}$ & $\begin{array}{l}\text { Collectea } \\
\text { Ieakage }\end{array}$ & Comments \\
\hline $\begin{array}{l}1-6-67 \\
1-7 \\
1-8 \\
1-9\end{array}$ & $\begin{array}{l}.48 \\
.43 \\
.43 \\
.45\end{array}$ & $\begin{array}{l}.51 \\
.56 \\
.47 \\
.48\end{array}$ & $\begin{array}{l}.33 \\
.33 \\
.32 \\
.31\end{array}$ & 60 psici \\
\hline $\begin{array}{l}1-10 \\
1-11 \\
1-12\end{array}$ & $\begin{array}{l}.23 \\
.33 \\
.33\end{array}$ & $\begin{array}{l}.42 \\
.47 \\
.37\end{array}$ & $\begin{array}{l}.19 \\
.19 \\
.20\end{array}$ & $30 \mathrm{psig}$ \\
\hline $\begin{array}{l}1-13 \\
1-14 \\
1-15 \\
1-16\end{array}$ & $\begin{array}{l}.13 \\
.42 \\
.39 \\
.21\end{array}$ & $\begin{array}{l}.27 \\
.18 \\
.27 \\
.50\end{array}$ & $\begin{array}{l}.21 \\
.21 \\
.20 \\
.20\end{array}$ & 15 psig \\
\hline $\begin{array}{l}1-17 \\
1-18 \\
1-19 \\
1-20\end{array}$ & $\begin{array}{l}.26 \\
.22 \\
.27 \\
.52\end{array}$ & $\begin{array}{l}.23 \\
.24 \\
.30 \\
.47\end{array}$ & $\begin{array}{l}.18 \\
.18 \\
.19 \\
.38 \leftarrow\end{array}$ & $\begin{array}{l}10 \text { psig } \\
\text { step increase, }\end{array}$ \\
\hline $\begin{array}{l}1-21 \\
1-22 \\
1-23\end{array}$ & $\begin{array}{l}.18 \\
.15 \\
.19\end{array}$ & $\begin{array}{l}.20 \\
.42 \\
.36\end{array}$ & $\begin{array}{l}.13 \\
.13 \\
.13\end{array}$ & $\begin{array}{l}.198 / \text { Cay } \\
5 \text { psig }\end{array}$ \\
\hline $\begin{array}{l}1-24 \\
1-25 \\
1-26\end{array}$ & $\begin{array}{l}.04 \\
.06 \\
.06\end{array}$ & $\begin{array}{ll} & .07 \\
& .003 \\
(-) & .45\end{array}$ & $\begin{array}{l}.07 \\
.07 \\
.06\end{array}$ & 1 psig \\
\hline
\end{tabular}

*Reference values are averages of multiple daily and overnight readings. **Absolute values aro enlarlated for approximately 24 hour intervals, from 1300 hours to 1300 hours daily. 
It may be seen from the data that the reference and absolute method of determining leakage rates generally agreed with each other except for some readings. Also, the sum of leakage rates from all known leakage points agreed with the reference method except for some cases. For this series of tests the reference method appears to be the more accurate method of determining leakage rates from the CSE vessel although this conclusion is based on a preliminary look at the data and could be modified by further calculations.

Xenon, traced with about one curie of Xe-133, was released into the containment vessel as part of the preparations for a series of tests at a nominal 0.1\%/day leakage rate. The purposes of this release were to evaluate the use of xenon as a tracer for determining leakage rates at individual leak points, and to evaluate the adequacy of sampling system performance and sample analysis equipment and techniques. Leakage rates determined by xenon tracer are not yet available.

Fission Product Transport Studies

Aerosol Generation. An attempt to demonstrate prolonged $\mathrm{UO}_{2}-$ Zr aerosol generation in air by induction heating in a CSE quartz furnace was made with partial success. The melt required increasing amounts of power to maintain a temperature at about $1900 \mathrm{C}$ until the induction heater tripped out and coupling was lost after 204 min. The increased power requirements are thought to be due to oxidation of the $\mathrm{UO}_{2}$ to $\mathrm{U}_{3} \mathrm{O}_{8}$ with attendant decreased electrical conductivity.

Analysis of the melt residue (selected to avoid the $\mathrm{UO}_{2}$ bed material) gave an $O / U$ ratio of 2.5. This corresponds to a mixture of $75 \% \mathrm{U}_{3} 0_{8}-25 \% \mathrm{UO}_{2}$. The aerosol release rate was $113 \mathrm{mg} / \mathrm{min}$.

Decomposition and release of cesium carbonate was investigated at $1200 \mathrm{C}$ using quartz and magnesium oxide boat materials. Is observed earlier with one gram masses of cesium carbonate, the quartz was severely etched. Magnesium oxide and magnesia-titania boats maintained their integrity but were too porous to contain the cesium oxide melt. Magnesia is one of the few materials which is nonreactive with alkali metal oxides systems and was considered an alternate to the use of nickel containers which are mechanically satisfactory but do produce traces of metal oxide fumes.

A three-component fission product simulant (cesium, ruthenium, and iodine) was released into an ADF containment vessel. The test was only partially successful since poor ruthenium recovery in the preparation of the radiochemical traced metal resulted in a low amount available for release to containment. In previous experiments 70-90\% conversion of $\mathrm{Ru}^{+3}$ to ruthenium metal has been obtained by reduction with magnesium metal in acid solution. 
Xenon traced with one curie of xe-133 was released to the Ia n CSE containment system for leakage rate testing and sampling syotern behavior. Pelease was obtained by transferring the Xe-133 containing ampoule to a 7.3-liter pressure vessel, adding stable xenon and pressurizing with nitrogen, then breaking the ampoule with stainless steel bearings contained within the pressure vessel. After equilibration of carrier and tracer in excess of four hours, the material was pressure released to containment.

Analytical Program. More than 70 samples from a zenon release to the main CSE containment vessel were analyzed. The samples were collected in charcoal packed stainless steel traps and gave a check on the gamma energy analytical system for these sample types. Chisquared goodness of fit numbers relating filed Xe-133 standard spectra with the xenon trap sample spectra from the above experiment were excellent. Some doubt existed prior to these tests on how reproducible xenon counting might be in the stainless steel traps both from the standpoint of sample trap variations and distribution of xenon within the $240 \mathrm{ml}$ charcoal volume. Duplicate sample volumes in different traps agreed within 1 응

one hundred fifty-odd samples from a three-component radionuclide mixture of Cs-137, Ru-106, and I-13I were analyzed. Analytical results appeared good for Cs-137 and I-13I whereas Ru-106 numbers were insignificant due to a much lower release than anticipated due to poor recovery of material to be released in the chemical preparation of ruthenium metal.

Sampling Equipment. Fifty additıonal Inaypack filter holders have been received for a total of about 150. These are being checked for defects.

A procedure to test the Maypack clusters has been established and test equipment fabricated. Testing of the 15 clusters for leaks, defective valves, and wiring errors is under way.

Deposition coupons for use in the large-scale contalnment experiments were ordered in quantities sufficient for 10 to 12 runs. Materials and coatings ordered inclucie carbon steel, stainless steel, silver plated copper, aluminum, carbon steel coated with Phenoline 302 , and carbon steel coated with imercoat 66 .

Small-scale containment studies. Three runs were carried out in the aerosol laboratory--two in the painted tank and one in the stainless steel tank. All runs were at nominal conditions of $80 \mathrm{C}$ $(175 \mathrm{~F})$ isothermal, atmospheric pressure, 50\% steam, and 50\% air.

The first run was to further define iodine behavior in the painted tank after 210-hr exposure of the palnt to steaming. The aerosol included $\mathrm{UO}_{2}$ and Zircaloy cladding fumes along with iodine. 
No significant difference in aerosol behavior was discernible when solid particles were present in the atmosphere compared to a prior run which had iodine without oxide fumes.

The purpose of the second run was evaluation of aerosol behavior in the absence of conciensation with other conditions as in the preceding run. The tank was heated initially with steam, then temperature was maintained by electrical heating of the tank wall. A. pool of two liters of conciensate in the tank at the start of the run was sampled periodically. Difficulty was experiencea in holding temperature constant, and a variation to a maximum of $85 \mathrm{C}$ ( $185 \mathrm{~F}$ ) and minimum of $78 \mathrm{C}(173 \mathrm{~F})$ occurred. Particle-associated activity in the atmosphere was 50-fold greater at the end of the run under the nonconciensing conditions than uncier the condensing conditions of the preceding run.

Material balance indicated $95 \%$ of the calculated iodine input had been adsorbed on the walls within 15 min of injection and remained so adsorbed in the absence of condensation.

When steaming was begun after the run, iocine was removed in the conciensate at about the same rate as in the previous concensingsteam run.

The purpose of the run in the stainless steel tank was to provide a three-component aerosol for evaliation of the gamma analysis program.

\section{Coolant Blowciown stuäies}

1. run plan has been prepare $\vec{i}$ for the first instrumented blowciown from the reactor simulator vessel. Whe objective is to test the operation of the system, train the personnel involvea, anci to measure some of the variables with a limitec number of sensors which are to be available at that time.

The blowciown is to be macie witir tile vessel $2 / 3$ full of ambient temperature water being forcea out of a 2-inch orifice in the bottom nozzle by a ciome of 600 psia nitrogen. Because of the simplicity of this system, accurate precictions can be made, anc thus the performance of the sensors can be assesseci. Sensors will measure mass flow rate, impact pressure, and reaction forces. Since the computer readback cocie is not yet finisiec, the sensor ciata for the first flow runs will be recorcieci on graphical reaciout devices such as high speec chart recorciers and recorcing oscilloscopes.

Dummy Core Design. Mine conceptual layout has been completed of a aummy core with attachments such that the core and blowdown can be arrange $\bar{c}$ to simulate both PVI's anci BWF's of current design. 
The basic structure is a simple core plate with holes into wicin simulated fuel element anci entrance restrictions can be screver anc to which a flow skirt, a core barrel, simulatec jet purps, anä other çevices whicir are desireci can be attacheá.

The material for the core plate is being obtaineci immeailately, even before the final prints are ready, so that there will be no cielay in construction and the plate will be reaciy when the single chamber blowciowns are completea and it is ciesirec to acid the flow restriction.

The strength of the simple core is expected to be at least twice that of the supporting lugs. I ciynamic analysis of the core has not been carried out penciing results of a ciecompression wave analysis. Dressure cirop measurements taken at Infr for a simple flow restriction showed a $200 \mathrm{~Hz} 100-200$ psi pressure fluctuation across the restriction during the subcooled portion of blowciown. Dressure effects of this nature should not be a severe problem.

The decompressor wave analysis has reachec the stage of being programmed for the computer.

ileat Plux Measurements

I computer program has been developea to calculate the heat flux to a wall basec on the initial temperature cistribution and the transient temperatures at each surface of the wall. The purpose is to provicie a means of aetermining the heat flux in two isolated situations: (1) the flux from the reactor vessel wall to the fluid during blowchown and (2) the rate of heat removal and the heat transfer coefficient during conciensation of steam on the containment wall and other interior surfaces curing anc. subsequent to tihe blowciown. $A$ recunciant system for analyzing input data was found to be necessary to insure program stability. The report is being written concurrently with trial runs of the computer program. Both will be completed in the first week of March.

The design of an experimental setup to evaluate transient condensation coefficients in the presence of nonconciensibles is being completed. This setup will also serve to check out the operational use of the computer program.

\section{Dressure Vessel Crack Monitoring (J. C. Spanner)}

Detection of Metal Overstress by Acoustic Emission

Development efforts continued on the program to apply acoustic emission in metals as the basis of a crack monitor system for surveillance of reactor pressure piping. Fabrication of three static burst 
test specimens has been completeci, anci initial cracking has been sroduced in one specimen preparatory to jurst testing. In the metiroü being useä, a flaw is inillea part way through the specimen wall, and a crack is formed by internal pressurization using cola water. $\pi$ stainless steel patch is then placeci over the inside of the crack using a thin copper boot. The crack can now be propagatec several inciles by pressurization with water before the copper boot iails. Tormation of the initial crack in the one specimen was monitorea for acoustic emission, but mucir of the significant information was obscured by noise from slippage of the end closures. These ciata were recorded without filtering for exploratory purposes.

Development of a seif-aligning electrostatic transciucer for detecting acoustic emission continueci, anä the work was concentratea $i$ in the area of inproving the cielectric vacuum cieposition techniques. Pinhole-free dielectric layers were obtainea with silicon monoxidesilicon cioxicie layers.

Dffsite commercial vacuum ceposition service, Thermonics Inc., of ilaywara, california, was contractec to cieposit, at high temperatures, several wo2 transcucers. It is expected these units will be receivea within the month. irorli is also continuing using onsite vacuum deposition facilities as manporer anc worl: scheciuling permit.

Design of an integrateci emission-rate analyzer system was completed, anci the circuits were testec in a breacboard assembly.

Laboratory instruments (oscilloscope and pulse generator) useci in the experimental system were replacec in the final ciesign with special purpose circuits. The system is now reaciy for final asserbly.

Work is in progress to upgracie the frequency response of the acoustic emission monitoring system presently being useci for spectral analysis. This is essential to a more comprehensive stucy of signal characteristics.

The acoustic emission program was summarized for the berefit of A. T. Pressesky, $A T C$ Division of reactor Development and Technology, et al, auring their visit to pichlanci on $1 / 18 / 67$.

$$
\text { Reactor Safety Enalysis anc Evaluation (P. C. Theeler) }
$$

Heavy Section Failure Fnalysis

This portion of the proçam is concernec with evaluating the failure behavior of irraciiatec thick-wall, low-alloy, steel pressure vessels from tests on large scale vessel mociels and large fracture mechanics specimens. 
One of the major problems of this work is finding suitable reactor facilities for irradiating the large specimens. P potential irradiation facility is the Sanciia Experimental Peactor Facility (SERF) in Albuquerque, New Mexico. During this perioa gamma heat monitoring experiments were performed in the SERF. These experiments measured the temperature fluctuation of a 18,780-gram, 6-inch diameter, block of 304 SS at three different vertical positions in the reactor cell during a $7-h r$ reactor operating cycle. A total of eight duplicate monitoring experiments were performed. Each experiment required continuous strip chart recording of the thermoelectric outputs of seven thermocouples. The strip chart data have been reduced to a usable graphic form and now provide a basis for predicting the gamma heat to be expected with the irradiation of large specimens in the SEPF.

Intermediate Level Waste Treatment (C. J. Touhil1)

Scavenging Mechanisms

Equipment was set up and reagents prepared for the start of an investigation of the ion exchange characteristics of hydrous oxide scavenging systems. Hydrous manganese oxide formed by the permanganate-manganous ion reaction was the system selected for study. F series of experiments was planned to study the ion exchange properties of this hyảrous oxide in systems containing trace amounts of radiocesium and/or radiostrontium. Experiments on the adsorption of cesium from aqueous solution are now in progress.

\section{Fission Product Aerosol Containment}

Pemoval of organic Iodides with Hyärazine (L. C. Schwendiman)

Shakeciown operation of the $4 \mathrm{~m}^{3}$ spray chamber continued with attention given to temperature control characteristics of the chamber. With steam as the initial heating agent, a maximum temperature of $95 \mathrm{C}$ was attained in one hour. Wall temperatures were 2 C higher. Heating with auxiliary electric heating allowed temperatures of 90$94 \mathrm{C}$ to be easily maintained. Condensate rates were measured during these tests. The safety aspects of the experiments to be conductea were reviewed and the draft of the Hazards Peview updated.

Physical Chemistry of the Hydrazine-Methyl Iodide Peaction (L. L. Burger)

A series of experiments was performed which showed the influence of hyarazine concentration on rates of removal of methyl iodide distributed in fine bubbles and passed through a pool of hydrazine. The 
contact time of the bubbles was about one second or somewhat less; nence, an approximate half-time of removal could be estimated. The half-time removal is an effective half-time which would include the t.lme required for diffusion from bubble volume to the bubble wall, transfer to the liquid, and the time for the reaction to occur. The effective half-time was of the order of 0.3 second for solutions of $33.6 \% \mathrm{~N}_{2} \mathrm{H}_{4}\left(95-96 \%\right.$ removal) and about 0.5 second for $3.5 \% \mathrm{~N}_{2} \mathrm{H}_{4}$ ( $79 \%$ removal, or $94 \%$ for twice the depth of solution). In the latter case, doubling the travel time of the bubble essentially coubled the number of half-lives during bubble rise, with the resulting marked increase in efficiency. The effective half-time, as rapiä as is indicated, is ajoubtless slower than the homogeneous liquid phase reaction in a well-stirred system. Solutions of 1\% $\mathrm{N}_{2} \mathrm{H}_{4}$ removed $82 \%$ of the methyl ioaide bubblea through it under conditions prevailing in the experiments described, corresponding to an effective half-time about that for removal with the $3.4 \%$ hyarazine solution. The effective removal of $\mathrm{CH}_{3} \mathrm{I}$ with dilute solutions of $\mathrm{N}_{2} \mathrm{H}_{4}$ continued to give encouragement for the use of hyärazine in packaged scrubbers or containment spray systems.

Methyl Iodide Removal - Rate Controlling Process (L. C. Schwendiman)

The mechanisms which control the rate of removal of methyl iocicie from a gas volume over a stagnant pool of a reacting liquid were studied theoretically. The objective was to interpret data reported earlier for the disappearance of methyl iodicie from the space over a solution of hydrazine. The observed rates were compared with rates predicted for three limiting cases. In the first case, gas phase diffusion was assumed to be controlling. In the secona, the homogeneous reaction rate in the liquid was considered controlling, and in the third, the rate was considered to be controlled by diffusion within the liquid and chemical reaction in the unstirred solution. The disappearance rates preaicted for the first two cases were much faster than the observed rate, which indicated that these mechanisms were not controlling the over-all removal rate. For the stagnant liquid and with the assumption of a diffusion-reaction situation, the predicted rates were $40 \%$ to $85 \%$ of the observea rates. Igreement was best for the experiment in which the liquia layer was relatively thin. A slight amount of mixing in the liquid phase could account for the discrepancy between the measured and preaictec removal rates. other uncertainties may contribute also to the difference. These considerations led to the conclusion that the transport processes in the liquid phase control the removal rate, and the "heterogeneous reaction" rates measured reflect the degree of mixing in the liquid phase. This analysis emphasized the need for reaction rate ciata obtained for homogeneous (single phase) systems or with sufficient agitation to give complete rapid mixing. Theoretical analysis of removal on droplets will require reaction rate data of the homogeneous liquid phase reaction. 
Disposal of peactor off-Gas into Soil systems (W. A. Haney)

Calculations for the single-well solution for gas injection problems were revised to scale all length dimensions to the total depth of the system, i.e., a depth from the ground surface to the water table. This scaling allows more meaningful representation of results, easier and faster preparation of computer input, and clearer explanation of the methods of obtaining and using the results.

Dimensionless travel times are a function of injection pressure as well as geometry factors. If problems are formulated so that dimensionless travel times would be dependent only on geometry factors, then the differential equations would be nonlinear and solutions in closed form impossible to obtain.

Certain aspects of the flow pattern can be conveniently represented on a set of dimensionless graphs. These graphs, in preparation, will illustrate the flow as a function of radial distance from the well under continued pumping.

Geophysical Exploration of Pattlesnake \#1 Well (W. A. Haney)

A bid package for Pattlesnake Hills test well re-opening and cleanout was completed and sent to prospective contractors. The bid package for geophysical logging was essentially completed and will be mailed in a few days. Drilling samples from the well were recelved from Stanaard oil Company of California, Western nperations. Drilling logs, lithologic logs and other data that haci not been previously released for the Rattlesnake Hills well were also received from Standara oil. Target aate for start of the re-opening and cleanout work is Ppril 1, 1967 .

\section{Columbia piver Seciimentation Studies (D. R. Kalkwarf)}

The radiochemical analysis of over 500 upriver water and sediment samples was completed, and the results were tabulated and delivered to U.S. Geological Survey. This completes the reconnaissance survey for radionuclides in the river above vancouver and the findings are being assembled for publication in the open literature. 
Padioactive Residue Solidification (P. M. Platt)

Pot Solidification

Process Technology. Solids in the feed caused several line blockages during WSE Pun 3 aespite the feed being agitated continuously. This prompted a detailea investigation of solids in PW-2 solutions to see if changes in procedures or composition might decrease the solids problem. Most of the precipitate in laboratoryprepared $\mathrm{PW}-2$ is a mixed sodium-rare-earth sulfate if the solution is not heated; other solids form when the solution is heated. Experiments with a $\mathrm{Na}-\mathrm{R} . \mathrm{E} .-\mathrm{SO}_{4}-\mathrm{NO}_{3}$ system at $\mathrm{PW}-2$ concentrations showed that the amount of precipitate is a minimum at about $2.0 \mathrm{M} \mathrm{HNO}_{3}$ and that if the sulfate concentration is decreased by a factor of less than three, the solubility product is no longer exceeded. A marked change in the solid form occurred between 25 and $50 \mathrm{C}$. Sodium-rareearth sulfate precipitated at $25 \mathrm{C}$ was very finely divided and easily suspended: when precipitated at $50 \mathrm{C}$ the particles were larger and formed an acherent scale and cake. This behavior has not been observed when all of the components of PW-2 were present although caking has been observed in aged $\mathrm{PW}-2$ precipitates.

Padioactive Demonstration

Waste Solidification Engineering Prototypes. WSEP Pun 3 using the pot calcination process was completed successfully using a modified $\mathrm{PW}-2$ feed composition ( $0.6 \mathrm{M} \mathrm{SO}_{4}^{-} \mathrm{Vs} 0.9 \mathrm{M}$ nominal and $\mathrm{AI}^{+3}$ substituted for the major portion of the $\mathrm{Fe}^{+3}$ ). A 12 -inch aiameter pot was fillea with approximately 1.7 kilowatts of radioactive heat. During the run 940 liters of feed were processed in a 42-hr period for an average feea rate of 22 liter/hr. While calcining, the feed batch for Pun 4 was concentrated in the waste evaporator to demonstrate batch operation.

During the terminal portion of the run, the theoretically predicted temperature maxima wave was observed. A calculated reduction in furnace temperatures was used to control the maximum temperature at the desired $850 \mathrm{C} \pm 25 \mathrm{C}$. Results of measured temperatures in the calcine indicate the simplified calcination shoula be adequate for temperature maxima control.

At month end WSEP Run 4 (Pot Calcination Run 3) was also completed.

Spray Solidification

Process Technology. Run 5 in wSEP will be a spray solidifier run in which $\mathrm{PW}-1$ is processed. Off-standard features of the run 
will be more than normal aluminum and a minor amount of sulfate introduced to the feed with the Purex 1WW used. Laboratory tests indicated neither the extra aluminum nor the sulfate would affect significantly the melt properties at the concentrations present. The effect of slightly higher aluminum concentrations (greater than $0.2 \mathrm{M}$ ) was to increase the calcine melting point and the melt viscosit $\bar{Y}$ even when the $M+/ P$ ratio was kept constant.

Eight more compositions in the ternary system $\mathrm{Na}_{2}: \mathrm{P}_{2} \mathrm{O}_{5}: \mathrm{PW}-1$ were examined to fill in data gaps. The results reinforced previous conclusions that a fairly large variation around the composition chosen for the present flowsheet can be tolerated without causing significant changes in melt properties.

Engineering Development

Spray Calciner Development. A spray nozzle test stand was fabricated, and eight pneumatic spray nozzles were evaluated with air and water. To evaluate the quality of atomization, an octagonal

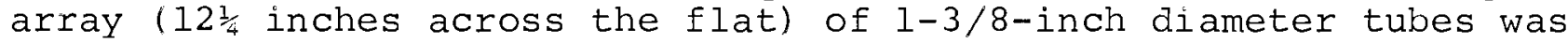
assembled. The tube array was placed 36 inches below a nozzle, and the liquid volume collected in the individual tubes was measured. It was determined that the percentage of the spray droplets which was collected in the central seven tubes of the 61 -tube array varied significantly ( 4 to 25\%) for the different nozzle types and was also dependent upon the mass ratio of air to water. Four of the nozzles which were tested were internal $\mathrm{mix}$, and four were external mix with one of the external mix being the present nozzle used on the prototype equipment. The evaluation of the nozzles revealed that the performance of the prototype nozzle was equaled or exceeded by the other seven nozzles of this group.

As another method of evaluating the performance of pneumatic atomizing nozzles, the size distributions of water ciroplets produced by several nozzles were measured and compared as a function of atomizing air flow. The nozzles selected for these drop size measurements were those which appeared to produce the finest atomization from a group of many nozzles which had been previously screened in a spray testing chamber; also included was the nozzle which had been used for the radioactive runs.

Spray droplet samples were collected in optical cells which were partially filled with high viscosity (950 poise) immersion oil. The immersion oil was covered with a layer of kerosene so that the aroplets penetrated the kerosene but were trappea on the oil surface. The kerosene prevented evaporation, while the yielding oll surface minimized both coalescence and distortion of the droplets. The sampling technique and materials were provided by personnel of the Particulate and Gaseous waste Research Unit. 
The droplet sizes were fitted to the logarithmic normal probability distribution and the maximum droplet sizes were arbitrarily taken to be the drop size where $99 \%$ of the droplets are smaller. The results of these measurements are tabulated below.

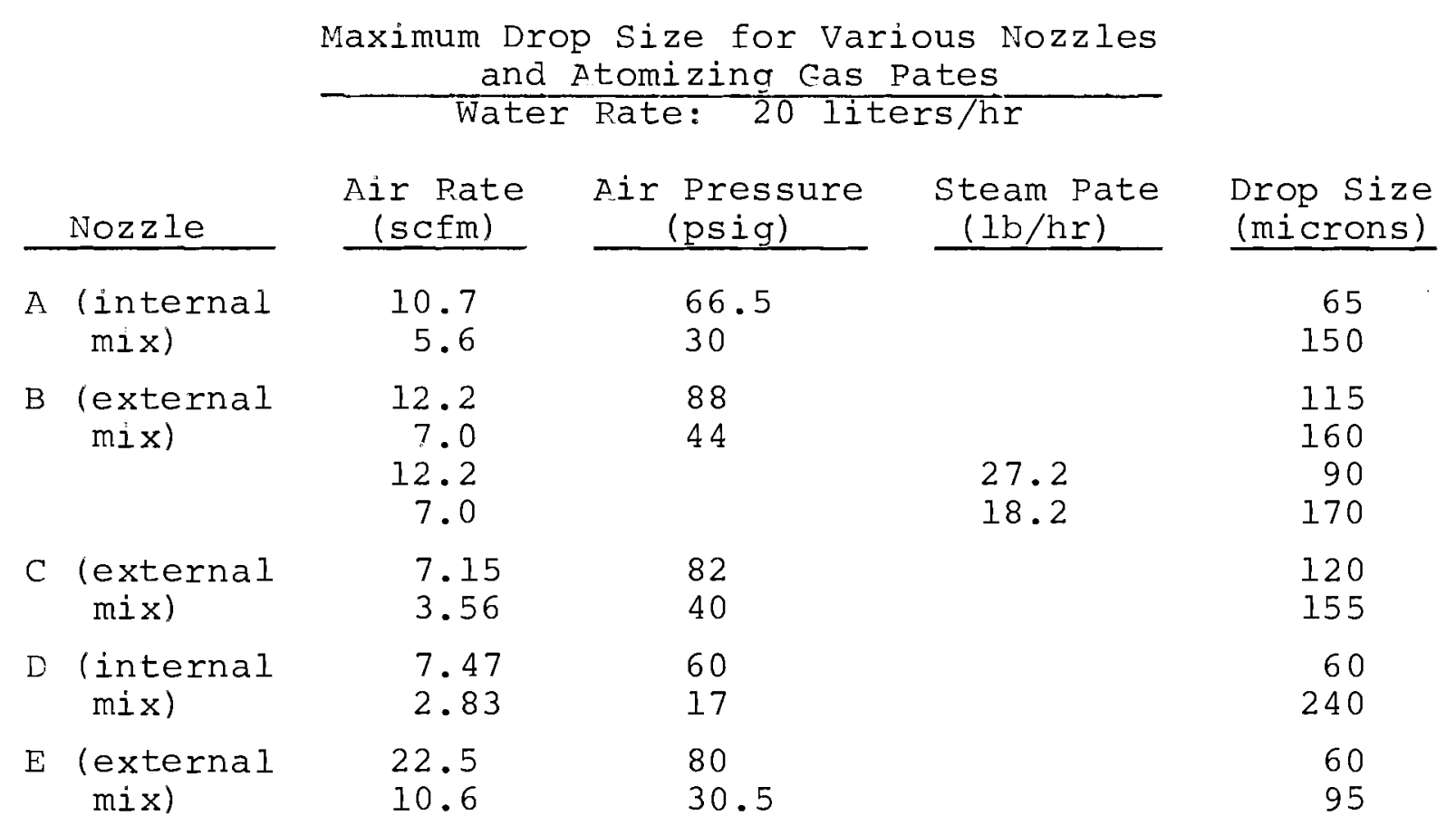

Nozzle $A$. was selected for testing in the developmental calciner unit, based upon both these data and the spray distribution data which were obtained in a separate test. Nozzle D was rejected from further consideration because of its very small liquid orifice, and Nozzle E was rejected because of high air consumption.

\section{Product Evaluation}

Laboratory Studies. Leach testing of a grab sample from WSEP Run 2 was started early this month in $325-\mathrm{C}$ Building hot cell. Analysis of results from the first two weeks of leaching indicates that the leach rate sample, the first radioactive WSEP sample tested, is of the same order of magnitude as rates obtained on nonradioactive laboratory-prepared samples of the same nominal composition.

Engineering Studies. The systematic product evaluation and data accumulation of filled waste pots has begun. Some difficulties were encountered with the welding operation on the first pot, and a new installation of purge air with welding leads was made. All pots containing calcine have been sealed. 
The scope drawing of an in-cell core driller to be used for pot sampling is ready for comment issue. The drill incorporates a commercially available air-powered, hydraulically-controlled unit which attaches to the existing B-Cell welder turntable. The core driller system incorporates a centrifugal dust collector and high efficiency exhaust filter to clean up off-gas from the drilling operation. The system is designed to obtain 7/8-inch diameter cores using air lubricant. It is also designed to obtain longitudinal cores on the pot centerline or at any position between the center and wall (excepting where thermowells interfere), and lateral cores at any radial position through the pot centerline. A trepanning cutter must be designed and tested for radial coring.

Fabrication of environmental test pods and supporting systems is continuing in an effort to have the first pod ready for $\mathrm{B}-\mathrm{Cell}$ installation by April 1, 1967.

An apparent electrical fault in the welding torch power supply wall plug caused a delay in closure of WSEP pots PC-2 and PC-3 and consideration of alternate welding power supply systems. The system currently being installed for PC-2 welding consists of a radiation resistant torch with remote lead connections at the torch and onepiece leads entering the cell through a 2-inch pipe wall sleeve. This system eliminates two in-cell connections and should improve system reliability and operability.

\section{Supporting Activities}

Laboratory studies. Three Sauereisen cements were applied as coatings on carbon steel coupons, and the coupons were exposed in PW-2 melt at $780 \mathrm{C}$ for $24 \mathrm{hrs}$. One cement was attacked by the melt, and one cracked and permitted attack on the substrate. The third cement was attacked only slightly by the melt and protected the substrate well. Mullite and zircon-mullite crucibles were tested in PW-2 melt at $1000 \mathrm{C}$. Neither was porous, but both reacted with the melt.

Engineering Studies. As-builts of Drawing H-3-21184, "Closed Circuit TV System," are in the final drafting stage prior to issue. Corrected drawings are required prior to writing and issuing operating procedures for the TV plug and TV system. There are no plans at present for mechanical TV plug as-builts. It is recommended that the function of the TV system should be reconsidered before committing additional dollars.

The C-Cell gallery pot development test stand is about $75 \%$ complete. The test stand is for the following purposes: (a) design verification tests on the Sciaky SWA-6 welding torch; (b) demonstration and development of manual welding for waste pot top and breeched opening closure; and (c) operations training for in-cell welding. 
An evaporator run, using a PW-1 feed composition, was tested to check an airlift feed control loop, to automate the evaporator control system and test the $\mathrm{PW}-1$ feed characteristics in the evaporator. The testing was terminated earlier than scheduled by plugged instrument probes. The pluggage is attributed to the chemical nature of the evaporator product when the material is evaporated to greater than $130 \mathrm{C}$. The control loops appeared to have functioned as intencled, and final instrumentation design will result on the basis of these tests.

\section{Simulation Modeling of Expected Thermal Generation in Selected Diver Systems (R. T. Jaske)}

Good progress was made in this program in developing the necessary punch card file for effective simulation of heat discharges from the Dresden reactors, both present and plannea. Weather data punched to the format useci by the digital simulation model has been arranged for directly with the U.S. Weather bureau in Asheville, South Carolina. Development of this mode of data exchange permits ready incorporation of any data in the U.S. Pecord Center at Asheville into regional water temperature studies at any location.

Upon completion of reservoir card keypunching, computer runs are planned for a series of cases and locations downstream from the Dresden facilities. Seven locations downstream and several levels of development at Drescien, including a speculative case beyond current licensing levels, is being programmed for simulation runs.

\section{CUSTOMEP \\ Assistance to Isochem, Inc. (W. I. Hampson, Jr.)}

Fuels Development

The purpose of this study was to test the removal of chlorine impurity from plutonia-urania powders during the sintering of pellets.

Two lots of experimental coprecipitated plutonium hydroxideammonium diuranate powders prepared by Isochem were used. The powders were sampled, analyzed, and found to contain $55 \mathrm{ppm}$ and $180 \mathrm{ppm}$ chlorine, respectively. Each lot was reduced in a $6 \% \mathrm{H}_{2}-94 \% \mathrm{~N}_{2}$ atmosphere, then blended, screened, and prepressed into green pellets. The pellets were granulated, screened, pressed again into pellets, and sintered for six hours at $1550 \mathrm{C}$ in $6 \% \mathrm{H}_{2}-94 \% \mathrm{~N}_{2}$ atmosphere. After sintering, the two lots of pellets were sampled, analyzed, and found to contain less than 10 ppm chlorine impurity. 
The results of the study show that sintering of the coprecipitated plutonia-urania powders lowers the quantities of chlorine impurity that may be present in feed powders to an acceptable level to meet fuel quality control specifications. 
Number of Copies

DISTRIBUTION

8

1

1

1

1

7

1

1

3

AEC-AECL, Chalk River, Canada

M. H. Hudson

AEC Division of Technical Information Extension

Aerojet-Nucleonics

P. O. Box 77

San Ramon, California

F. W. Titus

Aeroprojects, Inc.

W. B. Tarpley

Air Force Materials Laboratory

Wright-Patterson AFB

S. W. Bradstreet

Allis Chalmers Manufacturing Co.

Virginia D. Rose

Ames Laboratory

F. H. Spedding

Argonne National Laboratory

R. M. Aăams

L. R. Link (4)

C. E. Stevenson

R. C. Vogel

Armour Research Foundation

W. Loewe

Atomic Energy Commission, Division of Compliance Region IV, P. O. Box 15266, Denver

J.W. Flora

Atomic Energy Commission, DRD\&T Site Representative P. G. Holsted

Atomic Energy Commission, Washington

Advisory Committee on Reactor Safeguards

R. F. Fraley (17)

Division of Compliance

L. Kornblith, Jr.

Division of Licensing and Regulation 
Division of Operations Analysis and Forecasting

Division of Production

F. P. Baranowski

Division of Reactor Development and Technology

R. A. Brodsky

Col. K. Cooper

A. Giambusso

J. E. Robb

S. A. Szawlewcz

11. Shaw (16)

G. W. Wensch

Division of Research

G. A. Kolstad

Division of Safety Standards

M. Bolotsky

A. B. Holt

Office of Assistant General Counsel for Patents

R. A. Anderson

Space Electrical Propulsion Office

Col. G. K. Dicker

Atomic Power Development Associates, Inc.

W. H. Jens

Atomics International

A. A. Jarrett (2)

H. Pearlman

Babcock and Wilcox Company Lynchburg, Virginia

$\mathrm{H}$. S. Allen

R. A. Webb

Battelle Memorial Institute

D. L. Morrison

Bechtel Corporation

R. F. Griffin

Brookhaven National Laboratory

A. E. Castleman

Elizabeth J. Eäwarās

C. J. Raseman

D. G. Schweitzer 
1

2

1

1

1

1

11

1

4

5

1

2
Canoga Park Area Office

R. W. Richards

Carolinas-Virginia Nuclear Power Associates $\mathrm{H}$. T. Babb

Chicago Operations Office

Argonne, Illinois

D. M. Gardiner

$\frac{\text { Columbia University, New York }}{\text { J. E. Casterline }}$

Combustion Engineering

. O. Box 500

Windsor, Connecticut

W. P. Chernock

Dow Chemical Company, Rocky Flats

J. R. Seed

DUN

P. A. Carlson

J. R. Carrell

R. E. Dunn

G. C. Fullmer

D. R. Hogle (Atomics International)

C. G. Lewis

W. M. Mathis

Ii. G. Spencer

J. R. Spink

W. K. Wood's

R. W. Reici

Ebasco Services, Inc. T. A. Flynn, Jr.

E. I. aupont de Nemours and Co., Aiken

General Atomic Division

D. B. Coburn

E. Creutz

A. J. Goodjohn

S. L. Koutz

D. V. Ragone

General Electric Company, Cincinnati

S. Naymark, NMPO

General Electric Company, Pleasanton

L. P. Bupp

E. A. Evans 
General Electric Company, Richland
W. J. Dowis
A. E. Guay
M. Lewis
J. S. MCMahon
J. W. Nickolaus
J. W. Riches

General Electric Company, San Jose

K. P. Cohen

E. R. Kilsby

R. B. Richards

C. H. Robbins

E. L. Zebroski

General Electric Company, Schenectady

W. M. Cashin, KAPL

J. I. Michaelson, Aävanced Technology Lab., Bldg. 5

Idaho Operations office Nuclear Technology Div.

J. F. Kaufman

D. S. King

D. E. Williams

IIT Research Institute

P. O. Box 327

Argonne, Illinois

W. J. McGonnagle

i. A. Zaker

Isochem, Inc.

H. H. Hopkins

H. P. Shaw

R. E. Tomlinson

Los Alamos Scientific Laboratory

H. F. Redman

D. B. Hall

Massachusetts Institute of Technology Manson Benedict

National Bureau of Standards C. Muehlhause

National Reactor Testing Station (INC)

G. Bright (2)

J. A. Buckham

D. R. de Boisblanc

E. O. Mills

W. E. Myer (2)

F. Schroeder (2)

T. R. Wilson (2) 
1

New York Operations Office

A. J. Rizzo

C. Stahle

Nuclear Development Corporation of America W. A. Loeb

Nuclear Materials and Equipment Corp. C. S. Caldwell

$\frac{\text { Oak Ridge Operations Office }}{\text { D. F. Cope }}$

W. J. Larkin

Richland Operations Office

P. M. Midkiff

C. L. Robinson

R. K. Sharp (2)

Sandia Corporation J. Jacobs

San Francisco Operations Office

Sargent and Lundy

W. A. Chittenden

Union Carbide Copr. (ORNL)

F. L. Culler

W. B. Cottrell

J. H. Frye

R. W. MCClung

O. Sisman

D. B. Trauger (2)

M. S. Wechsler

$\frac{\text { United Nuclear Corp. }}{\text { C. Graves }}$

University of California

V. E. Schrock

$\frac{\text { University of Minnesota }}{\text { H. Isbin }}$

University of Texas

G. W. Watt

Westinghouse Electric Corp.
R. H. Fillnow
E. J. Kreh
R. G. McGrath
R. A. Wiesemann 


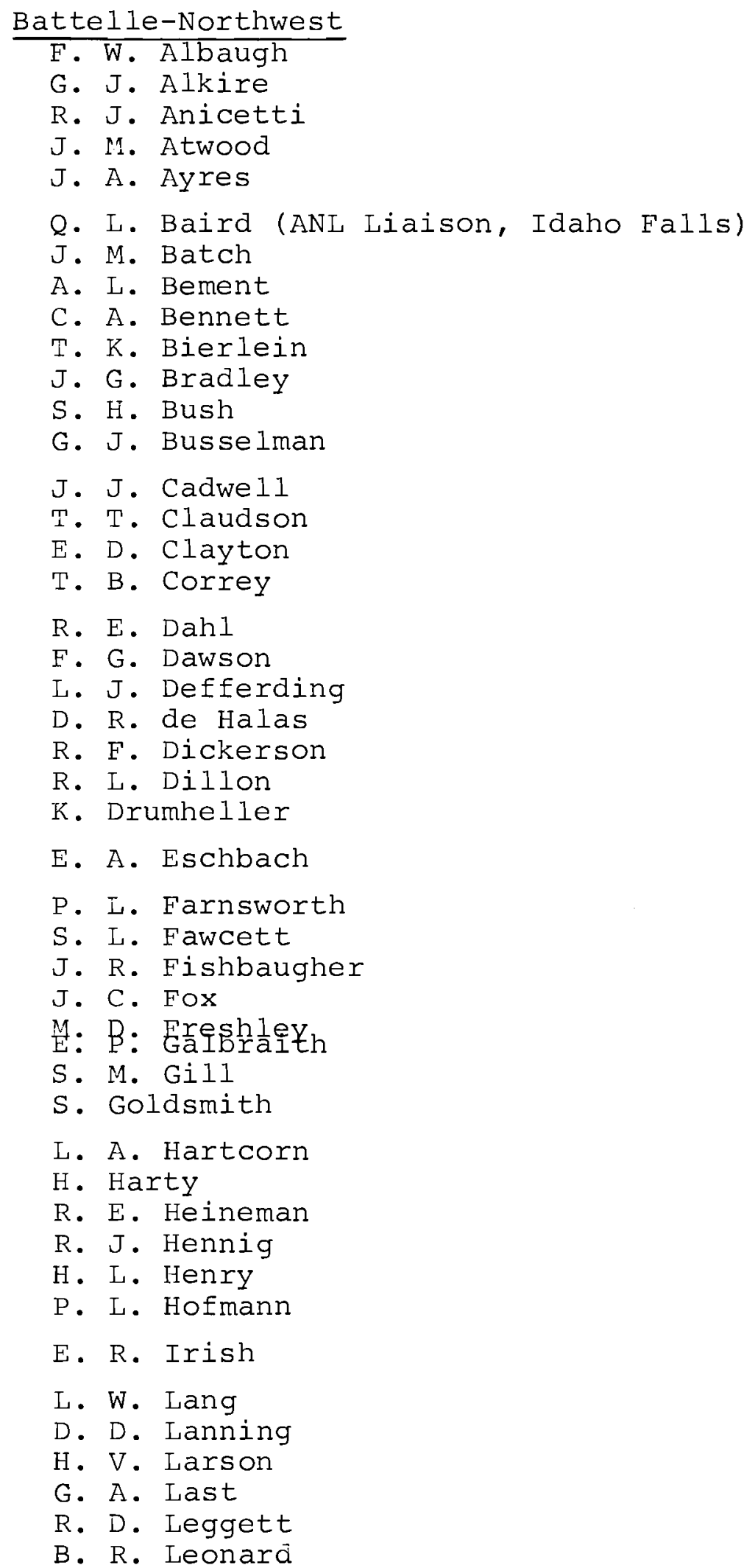


R. C. Likkala

C. W. Lindenmeier

W. W. Little

J. E. Minor

T. C. Nelson

C. E. Newton

R. E. livightingale

H. M. Parker

R. S. Paul

L. T. Pedersen

A. M. Platt

W. D. Richmond

W. E. Roake

G. J. Rogers

C. A. Rohrmann

I. C. Schmid

L. C. Schwendiman - C. E. Linderoth

R. J. Sorenson (3)

W. G. Spear

A. J. Stevens

R. W. Stewart

G. L. Tingey

C. R. T'ipton, Jr.

L. D. Turner

C. M. Unruh

F. W. Van Wormer

J. B. Vetrano

E. E. Voiland

R. G. Wheeler

O. J. Wick

F. W. Woodfield

D. C. Worlton

H. H. Yoshikawa

Technical Information Files

Technical Publications (2) 